NBER WORKING PAPER SERIES

\title{
ENDOGENOUS SKILL ACQUISITION AND EXPORT MANUFACTURING IN MEXICO
}

David Atkin

Working Paper 18266

http://www.nber.org/papers/w18266

\author{
NATIONAL BUREAU OF ECONOMIC RESEARCH \\ 1050 Massachusetts Avenue \\ Cambridge, MA 02138 \\ August 2012
}

Special thanks to David Kaplan and ITAM for computing and making available the IMSS Municipality level employment data. Thanks to Angus Deaton, Penny Goldberg and Gene Grossman for guidance and encouragement throughout. Further thanks to Joe Altonji, Treb Allen, Chris Blattman, Richard Chiburis, Dave Donaldson, Marco Gonzalez-Navarro, Leonardo Iacovone, Amit Khandelwal, Fabian Lange, Adriana Lleras-Muney, Marc Melitz, Mushfiq Mobarak, Marc-Andreas Muendler, Hannah Pitt, Guido Porto, Nancy Qian, Jesse Rothstein, Sam Schulhofer-Wohl, Eric Verhoogen, Glen Weyl and numerous seminar participants for their useful comments. Financial aid from the Fellowship of Woodrow Wilson Scholars at Princeton University is gratefully acknowledged. Any errors contained in the paper are my own. The views expressed herein are those of the author and do not necessarily reflect the views of the National Bureau of Economic Research.

NBER working papers are circulated for discussion and comment purposes. They have not been peerreviewed or been subject to the review by the NBER Board of Directors that accompanies official NBER publications.

(C) 2012 by David Atkin. All rights reserved. Short sections of text, not to exceed two paragraphs, may be quoted without explicit permission provided that full credit, including $\odot$ notice, is given to the source. 
Endogenous Skill Acquisition and Export Manufacturing in Mexico

David Atkin

NBER Working Paper No. 18266

August 2012, Revised July 2015

JEL No. F16,J24,O12,O14,O19

\begin{abstract}
This paper presents empirical evidence that the growth of export manufacturing in Mexico during a period of major trade reforms, the years 1986-2000, altered the distribution of education. I use variation in the timing of factory openings across commuting zones to show that school dropout increased with local expansions in export manufacturing. The magnitudes I find suggest that for every twenty-five jobs created, one student dropped out of school at grade 9 rather than continuing through to grade 12. These effects are driven by less-skilled export-manufacturing jobs which raised the opportunity cost of schooling for students at the margin.
\end{abstract}

David Atkin

Department of Economics

MIT

77 Massachusetts Avenue E19-750

Cambridge, MA 02139

and NBER

atkin@mit.edu 


\section{Introduction}

Many developing countries have experienced rapid periods of industrialization driven by expansions in low-skill manufacturing exports. The existing trade literature has found that exporting firms pay higher wages (Bernard and Jensen 1995; see Bernard 1995 for Mexico) and that export expansions are often associated with rises in the returns to skill (surveyed in Goldberg and Pavcnik 2007; see Cragg and Epelbaum 1996, Hanson and Harrison 1999 and Verhoogen 2008 for Mexico). From these two stylized facts, it is tempting to conclude that schooling will rise with the arrival of new exporting opportunities. However, such an inference ignores the fact that new exports jobs have the potential to significantly raise the opportunity cost of schooling. If the rise in the opportunity cost of schooling outweighs any rise in the return to schooling, some youths will drop out of school at younger ages. This paper exploits variation in the timing of factory openings across commuting zones to show that this is indeed what occurred in Mexico between 1986 and 2000.

The finding that export expansions can reduce school attainment has important ramifications. From a macro perspective, many countries pursuing export-led growth strategies also want to upgrade the skill level of their workforce, believing that the positive externalities from education drive long-run growth rates (Lucas 1988). Therefore, understanding the particular job characteristics that raise or lower educational acquisition is vital for designing industrial and trade policies that can increase short run growth rates without reducing education levels. In the last part of the paper, I address this question by exploring how heterogeneity in educational responses relates to industry and location characteristics of the new job arrivals.

New export employment opportunities have two offsetting effects. On the one hand, when a new firm opens, a student may drop out of school in order to take one of the abundant job openings at the time of the factory opening - the opportunity cost of schooling channel. On the other hand, if the student expects that vacancies will continue to be available and these jobs will sufficiently reward school acquisition, he or she may choose to stay in school longer - the return to schooling channel. Which effect dominates during periods of export-oriented industrialization is an empirical question.

Mexico provides a perfect setting to study the impacts of globalization on the labor force. Over the period spanned by the data (1986-2000), Mexico turned its back on an import substitution strategy and liberalized trade, joining GATT in 1986 and NAFTA in 1994. During these years, many new plants opened, often in the form of Maquiladoras, to manufacture products for export. Total employment in export manufacturing sectors rose from under 900,000 formal sector jobs at the beginning of 1986 to over 2.7 million jobs in 2000. The majority of these jobs were low skill, with more than 80 percent of employees in the year 
2000 possessing less than a high school degree. ${ }^{1}$

A unique dataset makes this analysis possible. I match cohort average education (my skill measure, calculated using 10 million schooling records from the 2000 census) to exportindustry job growth in the cohort's commuting zone in the year the cohort turned age 16 (calculated using annual firm-level employment data from social security rolls covering the universe of formal sector firms). ${ }^{2}$ At this "key exposure age", compulsory education concludes and formal employment is first possible. I can then compare the school attainment of cohorts within a commuting zone who reached their key exposure age at the time of substantial factory openings to slightly younger or older cohorts who did not.

The primary empirical difficulty is reverse causation; that local skill levels may themselves determine firm employment decisions. In the context of my panel of 1,808 commuting zones and 14 cohorts, the exogeneity requirement is that - conditional on commuting-zone fixed effects and linear trends, and state-cohort fixed effects - firm employment decisions do not respond to deviations in the schooling of individual cohorts. I instrument employment changes with changes attributable solely to large single-firm openings, closings, expansions and contractions. I argue that sizable expansions and contractions are associated with large fixed costs and not driven by changes in the labor supply of one or even several cohorts of youths. ${ }^{3}$

I find that the cohorts who reached their key exposure age during years of substantial expansions in export-industry employment in their commuting zone obtained relatively fewer years of school compared to less exposed cohorts. In terms of interpretation, this finding is not driven by new export manufacturing opportunities raising the education of all cohorts in the commuting zone but raising education least among cohorts at the key exposure age. (The change in school attendance of 16 year olds between 1990 and 2000 was smallest in the commuting zones with the largest export-industry employment growth). The magnitudes I find suggest that for every twenty-five new jobs that arrived, one student dropped out of school at grade 9 rather than continuing on through grade 12 .

I present multiple pieces of additional evidence to support my claim that export expansions reduced schooling by raising the opportunity cost of school: compared to other ages, the reduction in schooling is largest for jobs arriving at age 16 and dissipates entirely at older ages; I find similar patterns for grade-9 dropout rates but not primary school dropout where earlier exposure matters more; school attendance at the time of the 1990 census responds

\footnotetext{
${ }^{1}$ Trade liberalization in Mexico has been associated with an initial rise in the skill premium until the mid 1990's (Cragg and Epelbaum 1996, Hanson and Harrison 1999), followed by a skill premium decline thereafter (Robertson 2004, Airola and Juhn 2005). As I show in Section 5.1, education decisions respond to the skill premium (the wage difference between employees of different skill levels) and the opportunity cost of school.

${ }^{2}$ I restrict attention to the non-migrant population of Mexico since the location of migrants at age 16 is unknown. In Section 4.5.2, I show that composition bias due to selective migration cannot explain my findings.

${ }^{3}$ This is especially true in Mexico, where a large quantity of migrant and informal labor ensures that changes in the dropout decisions of individual cohorts have only a small impact on the set of potential hires.
} 
most to job shocks occurring in the previous year rather than earlier or later years, and the cohort aged 16 is most impacted; this drop in school attendance is matched by increases in the propensity to work in the export sector but not in other sectors; sex-specific school attainment responds more strongly to job shocks for that particular sex; the effects are not driven by parental work decisions or selective migration; and the returns to on-the-job training do not negate the reduction in formal schooling in wage terms.

The previous discussion focused on the schooling impacts of export manufacturing jobs. There are several reasons for this focus. First, the impact of trade on schooling decisions is of significant interest in its own right. Second, from a policy perspective, export manufacturing plays a special role in developing countries. While policymakers must often decide whether to encourage or restrict export manufacturing, especially FDI, such scenarios are rarer for services or non-export manufacturing. This comes in part from the additional policy levers available for export manufacturing (for example, Mexico's Maquiladora system that exempts exporting firms from tariffs on imported inputs). In contrast to their success in encouraging export manufacturing, Mexico and many other developing countries have struggled to generate employment growth in large-scale non-export manufacturing. Meanwhile, services are generally non tradeable and so location decisions are often tied to local demand.

In the last part of the analysis, I explore job creation across all sectors. While the arrival of formal jobs in non-export sectors at age 16 is also associated with reduced schooling, the effects size is significantly smaller than for export jobs. The effect disappears altogether when I restrict attention to highly-agglomerated industries where local demand shocks are less likely to bias estimates due to endogeneity. In order to understand the job characteristics generating this difference, I write down a conceptual framework that incorporates stochastic job opportunities and heterogeneous discount rates into an educational choice model. This framework highlights the particular job characteristics that determine whether job arrivals encourage or discourage educational acquisition. Drawing on schooling, wage and industry of employment data from the 1990 census to characterize job arrivals, I find that dropout is driven by job arrivals that require only a secondary school education, offer relatively high wage premia and arrive in locations where there are many youths on the margin between secondary and high school. Once these job characteristics are accounted for, new export jobs no longer generate statistically larger reductions in schooling than non-export jobs.

This paper provides evidence in support of models of trade with endogenous skill acquisition. Findlay and Kierzkowski (1983) endogenize human capital in a Heckscher-Ohlin model and show that trade exacerbates initial skill differences across countries by raising the return to the abundant skill - the Stolper-Samuelson effect. Trade can induce divergent growth paths if positive externalities to education are incorporated into such a model (Stokey 1991). 
Wood and Ridao-Cano (1999) test the hypothesis that trade reduces educational acquisition in unskilled labor abundant countries using a cross-country panel. However, it is difficult to infer causality in cross-country regressions, particularly when changes in education levels feed back into empirical measures of trade openness such as the ratio of exports to GDP.

The results are also consistent with the findings of studies in history and development. Goldin and Katz (1997) show that industrialization slowed the growth of high school education in the early 20th century United States, while Federman and Levine (2005) find industrialization increased enrollments in Indonesia. Closest to this paper, Le Brun, Helper, and Levine (2011) find industrialization had mixed effects in Mexico by looking at decadal changes in school attendance and manufacturing employment in the census. This paper improves on these studies by drawing on rich employment data at an annual frequency that both allows me to design an instrumental variables strategy that controls for potential reverse causality due to endogenous firm location choices and to explore heterogeneous effects by job type. ${ }^{4}$

Finally, a complementary literature looks at the educational impacts of the arrival of IT service jobs in India. Munshi and Rosenzweig (2006), Shastry (2012), Jensen (2012) and Oster and Steinberg (2013) all find positive enrollment impacts from the arrival of relatively high-skilled service job opportunities in India. ${ }^{5}$ All these studies explore new opportunities in a very specific sector in a small sample of locations. As these particular opportunities demanded relatively high skills compared to the local skill distribution, they substantially raised the return to schooling. ${ }^{6}$ By drawing on disaggregated employment data across many industries and locations, this paper contributes to this literature by identifying the job characteristics that raise educational attainment and those that lower it.

Section 2 introduces the rich data set and the empirical methodology. Section 3 investigates the impact of export-manufacturing job arrivals on educational attainment. Section 4 validates the methodology through a variety of additional exercises. Section 5 explores why export job creation leads to particularly pronounced reductions in schooling through the lens of a simple model. Finally, Section 6 discusses policy implications and concludes.

\section{Empirical Strategy}

\subsection{Data}

I combine two sources of data to explore the relationship between educational attainment and job opportunities in export manufacturing. Cohort education data come from a 10.6 percent subsample of the 2000 Mexican census collected by INEGI and available from

\footnotetext{
${ }^{4}$ This analysis focuses on youths at school-leaving ages at the time of the export job arrivals. For evidence on positive schooling effects of trade liberalization for younger children via the household income channel, see Edmonds and Pavcnik (2005) and Edmonds, Pavcnik, and Topalova (2010).

${ }^{5}$ Heath and Mobarak (2015) find similar outcomes for young Bangladeshi girls and the garment industry.

${ }^{6}$ India's experience may be regarded as the exception rather than the rule, as it is far more common for a developing country to have a revealed comparative advantage in low-skill manufacturing.
} 
IPUMSI (Minnesota Population Center 2007). The 10.1 million person records cover all 2,443 Mexican municipios (roughly equivalent to US counties). For reasons discussed in Section 2.3, I exclude Mexico City in my primary analysis.

The employment data originate from the Mexican Social Security Institute (IMSS), and cover the universe of formal private-sector establishments, including Maquiladoras. IMSS provides health and pension coverage and all employees must enroll. I construct the main employment variable, net new jobs, from annual changes in employment by industry within each municipio. ${ }^{7}$ The data cover 2.2 million firms between 1985 and 2000, with employment recorded on December 31st of each year. Table 1 reports sample means for both datasets.

For my primary analysis, I focus on the massive expansion of employment in exportoriented industries that dominated Mexico's manufacturing growth over the period of study. The IMSS data assign each firm to one of 276 industry categories, but do not indicate whether a firm exports. Thus, I define a firm as an exporter if it belongs to a 3-digit ISIC industry where more than 50 percent of output was exported for at least half the sample years. ${ }^{8}$ The resulting export industries are: Apparel; Footwear; Leather and Leather Products; Wood and Cork Products; Petrochemical Refinement; Metal Products; Electronic and Mechanical Machinery; Electrical Machinery; Transport Equipment; Scientific and Optical Equipment. ${ }^{9}$

Between 1986 and 1999, employment growth in these export-intensive industries accounted for 65 percent of the growth in IMSS-insured manufacturing employment. Figure 1 displays the annual employment growth in both export and non-export manufacturing industries as well as in non-manufacturing industries. While not all of the jobs in the industries that I classify as export manufacturing are in firms that export, the majority are. In 2000, there were 2 million formal jobs in my export manufacturing grouping. 1 million of these jobs were in Maquiladora firms according to INEGI Maquiladora statistics. (Maquiladora job growth accounts for 60 percent of export-industry job growth as shown in Figure 1.) All of these Maquiladoras are exporters since these export-assembly plants are legally required to export almost all their production. ${ }^{10}$ A large number of the remaining 1 million export industry jobs are also in exporting firms. For example, the 2000 Encuesta Industrial Annual (EIA) surveys 5,801 large non-Maquiladora firms. Of the 370,340 EIA jobs in my export industries, 51 percent are at firms that export more than 25 percent of their output. ${ }^{11}$ In

\footnotetext{
${ }^{7}$ The aggregations from the firm to municipio level were carried out at ITAM, where the data were held securely. Kaplan, Gonzalez, and Robertson (2007) contains further details on the IMSS data.

${ }^{8}$ The 276 IMSS industry categories, the 119 used by the Mexican census and the 72 used by ISIC (Rev. 2) were matched by hand. Export and output data come from the Trade, Production and Protection 1976-2004 database (Nicita and Olarreaga 2007). Results are robust to raising or lowering the 50 percent cutoff.

${ }^{9}$ Appendix Figure C.1 provides further details regarding firm export orientation by industry grouping.

${ }^{10}$ These firms were initially confined to border areas and employed mainly women, but by the year 2000 one quarter of firms were in non-border states and half the employees were male.

${ }^{11}$ Only 20 percent of the 623,020 non-export industry jobs are at firms exporting more than 25 percent.
} 
Section 3.1, I use these additional data sources to explore job creation at known exporters.

Figure 2 shows the education distribution of young workers - those aged 16-28, my sample cohorts - in each industry at the time of the 2000 census. Formal sector employees in export manufacturing industries are substantially less educated than formal sector workers in other industries; 81 percent of export-industry employees have less than a high school education compared to 75 percent of non-export manufacturing employees and 62 percent of employees in other formal sectors. (Informal jobs are the least skilled with 85 percent of employees having less than high school.) Export manufacturing employees are also younger with 18 percent of employees age 18 or under in the year 2000 as opposed to 13 percent for non-export manufacturing and 12 percent for other formal sector jobs (see Appendix Figure C.2).

I combine the education and employment data using the 1985 municipio boundaries. In order for each location to represent a single labor market, I create commuting zones by combining municipios in the same Zona Metropolitan (as classified by INEGI) or where a significant number of commuters moved between them in the 2000 census. ${ }^{12}$ The end result is a panel of 14 cohorts across 1,808 geographic units which I refer to as commuting zones. ${ }^{13}$

\subsection{Schooling Decisions and Export Employment Shocks at Age 16}

Regressing school attainment on levels of export employment in the cross-section is likely to provide biased estimates of the effect of export booms on schooling. If factories were drawn to the educated north of Mexico due to its proximity to the US, there would be a positive correlation between schooling and export employment. If factories were drawn to poorer locations due to low wages or government incentives, there would be a negative one. Rather than relying on this cross-sectional variation, my identification strategy exploits differences in exposure to export employment shocks at age 16 across cohorts within the same commuting zone. In this section, I justify why shocks to job opportunities at age 16 are likely to have particularly pronounced effects on educational choices.

My argument proceeds in two steps. First, I will argue that, conditioning on education, the returns to entering the labor force will vary by year-of-entry and depend on the net new job creation in that year. Second, I will argue that this heterogeneity in returns will disproportionately affect the educational decisions of the cohort aged 16 in that year.

Forward-looking students trade off the foregone earnings from staying at school this period (the opportunity cost of schooling) with the future wage benefits from more education (the returns to schooling). There are a variety of models that generate the prediction that

\footnotetext{
${ }^{12}$ I classify commuting municipios as those where more than 10 percent of the working population reported commuting to a nearby municipio. In the few cases where a municipio sends workers to two municipalities that do not send workers to each other, I create two synthetic municipios both containing the sending municipio (but with the weights of individuals from the sending municipio halved).

${ }^{13}$ Since the census was collected in February 2000, only firm data through 1999 is relevant. I lose one additional year of data when calculating employment changes leaving 14 years of data.
} 
this tradeoff depends, at least in part, on net new job creation that period (as opposed to the total stock of jobs in the location). In Section 5.1, I present (and motivate) one such model where youths are heterogeneous in their discount rates, and formal firms pay noncompensating wage differentials and ration jobs. A youth is more likely to drop out of school in a year when many formal firms are hiring workers of their education level since they are more likely to obtain a job in a firm that pays persistently higher wages. Conversely, they are more likely to stay on at school if the new jobs are high skilled. In a pure matching model, youths will search for job opportunities each period and stay in school if there is no match. Hence, dropout is more likely in periods of employment growth. Another possibility is that within-firm wage premia depend positively on labor demand conditions in the year of entry due to optimal lifetime contracts for risk-averse credit-constrained workers (Beaudry and DiNardo 1991). In each of these models, new job arrivals alter that year's schooling decisions by raising the opportunity cost of schooling as well as potentially changing the returns to schooling. The empirical specification is designed to uncover the net effect of these two forces.

At what age would we expect these shocks to the opportunity costs of schooling to be most pronounced? My main specification focuses on job arrivals in the year the youth turned 16. I dub this the "key exposure age" for two reasons. First, formal sector factory jobs first become a direct alternative to school at this age as the legal minimum age for factory work is $16 .{ }^{14}$ Younger cohorts cannot actually obtain these jobs and older cohorts would have been exposed to positive shocks in previous years. Therefore, there is a discrete jump at age 16 in the value of a factory job opportunity. Second, the density of youths on the margin between staying at school and dropping out is largest around this age. Compulsory schooling in Mexico ends with Secundaria (grade 9). Most children complete this grade at age 15 or 16. Although the compulsory schooling law only dates from 1992 and enforcement is rare, many youths drop out after this stage and a similar number enroll in high school but never complete 10th grade. Accordingly, age 16 is the most common age to leave school in Mexico and so shocks to the opportunity cost of schooling at this age will induce a particularly large number of youths to alter their education decisions.

Figures 2 and 3 provide empirical support for the claim that 16 is the key exposure age. Figure 2 shows that the modal level of completed schooling among young workers in the 2000 census is 9 th grade (29 percent of workers compared to 21 and 13 percent for grades 6 and 12 respectively). Figure 3 draws on school attendance data from the 1990 census that lies in the middle of my sample period. The solid line shows that the largest change in the proportion of the cohort attending school occurs between ages 15 and 16 (and the dash-dot line shows

\footnotetext{
${ }^{14}$ The minimum working age is 14 . However, children under 16 require parental consent, medical documentation, cannot work overtime or late hours and are forbidden from certain hazardous industries. These rules are enforced in formal manufacturing and the minimum working age is typically taken as 16 .
} 
the converse for the proportion of the cohort that is working). The primacy of age 16 is more pronounced looking at the dashed line that plots the change in the proportion of students in each cohort maintaining their correct grade for age. ${ }^{15}$ There is a dramatic drop at age 16 , with substantially fewer 16 years olds having completed 10th grade than 15 year olds having completed 9th grade. This drop dwarfs the changes at any other age. The dash-dot plot shows that grade completion rates conditional on attendance also plummet at age $16 .^{16}$

In conclusion, I expect new export opportunities to have a particularly pronounced effect on the educational decisions of cohorts aged 16 at the time compared to younger or older cohorts. Section 4.1 confirms this conjecture by repeating my analysis for other exposure ages.

\subsection{Empirical Specification}

In order to determine the impact of new export job opportunities on cohort schooling, I regress cohort schooling on local expansions in export manufacturing employment:

$$
S_{z c}=\beta l_{z c}+\delta_{z}+\delta_{z} c+\delta_{r c}+\varepsilon_{z c} .
$$

$S_{z c}$ is the average years of schooling obtained by February 2000 for the cohort born in year $c$ in commuting-zone $z,{ }^{17}$ and $l_{z c}$ is a measure of export employment shocks at age 16 that I describe below. I also include commuting-zone fixed effects, $\delta_{z}$, commuting-zone-specific time trends, $\delta_{z} c$, and state-time dummies, $\delta_{r c}$, where $r$ indexes the state. (Time and cohort trends are equivalent since the schooling of each cohort is observed only once in the year 2000.)

My export employment shock measure is the year-on-year employment growth in formal manufacturing firms in export-oriented industries located in commuting zone $z$ in the year the cohort turned age 16. Since a new factory hiring 100 workers will have a much more muted effect on local labor market conditions in a large city compared to a small rural municipio, I divide this employment change by the working age population: ${ }^{18}$

$$
l_{z c}=\frac{\text { export employment }_{z, c+16}-\text { export employment }_{z, c+15}}{\text { working-age population }_{z, 1990}} .
$$

As the working-age population may be endogenous to new factory openings, I use the commuting-zone population aged 15-49 from the 1990 census close to the beginning of the sample period. In order to get a sense of magnitudes, $l_{z c}$ ranges between -0.17 and 0.19 . A large expansion (the 90th percentile among the 7800 expansions or contractions) created

\footnotetext{
${ }^{15}$ Since schooling starts at age six, the correct grade is simply their age minus six years. Some youths would have only obtained grade $x-7$ if they progressed sequentially since age is recorded in February. However, this measurement error can not explain the discrete jump at age 16 .

${ }^{16}$ I estimate grade completion rates by dividing the proportion of youths age $x$ who have completed grade $x-6$ by the proportion of youths age $x$ - 1 who are both at school and have completed grade $x-7$.

${ }^{17} \mathrm{I}$ do not use data from 1990 census in calculating $S_{z c}$ as these data only cover 4 cohorts. Additionally, the sampling methodology for selecting who received the long-form surveys changed between 1990 and 2000.

${ }^{18}$ If the job shocks were not scaled by population in this manner, we would expect heterogeneous treatment effects across locations that would not be captured by the additive commuting-zone fixed effects.
} 
0.008 jobs per working age person or 0.16 jobs per member of the cohort aged 16 that year. Table 1 reports a range of additional summary statistics for these shocks.

The state-time dummies control in a flexible manner for the fact that education was trending upwards, but at different rates across Mexico. ${ }^{19}$ The commuting-zone-specific fixed effects and time trends control for the fact that educational outcomes vary across locations within a state, and low-education commuting zones may be catching up with high-education ones.

I restrict the sample to non-migrants, defined as someone who reports being born in the same state they are currently living in and who also lived in their current commuting zone in 1995. Including in-migrants confounds the impact of local job opportunities on education since the census does not ask where they lived when they were at school. Therefore, my estimates are only representative of the non-migrants who comprise 80 percent of the full census sample. In Section 4.5.2, I provide evidence that potential selection biases related to migration cannot explain my finding that export job arrivals reduced schooling.

I exclude Valle de México (the commuting zone that includes Mexico City) since it constitutes two entire states so is swept out by the state-time dummies. ${ }^{20}$ I weight each cohortcommuting-zone observation by the number of individuals the cell represents. Hence, my results are representative of the Mexican non-migrant population excluding Valle de México.

My empirical strategy compares the average schooling of a cohort who was heavily exposed to local factory openings in export-oriented industries at their key exposure age to older and younger cohorts in the same commuting zone who did not receive such a shock to their employment opportunities at this age. I flexibly control for time trends using cohorts of the same age living in nearby commuting zones where factories did not open at the key exposure age. I now turn to discussing the potential threats to identification and present a novel instrumentation strategy.

\subsection{Threats to Identification and Instrumentation Strategy}

I address three econometric concerns: omitted variables, reverse causality and measurement error. Omitted variables will bias coefficients if a third factor affects both a commuting zone's education level and its attractiveness as a location for a firm. The commuting-zone fixed effects sweep out time-invariant features of the commuting zone. The state-time dummies control for omitted variables that change over time within the 32 states of Mexico. Finally, commuting-zone-level time trends control for omitted variables that change over time within a commuting zone in an approximately linear fashion.

There are two obvious omitted variables that may affect schooling and correlate with detrended local employment changes. First, a factory may agree to make complementary

\footnotetext{
${ }^{19}$ The state-time dummies also remove trends that arise because younger cohorts have had less time to complete their education, and the degree of measurement error for younger cohorts may vary by state.

${ }^{20}$ As a robustness check, I replace state-time dummies with region-time dummies and include Mexico City.
} 
investments when it opens, for example building a school. Unfortunately, there are no annual data at the municipio level from which to construct controls. Therefore, I rely on the fact that such investments affect all cohorts, with younger cohorts exposed for more years and likely to see larger effects (the opposite to what I find). Additionally, Helper, Levine, and Woodruff (2006) report that school building decisions in Mexico were made nationally prior to 1992 and at the state level afterward, with little municipio say in either period. Second, there may be local demand shocks that both affect schooling decisions and alter the demand for local manufacturing output. My focus on export industries mitigates this concern as demand comes from foreign rather than local consumers. ${ }^{21}$

The second econometric concern is reverse causality. The local education distribution determines the relative wages of different skill groups, and relative wages affect firm employment and location decisions. ${ }^{22}$ If new factories lower education, and low schooling levels also attract factories, $\hat{\beta}$ will be biased in an ambiguous direction. In my panel setting, bias occurs if deviations in de-trended cohort schooling (i.e. after accounting for commuting-zone fixed effects and linear trends, and state-time fixed effects) affect past, present or future firm employment decisions. Therefore, while a firm may wish to locate in a low-skill location, or in a location where skills are declining over time, one or several cohorts with an unusually strong aversion to schooling must not influence a firm's decision to open in a location.

To deal with reverse causality, I require an instrument for $l_{z c}$, the net new export jobs per worker defined in equation 2 above. My instrument is the net new export jobs per worker generated by large single-firm expansions/openings and contractions/closings - positive or negative changes of 50 or more employees in a single year at a single firm. As these large single firm changes comprise 79 percent of the total change in employment over the period, the instrument correlates strongly with $l_{z c}$. For the instrument to be exogenous to the error term in equation 1, firms can only respond to deviations in cohort schooling - those not accounted for by the commuting-zone fixed effects and linear trends, and the state-time fixed effectsthrough the small expansions and contractions that are excluded from my instrument.

I argue that this exclusion restriction is plausibly satisfied. The large (and hence costly) expansions and contractions in the export industries I focus on are typically driven by external demand shocks interacted with stable commuting-zone characteristics (distance to US border, existing input suppliers etc.), ${ }^{23}$ not by changes in local labor supply. Even in

\footnotetext{
${ }^{21}$ In Appendix D, I further focus only on industries where production is geographically agglomerated and hence job creation is driven by national rather than local demand factors.

${ }^{22}$ Bernard, Robertson, and Schott (2004) show that factor prices are not equalized across Mexico, resulting in an inverse relationship between relative wages and relative skill levels. In the extreme, if there is no informal sector, unemployment or migration, one additional dropout results in one new formal employee.

${ }^{23}$ Very large firms may expand or contract by more than 50 people even absent an external demand shock. For robustness, I restrict attention to expansions and contractions that are unusually large for a given firm.
} 
cases where changes in labor supply do drive firm location decisions, deviations in the school attainment of 16 year olds will play a negligable role for two reasons. First, a cohort of 16 year olds is a very small component of the local skill distribution in Mexico - where a large number of both informal and migrant workers compete for formal sector jobs ${ }^{24}$ —and so total labor supply will be little affected by small deviations in local dropout rates. Second, in order to base location decisions on these deviations, entrepreneurs must obtain cohort-varying information about education levels in a commuting zone, which is not readily available.

For the reasons above, large single-firm expansions and contractions are unlikely to be influenced by deviations in the schooling of the cohort aged 16 at the time. However, multiple years of serially-correlated schooling shocks, for example due to a school closure, could both have non-negligible effects on total labor supply and be observable to entrepreneurs. Three factors limit the size of the bias in this case. First, any correlation between past schooling deviations (the deviations that are plausibly observable to the entrepreneur) and current location decisions will be divided by the number of cohorts in my panel (fourteen). Second, older cohorts have progressively smaller impacts on the pool of local labor a firm can hire as many will no longer be seeking employment. Third, any persistent trends in schooling will be absorbed by the commuting-zone linear time trend.

In Section 4.3, I provide explicit evidence in support of the instrumental variable strategy. I show that large expansions and contractions in the late 1980's correlate with education decisions recorded in 1990, but large expansions and contractions in the early 1990's do not.

An additional specification addresses reverse causation head on. I explicitly control for the schooling levels of previous cohorts by including four lags of $S_{z c}$. These lags soak up the component of the error term correlated with $l_{z c}$ through the serial correlation in schooling. ${ }^{25,26}$

The third econometric concern is measurement error in $l_{z c}$. IMSS registration defines firm formality. However, some firms existed informally prior to registering with IMSS, thus formalization appears as new job creation. Such measurement error attenuates $\hat{\beta}$ and could also bias my results if an omitted variable both encouraged firms to register and affected education choices. The IV strategy above mitigates this concern since large firm expansions and contractions occur in larger firms that would find it difficult to evade IMSS registration.

Finally, I cluster all standard errors at the commuting-zone level to prevent misleading inference due to serial correlation in the error term across years within a commuting zone

\footnotetext{
${ }^{24}$ Only one third of Mexican working-age adults are in formal private sector employment.

${ }^{25}$ To be more precise, imagine the true data generating process is $S_{z c}=\beta l_{z c}+u_{z c}$, where shocks to average cohort schooling may be positively serially correlated: $u_{z c}=\varrho u_{z c-1}+v_{z c}$ with $0<\varrho<1$. Firms locate where there is a high proportion of dropouts in the previous cohort of 16 year olds: $l_{z c}=\pi S_{z c-1}+\epsilon_{z c}, \pi<0$. If I run the regression $S_{z c}=\beta l_{z c}+\varepsilon_{z c}, \hat{\beta}$ will be negatively biased. Running $S_{z c}=\beta l_{z c}+\gamma S_{z c-1}+\varepsilon_{z c}$ results in unbiased estimates of $\beta$. If factory openings are also serially correlated, $\hat{\beta}$ will be attenuated towards zero.

${ }^{26}$ As lagged dependent variables are necessarily correlated with the error term in a panel regression, I exclude the commuting-zone fixed effects and trend.
} 
(Bertrand, Duflo, and Mullainathan 2004). The large number of groups (1808 commuting zones) mitigates concerns regarding spurious correlation.

\section{Basic Results}

Table 2 presents the results from running the regression specification in equation 1 . Column 1 contains the ordinary least squares (OLS) results. Column 2 contains the instrumental variable (IV) results, in which I instrument net new export jobs per worker with net new export jobs per worker attributable to changes of 50 or more employees in a single firm in a single year. As expected, the first stage of the IV is highly significant. Column 3 contains the reduced form (RF) results from regressing cohort schooling directly on the instrument. Column 4 repeats the RF specification but also includes a control for general employment trends at the commuting-zone level (the net new jobs per worker at age 16 created through large expansions and contractions in non-export industries). Column 5 repeats the RF specification but includes four lags of cohort schooling instead of the fixed effects. (Appendix Figure C.3 presents a visual plot of the RF strategy for the 30 commuting zones that experienced the largest change in export employment over the sample period.)

In all five specifications, the arrival of new export-manufacturing jobs at age 16 significantly reduces cohort schooling $(\hat{\beta}<0)$ with coefficients between -3.155 and -3.380 . The effect size for formal non-export job arrivals is significantly different and one third as large (a finding I return to in Section 5). The differences between the OLS and IV results are small, suggesting that any bias due to reverse causation or measurement error is not severe.

The interpretation of the coefficients from the IV and RF specifications are subtly different. The RF coefficient estimates the effect of the subset of new export jobs that were created through large openings/expansions and closings/contractions. The IV coefficient scales the RF coefficient by the first stage in order to provide an estimate of the impact of all export job arrivals. However, a single large factory opening or expansion will be highly salient, and hence may have different educational impacts compared to an equivalent number of small expansions. In this scenario, where treatment effects are heterogeneous, there are well known difficulties in interpreting the IV coefficient. In contrast, the RF coefficient is straightforward to interpret, unbiased if the instrument is exogenous, and potentially the coefficient of interest for policymakers hoping to encourage new factory openings or substantial expansions. Accordingly, for the remainder of the paper I report only the RF coefficients.

The magnitude of the coefficient in Table 2 implies substantial educational impacts. As a concrete example, the 90th percentile of the distribution of large firm expansions corresponds to 0.017 net new export jobs per worker. Using the reduced form coefficient, such a shock results in the exposed cohort obtaining 0.06 years less school on average. Alternatively, I would find the effect size I do if for every twenty-five new export jobs that arrived, one 
student in the cohort dropped out at grade 9 rather than continuing on to grade $12 .^{27}$

As with any difference-in-difference regression, my results only imply that the education of cohorts heavily exposed to new factory openings at age 16 fell relative to other cohorts in the commuting zone who were less exposed at these ages. It is possible that, due to a new factory opening, education actually rose across every cohort in the commuting zone but relatively less for the cohorts aged 16. This interpretation would imply that the commuting zones which experienced the largest growth in export employment also saw the largest increases in the school attendance of 16 years olds between the 1990 and 2000 censuses. To tease apart these two interpretations, I run the following regression:

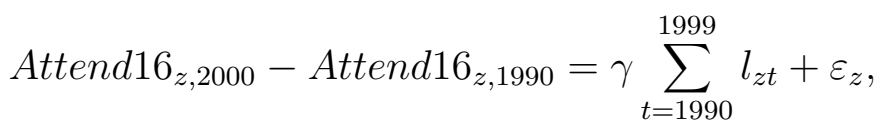

where Attend $16_{z, t}$ is the proportion of the commuting zone $z$ cohort aged 16 at the time of the year $t$ census who are currently attending school. The independent variable, $\sum_{t=1990}^{1999} l_{z t}$, is the total change in the number of export jobs per worker between January 1st 1990 and December 31st 1999. Once more, I present OLS results as well as IV and RF regressions using the large expansions/contractions instrument. I also report results that include the initial level of school attendance as an independent variable to control for low education commuting zones catching up (either the initial value for the cohort aged 16 or the initial value for the cohort one year older for which there are less obvious endogeneity concerns).

Table 3 presents the results of the regression in equation 3. The estimate of the coefficient on the change in export employment, $\hat{\gamma}$, is significantly negative in all specifications. School attendance rose least in the commuting zones that saw the most export job growth over the decade. Therefore, I conclude that export expansions in a locality led not just to relative but also absolute declines in schooling for the cohorts aged 16 at the time. ${ }^{28}$

\subsection{Alternative Methodologies for Classifying Exporting Firms}

The nature of the IMSS data means that I am not able to identify the actual export status of each employer. In this section, I explore a range of alternative codings for export status.

I first explore two alternate classifications of the IMSS industry codes. My main spec-

\footnotetext{
${ }^{27}$ If one out of twenty-five new jobs induced a member of the cohort of non-migrants aged 16 to forgo 3 years of education, cohort schooling would fall by $3 / 25=0.12$ years with the arrival of as many new jobs as members of the cohort. If one job arrived for every person of working-age, cohort schooling would fall by approximately 25 times as much, $0.12 \times 25=3$, since 16 year old non-migrants comprise 3.87 percent of the Mexican population aged 15-49 in the 2000 census. This is the approximate effect size I find-i.e. a 3 year reduction in cohort schooling from 1 new export job per worker, $l_{z c}=1$. Of course, the cohort can obtain a higher or lower proportion of the new jobs if some students would have dropped out anyway or dropout and don't find a job. These proportions seem reasonable: in the 2000 census, 11.5 percent of formal export manufacturing workers are aged 18 or younger, 74 percent of whom were non-migrants.

${ }^{28}$ It seems implausible that the new export jobs led to educational attainment of 16 year olds rising across Mexico but less in the particular locations where the jobs were actually arriving.
} 
ification classifies the 58 3-digit manufacturing industries as "export" if more than half of output was exported for at least half the sample years. Column 1 of Table 4 reruns the basic specification, equation 1, but codes an industry as export if real exports per worker during the sample period were in the top quartile of all manufacturing industries. Column 2 allows industries to change status over time by coding export industries as those exporting more than half their output that year. Results are similar under both alternative classifications.

It is possible to approximately identify the IMSS firms that are Maquiladoras by matching the firm level employment data to INEGI statistics on annual Maquiladora employment by industry, state-industry and municipio. ${ }^{29}$ Since Maquiladoras are legally required to export almost all their output, these firms are exporters and accounted for 985,232 net new jobs between 1986 and 1999 (and 816,708 of 1,370,950 net new jobs in industries I classify as export). Column 3 of Table 4 reruns the basic specification but focuses only on job growth at these "known" exporters. Column 4 uses an alternative concordance provided by IMSS where Maquiladoras are identified by matching firm-level IMSS data with records from the Maquiladora census. ${ }^{30}$ In both cases I find significant, if slightly smaller, declines in schooling.

Finally, I draw on the Encuesta Industrial Anual (EIA) and Encuesta Industrial Mensual (EIM). These surveys cover 3,200 to 6,800 large non-Maquiladora firms depending on the year (out of 87,000 to 142,000 non-Maquiladora manufacturing firms in IMSS). I code a firm as an exporter if more than 25 percent of output is exported. Unfortunately, the INEGI sampling methodology is not designed to capture new firm openings since the firm list was refreshed only once over the sample period and there are no clear criteria for inclusion. Additionally, data prior to 1993 do not contain municipio identifiers. Therefore, I follow the methodology of Verhoogen (2008) exactly and create a consistent EIA panel of 1,114 firms that are present in every period and calculate the annual change in employment among exporters in each commuting zone (creating 59,753 net new jobs between 1986 and 1999). The resulting variable contains intensive margin changes for the set of (not necessarily representative) firms that were both large and in business throughout the sample. ${ }^{31}$

In contrast to Maquiladoras, column 5 of Table 4 shows an insignificant positive schooling impact of job growth in the EIA panel. Columns 6 and 7 combine both Maquiladora and EIA firms and show that the coefficients differ significantly (with p-values of 5.2 and 6.2 percent respectively). These results are not particularly surprising. The skill level of the jobs is likely

\footnotetext{
${ }^{29}$ These data come from the INEGI website. I classify firms as Maquiladoras when the number of employees in a given cell of the INEGI statistics (e.g. year-state-industry) is equal or greater than the employees in that cell in the IMSS data. As firms appear in several overlapping aggregates, I can iterate this process until convergence. I am able to classify all the potential Maquiladoras in 4 iterations.

${ }^{30}$ About 80 percent of total Maquiladora employment can be matched using this concordance.

${ }^{31}$ These data are confidential and only year-municipio-industry level aggregates were available precluding the use of my RF specification here. As a firm may become an exporter during the sample period, some export job creation comes from non-export jobs becoming export jobs.
} 
to be a major determinant of schooling impacts. Maquiladoras are export assembly operations known for demanding low levels of skill. In contrast, Verhoogen (2008) shows that, for this panel of large non-Maquiladoras, demand for skill is higher among exporters than non exporters. Column 8 provides support for this explanation by breaking job growth in EIA firms into blue and white collar jobs. As expected, the positive effect is driven by more-skilled white collar job growth, with a negative coefficient on less-skilled blue collar job growth. Section 5 explores heterogeneity by skill level in more detail using skill measures from the 1990 census.

\subsection{Alternative Samples and Specifications}

In Appendix A, I demonstrate the robustness of my main finding to many additional specifications: removing the various time fixed effects and trends, considering alternative samples (excluding 781 small commuting zones with no formal sector, excluding metropolitan areas or big cities, including Mexico City, not weighting by cohort size, breaking results up by region, controlling for the roll out of Progresa) and exploring alternate specifications (using different schooling measures, extending the 50 employee threshold of my instrument, restricting attention to unusually large expansions/contractions at the firm level, separately exploring expansions and contractions, and allowing for state-level spillovers). Summarizing, there is a negative impact of new export job arrivals on the educational attainment of cohorts aged 16 at the time that is robust to alternative samples and specifications.

\section{Validating the Methodology}

In the previous sections, I argued that new export opportunities alter the returns to and opportunity cost of schooling; and that I identified the net effect on school attainment by comparing heavily exposed cohorts to less exposed cohorts within and across commuting zones. In this section, I present a range of additional evidence in support of this claim.

\subsection{The Age 16 Exposure Window and Effects at Other Ages}

My identification strategy is built on the assumption that youths are disproportionately affected by new employment opportunities at age 16. In Section 2.2, I justified this assumption by appealing to the fact that this age is both the legal factory employment age and the time when students are deciding whether to attend high school or not.

This assumption can be tested. To do so, I repeat my basic specification, equation 1, but replace net new export jobs per worker at age 16 with job shocks at other ages. I run 17 regressions, one for each age of exposure between 7 and 23. As previously, my job shocks

include only large expansions and contractions. Figure 4 plots these 17 coefficients and the associated 95 percent confidence intervals. Reassuringly, the largest negative impacts on cohort schooling occur from export employment shocks at age 16. There are also significant negative effects from export employment shocks at three other ages around which students transition between school stages (ages 13, 15 and 18) but these are substantially smaller in 
magnitude. Shocks at the youngest ages of 7-11 and the older ages of 20-21 raise cohort schooling, although only the first of these is significant at the 5 percent level.

As export employment shocks are likely to be serially correlated, running separate regressions for each age of exposure may be misleading. Instead, I can include multiple ages of exposure in same regression at the cost of further shrinking the sample size (for each additional age of exposure, I lose one year of my short 14 year panel). Simultaneously including five ages of exposure centered around age 16, I still find that exposure at age 16 leads to the largest reduction in school attainment (the full results are reported in Appendix Table C.1). ${ }^{32}$ In summary, the more pronounced effects at age 16 are consistent with the maintained assumption that age 16 is the key exposure age.

\subsection{Are Students Really Dropping Out of School at Age 16?}

Up to this point, my dependent variable has been school attainment - as measured by the highest completed grade at the time of the 2000 census. In the absence of true panel data that tracks school attendance in every year, completed schooling is a sensible metric since not all students are at the same grade at age 16, the age factory employment is first legal. In this section, I explore an alternative metric, the grade-9 dropout rate.

As emphasized in Section 2.2, if new job arrivals at age 16 raised the opportunity cost of schooling, we would expect the bulk of the reduction in school attainment to come from students dropping out during the transition between secondary and high school (grades 9 and 10). Hence, I now turn to analyzing grade-9 drop out rates directly. I can also perform a placebo-like test. If the opportunity cost of school channel is at play, dropout rates for youths transitioning between secondary and high school should respond most to shocks at age 16 compared to other ages. In contrast, whether students ever reach this stage (i.e. complete secondary school) should respond most to shocks at younger ages when this preceding schooling decision is typically made.

I calculate grade-9 dropout rates for each cohort and commuting zone by dividing the number of students obtaining exactly 9 years of school by the number of students obtaining 9 or more years of school. ${ }^{33}$ With this measure in hand, I reproduce the multiple-exposure-age regressions presented in Section 4.1 but replace cohort average schooling with the grade-9 dropout rate. Figure 5 plots the coefficients for each age of exposure between 7 and 23 . As hypothesized, the largest grade-9 dropout rates occur for export employment shocks at age 16. The magnitude of the coefficient on exposure at age 16 is a sizable 0.374 (significant at

\footnotetext{
${ }^{32}$ The magnitude of the coefficient on shocks at age 16, -4.09, is even larger than in the baseline specification. The second largest coefficient is on shocks at 18,-1.60, and borderline significant at the 10 percent level.

${ }^{33}$ I restrict attention to cohorts aged 16 and above at the time of the 2000 census and include in the denominator 16 year olds who are both currently attending school and have completed grade 9 . Of course, these are not true dropout rates since a youth who repeats a grade may appear to have dropped out while a student who did dropout but later returned to school would not appear as a dropout.
} 
the 5 percent level). This coefficient implies that a shock at the 90th percentile of large firm expansions would increase grade- 9 dropout rates by 0.64 percentage points.

I perform a similar exercise but replacing the proportion of students dropping out between secondary and high school with the proportion of each cohort that have not graduated secondary school by the time of the 2000 census (i.e. they dropped out pre grade 9 ). In contrast to the results with the grade- 9 dropout rate, Figure 5 shows that the largest increases in this pre-grade-9 dropout rate occurs with export employment shocks at ages 11 to 13, consistent with the fact that these are the ages at which the decision to enter secondary school is made.

As before, I can combine multiple ages of exposure in the same regression. Appendix Table C. 1 reports these regressions of both grade- 9 and pre-grade- 9 dropout rates on the five ages of exposure centered around age 16 and age 13. Complementing Figure 5, the largest coefficients across the four regressions are those for shocks at age 16 on grade- 9 dropout rates and shocks at age 13 on pre-grade-9 dropout rates.

\subsection{Cross-Sectional Evidence from the 1990 Census}

I now turn to another data source that has been used sparingly up to this point: the census conducted in March 1990. As this census falls in the middle of my sample period, I can use contemporaneous school attendance and employment measures to: (1) provide further evidence that age 16 is the key exposure age, (2) show that youths did drop out to work in export manufacturing, and (3) provide support for my identification assumption that large employment shocks are not driven by educational decisions made in prior years.

To provide further support for my key exposure age, I run a linear probability model and regress a dummy for individual i's school attendance at the time of the March 1990 census, $A_{i z c}$, on export employment shocks in three preceding and three subsequent years. In order to trace the impact on different age groups, I include all cohorts $c$ aged between 12 and 19 at the time of the census alongside cohort fixed effects $\delta_{c}$, and allow the coefficients $\beta_{c t}$ on the net new export jobs per worker in year $t$ to differ for each cohort:

$$
A_{i z c}=\sum_{t=1987}^{1992} \beta_{c t} l_{z t}+\delta_{c}+\varepsilon_{i z c} .
$$

This specification compares the school attendance of youths in commuting zone $z$ shocked in 1989, the year preceding the March census, to youths of the same age in similar commuting zones that did not receive shocks that year. (And provides estimates based on similar comparisons for shocks in other years and at other ages.)

As in my panel specification, I restrict attention to large expansions and contractions that are plausibly exogenous. However, here I do not include commuting-zone fixed effects. Such fixed effects sweep out the shocks for one age group and cannot capture the highly non-linear 
differences in school attendance at different ages between high and low schooling locations. ${ }^{34}$ However, since locations do differ in their schooling dynamics, I restrict attention to a comparable set of locations; the 178 commuting zones that experienced an expansion in export manufacturing employment in at least one year between 1987 and 1992. Appendix C reports qualitatively similar results using all commuting zones and commuting-zone fixed effects (with each set of coefficients relative to the omitted category, shocks at age 16), as well as results for a similar exercise that also incorporates the 2000 census and shocks between 1997 and 2000 .

The leftmost panel of Figure 6 plots the 48 coefficients (6 annual shocks plotted separately for each of the 8 age cohorts) from estimating equation 4. Export employment shocks in 1989 (the year immediately preceding the survey) significantly reduce school attendance at age 16 with a $\hat{\beta}_{16,1989}$ of -1.90 and a standard error of 0.88 . (The raw coefficients, both here and in the remainder of this section, are relegated to Appendix C.) Consistent with 16 being my key exposure age, the negative effect on school attendance is most pronounced for 1989 employment shocks on the cohort aged 16 in comparison both to shocks in other years for this same cohort or to shocks in any year for older and younger cohorts.

The second purpose of this section is to show is that these 16 year olds really are dropping out of school to take up export jobs. I repeat the specification above but now replace the school attendance dummy with a dummy for whether the youth is working full time; or alternatively, working full time in an export manufacturing industry. The coefficients from these regressions are plotted in the second and third panels of Figure 6. For the cohort aged 16 , both the proportion of the cohort working and the proportion working in exports respond most to export employment shocks in 1989. Thus, the previously-documented decline in school attendance is mirrored by a rise in export manufacturing employment. Reassuringly, both the attendance and employment coefficients are of similar magnitudes (-2 and +2 respectively). The coefficient on export employment is slightly lower at 1.4, suggesting that some of those dropping out due to export shocks either end up in other sectors or are misclassified by census enumerators.

I can further explore these sectoral employment choices by replacing school attendance in equation 4 with dummies for employment in the other industries reported in the 1990 census (services, primary industries, non-export manufacturing, insufficiently specified manufacturing, and unclassified). In contrast to the large response of export manufacturing employment noted above, employment propensities in these other industries do not appear to respond to export employment shocks (see Appendix Figure C.6). For example, for 1989 shocks on the cohort aged 16, the magnitude of the change in employment in export manufacturing is more than 4 times greater than the change in the sector with the second largest effects (insuffi-

\footnotetext{
${ }^{34}$ To see this non-linearity note that attendance gaps between better and worse locations only appear between ages 14 and 21 (before which almost everyone is in school and after which almost no one is).
} 
ciently specified manufacturing - the sector where misclassified export jobs would show up).

Although employment impacts seem concentrated in export manufacturing, I cannot rule out that some of these new jobs may be at informal export manufacturing firms. ${ }^{35}$ For example, if a new factory generates demand for informal subcontracting, my estimated schooling impacts combine the effects of both these types of job creation.

The final purpose of this section is to provide support for the IV strategy outlined in Section 2.4. I argued that large firm expansions and contractions (which I use to calculate my employment shocks) are plausibly exogenous to education decisions made in prior periodsconditional on commuting-zone-specific fixed effects and trends, and state-time fixed effects. To test this claim, I explore whether employment expansions and contractions in the years immediately following 1989 are related to educational choices made by youths in the March 1990 census. As can be seen from any of the panels in Figure 6 (or C.6), there is no evidence that the shocks after the census of March 1990 are related to either school attendance or employment outcomes. For all age groups and all three dependent variables, the coefficients are bunched around zero for shocks in the years following 1989. More formally, focusing on the school attendance regression in equation 4 above and the coefficients for cohorts aged 16, I cannot reject the null hypothesis that the coefficients on export shocks in the three years following the census are equal to zero (an F-statistic of 0.0083 distributed $\mathrm{F}(3,163)$ ). In contrast, shocks in prior years do alter school attendance propensities: I can reject the null that the coefficients on shocks in preceding years are zero at the 1 percent level (the F-statistic is 4.05).

\subsection{Gender Differences}

The main analysis groups males and females together. In this section, I explore heterogeneity across genders. As a first pass, columns 1 and 2 of Table 5 rerun my main specification by gender. I replace cohort average schooling in equation 1 with either $S_{z c m}$, the average schooling of males in the cohort, or $S_{z c f}$, the average schooling of females in the cohort. As I run the two regressions separately, I allow for gender-specific trends. Although both male and female schooling significantly decline with new export job arrivals, male schooling declines more than female with coefficient estimates of -4.4 and -2.5 respectively.

The independent variable, net new export jobs per worker at age 16, is the same in both specifications. Thus, these gender differences can come about either because boys and girls respond differently to the same job opportunities, or because some job opportunities are gender-specific. In the latter case, new export jobs that are particularity suited to women will have a more pronounced effect on female schooling than male and vice versa. Verifying this prediction serves as a simple test of my assumed mechanism, that schooling responds to new export opportunities through changes in the opportunity cost and returns to school.

\footnotetext{
${ }^{35}$ Unfortunately, the 1990 census doesn't distinguish between formal and informal jobs.
} 
In order to carry out this test, I utilize the fact that the IMSS employment data provide firm-level employment by gender. These data cannot be used directly, since the sex ratio in a factory may be endogenous to boys' and girls' schooling choices. Accordingly, I use the sex ratio among new jobs created during the first 5 years of my sample (1985 to 1989) to create a commuting-zone and 3-digit-industry specific sex ratio and assume subsequent employment changes in that location-industry pair maintained this ratio. ${ }^{36}$ I then multiply these sex ratios by the total employment shocks for that location-industry pair to provide annual measures of gendered local labor demand that are plausibly exogenous to contemporaneous education decisions. I also present a second variant that multiplies the total employment shocks by the sex ratio at plants in that location-industry pair in 1985, the first year of my IMSS data. ${ }^{37}$

With these two sets of sex-specific export employment shocks $\hat{l_{z c m}}$ and $\hat{l_{z c f}}$ in hand, I run:

$$
S_{z c f}=\beta_{m} \hat{l_{z c m}}+\beta_{f} \hat{l_{z c f}}+\delta_{z}+\delta_{z} c+\delta_{r c}+\varepsilon_{z c}
$$

for female schooling, or similarly for male schooling by replacing $S_{z c f}$ with $S_{z c m}$. I hypothesize that $\beta_{f}<\beta_{m}$ if female schooling is the dependent variable and $\beta_{m}<\beta_{f}$ if male schooling is.

Prior to presenting the results of this test, I confirm that these predicted sex-specific shocks are correlated with the realized sex-specific employment shocks $l_{z c m}$ and $l_{z c f}$. I replace the schooling dependent variable with either $l_{z c m}$ or $l_{z c f}$ in the specification above. These results are presented in Columns 3-6 of Table 5. Reassuringly, for both variants of shock-using either $\Delta 1985$-1989 sex ratios or 1985 sex ratios - I find that male jobs are stronger predictors of male job creation than female ones and vice versa for female job creation. Columns 7-10 of Table 5 present the test itself. As hypothesized, and for both variants, male schooling declines significantly with male export employment shocks but there is a substantially smaller and insignificant decline in response to female shocks. ${ }^{38}$ Similarly, female school attainment declines more with female export employment shocks than with male shocks (although the coefficient on female shocks in female columns is smaller than for male shocks in male columns, and it is not significantly different from zero). Youths respond more to employment shocks specific to their gender, and the response is larger for males.

\subsection{Alternative Mechanisms}

The previous sections provide a range of evidence that new export opportunities lower school attainment by raising the opportunity costs of schooling and hence inducing youths on the margin to drop out of school. Here I directly dismiss three alternative mechanisms.

\footnotetext{
${ }^{36}$ For commuting zones where there is no job creation in that industry between 1985 and 1989, I use the sex ratio for local job creation at the 2-digit industry level, then at the 1-digit level, then at the 3-digit state level, and finally the 3-digit national level. I obtain similar results using different orderings of this algorithm.

${ }^{37}$ The first measure is preferred since few locations had factories in 1985 and the sex ratio of jobs created in the export booms of the 1980s and 1990s differed substantially from the prior sex ratio.

${ }^{38}$ I find marginally insignificant p-values of 0.15 and 0.16 (columns 7 and 9 ) for the test of the $\beta_{m}=\beta_{f}$ null.
} 


\subsubsection{Parental Work Channels}

New export jobs may also attract adult family members, not just youths. As education is a normal good, new jobs should increase household income and hence raise schooling. To explain the reduction in schooling I find, adults who previously looked after the young children in the household would have to enter the workforce and make a youth stay home instead.

The cross-sectional methodology introduced in Section 4.3 allows me to dismiss this parental employment explanation. I rerun the specification in equation 4 on the cohort aged 16, but allow the coefficients on export employment shocks to differ depending on whether one of the youth's parents is employed in export manufacturing at the time of the census. ${ }^{39}$ If my results were driven by parental work channels, I would expect the reduction in school attendance due to shocks in 1989 to be most pronounced in households where a parent is working in export manufacturing. In fact, the opposite is true, with reductions in attendance driven by youths in households where parents are not employed in export manufacturing. I reach a similar conclusion looking at households where any household member (e.g. a sibling) works in exporting. These results are shown in Appendix Figure C.7 where I also show that export employment shocks do not change the probability that parents work but do increase the probability they work in export manufacturing.

\subsubsection{Selective Migration}

As discussed in Section 2.3, the census does not record where migrants were living at age 16. As I cannot match migrants to local job opportunities at their key exposure age, I excluded them from my sample and my results only pertain to the non-migrant population. ${ }^{40}$

One fifth of export manufacturing workers are internal migrants. My results understate the true educational decline if potential future migrants reduce their schooling in response to new opportunities at exporters in other commuting zones. I cannot evaluate this claim using my identification strategy. However, suggestive of this hypothesis, McKenzie and Rapoport (2006) find that the option to migrate to the US lowers educational attainment in Mexico.

Migration could bias my results if local labor market conditions alter the composition of out-migrants. For example, a new factory opening may deter a low-skill worker from migrating, but have no impact on the migration decision of a high-skill worker. The average education of non-migrants would then fall due to reduced out-migration of low-skill workers. I address this concern in Appendix B. First, I show that new export-manufacturing jobs do not increase the size of the sample cohort or the sample cohort's share of the working population.

\footnotetext{
${ }^{39}$ Note that I am not able to append family backgrounds in the main analysis since older cohorts in my sample have left their parental homes by the time of the 2000 census.

${ }^{40}$ Rural youths will be underrepresented in this sample if they are more likely than urban youths to migrate in search of jobs. As urban areas contain three quarters of Mexico's population and most of its formal sector jobs, this underrepresentation will only have a small impact on my population-weighted estimates.
} 
Second, I use data from the 2000 census on the municipio of residence in 1995 to show that new export jobs arrivals deter relatively more educated youths, rather than less educated youths, from migrating internally. This parallels Chiquiar and Hanson (2005) who find that emigrants to the United States are more skilled than non-emigrants. ${ }^{41}$ Therefore, the negative schooling impacts I find are potentially even larger in magnitude since compositional effects due to selective out-migration will likely bias the coefficient towards positive values.

Another concern is that exogenous inflows of migrants may alter both education and factory location decisions. An inflow of low-skill migrant labor would lower local unskilled wages, attracting factories and encouraging local students to acquire more education. As with selective out-migration, such migrant inflows bias my negative point estimates towards zero.

Of course, in-migration may reduce the responsiveness of non-migrant education to new factory openings (since locals are less likely to obtain these factory jobs and in-migrants would put downward pressure on the wages the jobs paid). In Appendix B, I show that this hypothesis is correct. A large number of migrants working in the export sector of a particular commuting zone attenuates the educational impacts of new export job arrivals. In fact, consistent with the opportunity cost of schooling channel, the regression estimates imply that if all local export workers are migrants there would be no negative effects at all.

\subsubsection{Income Effects and High Returns to On-the-Job-Training}

One explanation for my findings is that the return to on-the-job training exceeds the return to schooling for students who choose to drop out as a result of new export job arrivals. In this section, I show that there is no support for such a conjecture. By the year 2000, the youths induced to drop out by the arrival of export jobs are earning, if anything, lower wages than they would have earned had these jobs never arrived in their localities.

The 2000 census records the total income, the earned income and the hours worked in the previous month. I replace the dependent variable in equation 1 with several cohort-level income measures. The identification arguments are the same as those discussed in Section 2.4. However, reverse causality is less worrisome here as cohort income deviations in the year 2000 are unlikely to influence factory location decisions in previous years.

Table 6 presents these results. To capture both extensive and intensive margins, columns 1 and 2 present results with the average total or earned income of the cohort as the dependent variable (including the zeroes in the averages). Columns 3 and 4 focus on the intensive margin and replace the dependent variable with the average log wage or log income among full time workers in the cohort. Finally, column 5 replaces the dependent variable by a simple proxy for the Mincerian rate of return; the schooling coefficient from a commuting-zone and

\footnotetext{
${ }^{41}$ Of course, these emigration patterns to the US may not have been driven by local labor demand shocks so the international migration evidence is only suggestive.
} 
cohort specific regression of log earned income on both years of schooling and a sex dummy. ${ }^{42}$

If the return to on-the-job training in the export sector exceeds the return to school we would expect positive effects of export jobs on incomes. Instead, all five coefficients are negative although not significantly so (the coefficients are of reasonable magnitudes but the standard errors are too large to detect such effect sizes given the noise in the census income data). Of course, income losses do not imply welfare losses. Impatient or credit-constrained students will rationally forgo schooling for immediate income gains, knowing that in a few years their salaries will be lower than if they had stayed at school (particularly if year-of-entry wage premia fade). Policymakers could still have paternalistic concerns for their citizens if they believe adolescents discount the future particularly heavily when faced with delayed gains. Similarly, peer effects at this stage of life are particularly strong, and may cause excessive dropout rates.

The magnitudes of the coefficients imply low returns to schooling for these cohorts. I find a coefficient of -0.05 for $\log$ income and -0.07 for log wages. Combining these with the schooling coefficients in Table 2 implies Mincerian "rates of return to schooling" of around 2 percent. ${ }^{43}$ This return to an additional year of school is lower than returns of around 7.5 percent found by Psacharopoulos, Velez, Panagides, and Yang (1996) for Mexico. A low estimate of the return to schooling is not surprising. These estimates are identical to local average treatment effects (LATEs) from regressing log income on schooling where schooling is instrumented by net new export jobs. The LATE is likely to be lower than the average returns to school since new export jobs directly raise wages and the LATE group (youths whose decisions are altered by factory openings) are likely to have lower returns to education.

\section{What is Different about Export Manufacturing?}

The previous sections have focused on the schooling impacts of export manufacturing jobs. The introduction outlined several motivations for this focus. However, in order to better understand the mechanisms at play, I now explore whether the schooling impacts of export jobs differ from job creation in other sectors? And if so, why?

Recall that in column 5 of Table 2, I modified equation 1 to include net new jobs in non-export industries as a control (again focusing on large expansions and contractions). Figure 7 plots the coefficients on both export and non-export jobs from running this specification for every age of exposure between 7 and 23. Across the age distribution, the schooling impacts of new export job opportunities closely track the impacts of new job opportunities in other sectors. The striking exception is at age 16 where new export jobs lead to substantially greater reductions in school attainment (recall the coefficient on export jobs was -3.25 compared to -1.17 for all other jobs, with the difference significant at the 1.2 percent level).

\footnotetext{
${ }^{42}$ Given that the effects found in this paper operate on schooling margins between primary and high school, I restrict attention to the rate of return within this schooling range.

${ }^{43}$ The return to schooling is simply the wage or income coefficient divided by the coefficient on schooling.
} 
Endogeneity issues are a greater concern for new non-export jobs, even using large expansions and contractions. Unlike exports, demand in these industries may be driven by local consumption patterns that are correlated with local unobservables. In order to mitigate these concerns, Appendix D reports similar patterns using only job growth in industries that are highly geographically concentrated and so shocks are likely to be driven by national or international, rather than local, demand. ${ }^{44}$ In fact, using only shocks in these highly agglomerated industries, new export job arrivals at age 16 continue to significantly reduce schooling while non-export job arrivals lead to small (and insignificant) increases in schooling.

Why are the effects of new export jobs so pronounced at age 16 yet this is not the case for jobs in other sectors? This is the age I dubbed the key exposure age, where the opportunity cost of schooling channel is strongest. Hence, it is reasonable to think that the opportunity cost channel is particularly strong for new export jobs, either because of the skills these jobs demand, the wages they pay, or the characteristics of youths in the locations they open. In order to explore these explanations, I lay out a conceptual framework that clarifies how these characteristics affect schooling choices.

\subsection{A Conceptual Framework for Understanding Educational Choices}

Forward-looking youths in a particular commuting zone choose among three discrete education levels, $s=(1,2,3)$, corresponding to primary school, secondary school and high school respectively (the three most common educational levels in Mexico). Youths make an irreversible decision in each period $t$ to either stay on at school and obtain an additional level of education or enter the labor force with their current level of schooling.

A student at school receives $u(\bar{y})$ utility that includes any family support and the direct utility from schooling. A worker with schooling $s$ who entered the labor force in period $i$ earns a wage of $y_{s, i, t}$ in period $t$. I assume log utility and a Mincer-like wage function:

$$
u\left(y_{s, i, t}\right)=\ln y_{s, i, t}=a_{0}+\gamma s+b[t-i]+\varepsilon_{s, i},
$$

where $a_{0}$ is the base salary, $\gamma$ is the return to an additional level of school, $b$ is the return to experience, and $\varepsilon_{s, i}$ is a stochastic and persistent year-of-entry wage premium specific to skill $s$.

These year-of-entry wage premia exist as only certain firms will offer a worker a job in any given year. In a year when more formal firms are hiring, a student is more likely to obtain a job at a firm paying persistently higher wages. ${ }^{45}$ Accordingly, these wage premia are a weakly

\footnotetext{
${ }^{44}$ I restrict attention to 95 of the 276 4-digit IMSS industries that had spatial Hefindahl indexes of more than 0.1 in 2000. This strategy also mitigates concerns that export shocks are partially driven by local demand shocks for non-export production in industries I categorize as export.

${ }^{45}$ Firm-specific premia may derive from efficiency wage, fair wage, insider bargaining or search models. Frias, Kaplan, and Verhoogen (2009) document firm-specific wage differentials in Mexico. Duval Hernandez (2006) presents evidence of formal sector job rationing in Mexico. Oreopoulos, von Wachter, and Heisz (2012) and Beaudry and DiNardo (1991) present evidence for year-of-entry wage premia across and within firms, respectively.
} 
increasing function of new job opportunities, $l_{i}$, in the year of entry into the labor force;

$$
\varepsilon_{s, i}=\omega_{s, i} \phi_{s, i} l_{i}
$$

where $\phi_{s, i}$ is the proportion of the new jobs available to workers with school $s$ and $\omega_{s, i} \geq 0$ captures the premia the new jobs pay compared to job opportunities in a normal year.

A student lives forever, cannot borrow or save and discounts at the rate $\rho$. The dropout decision of an enrolled student in period $t$ depends on whether her discount rate is above the discount-rate cutoff, $\bar{\rho}_{s, t}$, obtained by equating the net present value of dropping out with school $s$ with the net present value of obtaining exactly one more school stage, $s+1$ :

$$
\bar{\rho}_{s, t}=\frac{\gamma+\mathbb{E}_{t} \varepsilon_{s+1, t+1}-b-\varepsilon_{s, t}}{a_{0}+\gamma s+\varepsilon_{s, t}-\ln \bar{y}} \equiv \frac{R S_{s+1, t}}{O C_{s, t}} .
$$

This expression is intuitive. The numerator corresponds to the perceived per-period utility gain from possessing an additional level of schooling (which I define as the "return to schooling" $\left.R S_{s+1, t}\right)$. The denominator corresponds to the utility difference between working this period and being at school (which I define as the "opportunity cost of schooling" $O C_{s, t}$ ). An impatient student with a high discount rate, $\rho \geq \bar{\rho}_{1, t}$, will choose $s=1$ in period $t$; in period $t+1$ a student with an intermediate discount rate, $\bar{\rho}_{1, t}>\rho \geq \bar{\rho}_{2, t+1}$, will choose $s=2$ and a patient student with a low discount rate, $\rho<\bar{\rho}_{2, t+1}$, will choose $s=3$. $^{46}$

\subsubsection{Aggregate Schooling of the Cohort Aged 16 and New Plant Openings}

I first derive an expression for the average schooling of the cohort at my key exposure age, age 16. In order to generate within-cohort variation in schooling, I assume that youths are heterogeneous in their discount rates but otherwise identical. ${ }^{47}$ Since many Mexicans start school late or repeat grades ${ }^{48}$ — and the effect of new job arrivals will depend on a youth's pre-existing level of education-I divide the cohort into two groups: a proportion $\theta$ of youths who are not lagging behind (i.e. if they chose to stay at school they have $s=2$ at age 16) and a proportion $1-\theta$ who are lagging behind one period (i.e. they have only just completed $s=1$ at age 16). I allow the two groups to draw from different distributions of discount rates: $\rho$ is distributed with a p.d.f. $f(x)$ and c.d.f. $F(x)$ across the continuum of non-lagging youths, and with a p.d.f. $g(x)$ and c.d.f. $G(x)$ across lagging youths. These c.d.f.s and the discount-rate cutoffs pin down aggregate schooling, $S$, of the age-16 cohort in period $T$ :

$$
S=1+\theta\left[F\left(\bar{\rho}_{1, T-1}\right)+F\left(\bar{\rho}_{2, T}\right)\right]+(1-\theta)\left[G\left(\bar{\rho}_{1, T}\right)+G\left(\bar{\rho}_{2, T+1}\right)\right] .
$$

I now examine an unanticipated and one-off plant opening in period $T$. The opening gen-

\footnotetext{
${ }^{46}$ I restrict attention to the simple case where both the return to and opportunity cost of schooling are positive and the $\varepsilon$ shocks are small enough that the ranking $\bar{\rho}_{1, t}>\bar{\rho}_{2, t+1}$ is always preserved.

${ }^{47}$ Youths may also differ in their ability which would affect wages and $\bar{y}$. This additional heterogeneity will not alter the sign predictions as long as ability is observable and $\varepsilon_{s, i}$ is weakly increasing in $l_{i}$ for all abilities.

${ }^{48}$ For example, 33.6 percent of 16 year olds attending school in the 1990 census had not completed grade 9.
} 
erates a large number of vacancies, $l_{T}>0$, as the whole plant must be staffed at the time of opening. In subsequent periods there are smaller (known) vacancy shocks, $l_{T+t}=\delta^{t} l_{T}$ with $\delta \in[0,1)$, demanding the same skills and paying the same premium. Taking a first-order Taylor expansion of equation 9 around $l_{T}=0$ - the counterfactual of no plant opening-I obtain the resulting change in cohort schooling:

$$
\begin{aligned}
&\left.S\right|_{l_{T}>0}-\left.S\right|_{l_{T}=0}= \underbrace{\left.\frac{d\left(\bar{\rho}_{1, T}\right)}{d \varepsilon_{1, T}}\right|_{l_{T=0}}}_{<0} d_{1, T} \omega_{1, T} \phi_{1, T} l_{T}+\underbrace{\left.\frac{d\left(\bar{\rho}_{1, T}\right)}{d \varepsilon_{2, T+1}}\right|_{l_{T}=0}}_{>0} \delta d_{1, T} \delta \phi_{2, T} l_{T} \\
&+\underbrace{\left.\frac{d\left(\bar{\rho}_{2, T}\right)}{d \varepsilon_{2, T}}\right|_{l_{T}=0}}_{<0} d_{2, T} \omega_{2, T} \phi_{2, T} l_{T}+\underbrace{\left.\frac{d\left(\bar{\rho}_{2, T}\right)}{d \varepsilon_{3, T+1}}\right|_{l_{T}=0}}_{>0} \delta d_{2, T} \omega_{3, T} \phi_{3, T} l_{T} .
\end{aligned}
$$

where $d_{1, T} \equiv g\left(\bar{\rho}_{1, T}\right)(1-\theta)$ is the density of youth on the primary/secondary school margin and $d_{2, T} \equiv g\left(\bar{\rho}_{2, T}\right)(1-\theta) \delta+f\left(\bar{\rho}_{2, T}\right) \theta$ is the density of youth on the secondary/high school margin (with the lagging-youth density adjusted by $\delta$ as they receive the shock one period later).

The first term captures the impact of any job arrivals that require only primary school. These jobs induce students on the margin between primary and secondary school to drop out by raising the opportunity cost of school $\left(O C_{1, T}\right)$, lowering the return to school $\left(R S_{2, T}\right)$ and hence lowering the discount-rate cutoff $\bar{\rho}_{1, T}$. Since non-lagging youths already have $s=2$ (or chose to dropout), only the lagging proportion $1-\theta$ respond to these lowest-skill jobs.

The next two terms capture the impacts of job arrivals requiring secondary school. For lagging students on the margin between primary and secondary, these jobs induce school acquisition by raising the return to school $\left(R S_{1, T}\right)$ and hence the discount-rate cutoff $\bar{\rho}_{1, T}$ (term two). These same jobs induce school drop out for students on the margin between secondary and high school in both groups by raising the opportunity cost of school $\left(O C_{2, t}\right)$, lowering the return to school $\left(R S_{3, t}\right)$, and hence lowering the $\bar{\rho}_{2, T}$ and $\bar{\rho}_{2, T+1}$ cutoffs (term three).

Finally, any new jobs requiring high school raise the returns to school for both groups and encourage youths on the margin between secondary and high school to acquire more education (term four). Appendix Figure C.8 illustrates these shifts in discount-rate cutoffs.

The return to schooling in Mexico rose pre-NAFTA before falling in the late 1990s (see footnote 1). Against this backdrop, I note that a plant opening can lead to lower cohort schooling despite the return to schooling rising if the opportunity cost of schooling also rises (for example, if new export jobs pay high wages but relatively more so for high-skill positions).

\subsection{Exploring Heterogeneity in the Impact of New Job Arrivals}

The framework above suggests that the relationship between employment expansions at age 16 and schooling is ambiguous and mediated by three factors: the skill level demanded by the new jobs (the $\phi_{s, T}$ 's), the wage premia these jobs pay over existing job opportunities (the $\omega_{s, T}$ 's), and the density of youths on the dropout margin at age 16 (the $d_{s, T}$ 's). The importance of the skill demanded was apparent from Table 4 which showed that new 
Maquiladora and blue collar EIA jobs reduced schooling, but white collar EIA jobs did the opposite. In this section, I expand on the analysis using census data on schooling and wages matched to an individual's industry of employment (recall IMSS does not record schooling). To minimize endogeneity concerns, I use data on younger workers (those aged 16-28) in the 1990 census to characterize the post-1990 job arrivals, and then explore how these characteristics relate to heterogeneity in the schooling impacts of these job shocks.

In terms of the first factor, the skill level, I categorize jobs in each state-industry cell (for the 86 industries I can match across the census and IMSS) by the proportion of workers in each of three schooling bins: workers without completed secondary schooling (grade 8 or less), with secondary school but without completed high school (between 9 and 11), and high school and above $(12+)$. I can then impute the skill distribution of new jobs by multiplying the IMSS job arrivals by the census skill proportions for the corresponding state-industry pair.

The top left panel of Figure 8 plots, by sector, the imputed skill distribution of net new job arrivals per worker in the years 1991-1999 attributable to large firm expansions and contractions (the variation used in my preferred regression specifications). ${ }^{49}$ Export industries have a much larger share of employees falling into the first two bins, workers without high school, compared to non-export sectors (89 percent compared to 72 percent). As all my IMSS shocks are formal, this skill discrepancy may be due to the fact that export sectors have more informal jobs and formality is not recorded in the 1990 census. The top right panel of Figure 8 shows this is not the case, with an even larger discrepancy when I repeat the exercise using data from the 2000 census where formality is recorded.

I use wage income from the census to calculate proxies for wage premia (the ratio of wage income for full time employees in an industry relative to the average wage in that locality for that skill level), again at the state-industry level. The middle panels of Figure 8 plot the average value of these premia by sector and skill, imputed as above from the composition of the 1991-1999 IMSS job shocks. New formal jobs arrived in industries that paid above average wages for their localities, although slightly more so for jobs in non-export than export sectors.

Finally, I require proxies for the density of youths on the secondary and high school dropout margins. It is straightforward to show that the densities are simple functions of three objects: (1) the proportion of the entire cohort dropping out at that educational stage; (2) the proportion of the cohort that is both non-lagging and drops out at that stage; and (3) the persistence of job shocks across years, $\delta .{ }^{50}$ The first two objects I can estimate separately for each commuting zone from the school attainment and attendance data from recent cohorts of 16 year olds in the 1990 census. ${ }^{51}$ The third, the perceived persistence rate, is unobservable,

\footnotetext{
${ }^{49}$ Appendix Figure C.9 repeats this exercise using job shocks across all years (1986-1999) and all firms.

${ }^{50}$ The density in the first term of equation $10, g\left(\bar{\rho}_{1, T}\right)(1-\theta)$, can be rewritten as $h\left(\bar{\rho}_{1, T}\right)-f\left(\bar{\rho}_{1, T}\right) \theta$ where $h(\cdot)$ is the p.d.f. of the entire cohort. Similarly, $g\left(\bar{\rho}_{2, T}\right)(1-\theta) \delta+f\left(\bar{\rho}_{2, T}\right) \theta$ equals $\delta h\left(\bar{\rho}_{2, T}\right)+(1-\delta) f\left(\bar{\rho}_{2, T}\right) \theta$.

${ }^{51}$ In terms 1 and 3 of equation 10, job arrivals induce dropout for youths with $\rho$ s just below the (pre-
} 
and so I assume $\delta=0.5$. I explore alternate proxies for these objects later in this section.

The bottom left panel of Figure 8 summarizes these density measures by sector. I subdivide the skill proportions from the top left panel into terciles of the relevant density term for that skill level from equation 10 (where there are two relevant densities for jobs that demand secondary school, and so two blocks of three bars). The higher the third bar in each block relative to the first two, the larger the share of jobs arriving in locations with many youths on the relevant schooling margin. Compared to non-export jobs; export jobs demanding primary school arrive disproportionately in locations with many youths on the primary/secondary margin (the first block), and export jobs demanding secondary school arrive disproportionately in locations with many youths on the secondary/high school margin (the third block).

In the right panel of Figure 8, I use data from the 2000 census that exclude informal jobs. Patterns are similar except that there is a substantial increase in the share of nonexport jobs demanding primary school that arrive in locations with many youths on the primary/secondary margin. This suggests that inference using measures from the 1990 census, where I cannot exclude informal jobs, may be misleading for the least-skilled IMSS jobs.

I now turn to supplementing my baseline regression specification, equation 1, with the four job-characteristic controls derived in equation 10 :

$S_{z c}=\beta_{0} l_{z c}+\beta_{1} d_{1 z} \omega_{1 z} \phi_{1 z} l_{z c}+\beta_{2} \delta d_{1 z} \omega_{2 z} \phi_{2 z} l_{z c}+\beta_{3} d_{2 z} \omega_{2 z} \phi_{2 z} l_{z c}+\beta_{4} \delta d_{2 z} \omega_{3 z} \phi_{3 z} l_{z c}+\delta_{z}+\delta_{z} c+\delta_{r c}+\varepsilon_{z c}$.

I calculate $\omega_{s z} \phi_{s z} l_{z c}$-for cohort $c$ and for each of the three skill bins $s$-by multiplying net new jobs $l_{z c j}$ in industry $j$ in the year the cohort turned 16 by the state $r$-industry $j$ specific wage premia and skill proportions described above, and then summing across all 86 3-digit industries: $\sum_{j} \omega_{s r j} \phi_{s r j} l_{z c j}$. The $d_{s z}$ density terms, also described above, pre-multiply this summation. As explained above, I focus on job shocks post 1990, the year my proxies are measured, and again restrict attention to large single-firm expansions and contractions.

Columns 1-4 of Table 7 present results for all IMSS job arrivals (columns 5-8 show results just for the export industries that were my focus up to now). I build the analysis in steps. Column 1 presents the specification without characteristic controls. Using post-1990 shocks only, there is no negative effect of all-industry job shocks (column 5 shows that export shocks post 1990 had significant negative impacts on schooling, as they did in the full sam-

shock) secondary and high school dropout cutoffs, respectively. Thus, for object (1), I use the proportion of the cohort with exactly 9 (the schooling of youths with $\rho$ s just below $\bar{\rho}_{1, t}$ ) or 12 (the analog for $\bar{\rho}_{2, t}$ ) years of school. I take a weighted average of the 5 cohorts aged 20-24 that have had time to complete high school. For object (2), I use the change in the proportion of the cohort at the correct age-for-grade and at school in the final year of secondary school, grade 9, and the proportion for the cohort one year older in grade 10 (and similarly for the high school to college transition). In terms 2 and 4 of equation 10, job arrivals induce school acquisition for youths with $\rho$ s just above the cutoffs. Thus, I calculate similar measures for object (1) but use the proportions with exactly 7-8 years of school (the school attainment of youths who start but do not complete secondary school) or 10-11 years of school (the analog for high school). For object (2), I use the change in attendance of students at the correct age-for-grade between 7 and 8, or 10 and 11, years of school. 
ple). Columns 2-3 add the skill and skill-wage interactions, respectively. ${ }^{52}$ The coefficients on the key secondary school job shocks - recall that secondary school was the modal level of education for export sector employees in my 2000 census sample - are negative but only significantly so when the wage interactions are also included. However, as is clear from equation 10, a weak negative coefficient on these intermediate-skill job shocks is not surprising since it conflates two effects: lagging youths who acquire more education due to these jobs, and non-lagging youths whose dropout rates increase.

Column 4 includes the full set of controls that allows me to disentangle these two effects. The coefficient on the third interaction is negative, large, and highly significant. School dropout is driven by jobs demanding secondary school arriving in locations with many youths on the secondary/high school dropout margin. I find support for the sign predictions on two of the three other interactions. As predicted, both secondary and high school jobs induce skill acquisition if a sufficient number of youths are on the relevant margin (although only the former is significant). Less intuitively, jobs demanding primary school induce school acquisition for youths on the relevant margin (although, as noted earlier, proxies drawn from the 1990 census may be particularly misleading for this category as formality is not recorded).

Once the job characteristics captured by the interaction terms are accounted for, export jobs no longer have a differentially negative effect on school dropout. Column 9 adds export job shocks to the all jobs specification in column 1, and column 10 further includes the four interaction terms. The coefficient on new export jobs - i.e. the differential impact of exports - shrinks from a significant -1.920 to an insignificant -0.862. The interaction terms have substantial explanatory power. Running the non-export shocks over the sample period through the coefficients on the interaction terms in column 10 and rescaling by the average shock size, I find that non-export job arrivals reduced average schooling by 0.046 years for a shock size of 1 (i.e. one job arrival per worker). Running export job shocks through the same coefficients, I find export jobs reduced average schooling by 0.547 years, or a differential impact of 0.501 . This explained component is $2 / 3 \mathrm{rds}$ of the unexplained component. ${ }^{53}$

Columns 11-16 find qualitatively similar results using a range of alternative proxies. Column 11 calculates wage premia using hourly rather than total wages. Column 12 calculates density measures using cohorts aged 17-21 rather than 20-24 at the time of the 1990 census. Column 13 uses estimates of $\delta$, the vacancy persistence rate, from an $\mathrm{AR}(1)$ regression of net new job arrivals at the industry-commuting zone level. Column 14 replaces the density proxies in terms two and four of equation 10 with those used in terms one and three, respectively. Finally, columns 15-16 redo the analysis using only job shocks in the highly-agglomerated industries described in Appendix D. The bulk of high-skill job creation occurs in non-export

\footnotetext{
${ }^{52}$ One skill interaction drops out since the sum of job shocks in all skill bins equals the total job shock.

${ }^{53}$ The unexplained component is the effect of new export jobs in row 2 of column 10.
} 
sectors where local demand shocks may drive labor demand. In column 16, where these endogeneity concerns are mitigated, the high-skill interaction term is positive, significant, and large in magnitude -implying that more skilled jobs encourage school acquisition.

In summary, the negative schooling impacts induced by the large influx of export manufacturing jobs in Mexico seem to be driven by the fact that many of these jobs demanded workers with secondary educations, paid reasonably high wages and arrived in locations where many youths were on the margin between secondary and high school. These export jobs were not intrinsically different to other jobs, they just possessed a set of characteristics that disproportionately induced school dropout.

\section{Conclusions}

This paper finds that for Mexico during the period 1986 to 2000, the new manufacturing opportunities generated by trade liberalization altered the distribution of education. In particular, the influx of new export-manufacturing jobs reduced the schooling of cohorts at their key exposure ages at the time. The magnitudes I find suggest that for every twenty-five new jobs created, one student dropped out at grade 9 rather than continuing on through grade 12.

The specific characteristics of export manufacturing in Mexico can explain these negative schooling impacts. Export manufacturing generated an abundance of new low-skill jobs which substantially raised the opportunity cost of schooling for youths on the dropout margin at age 16. My findings suggest that there would not have been the same negative schooling impacts had these jobs demanded more educated workers and had they arrived in parts of the country where fewer youths were on the dropout margin at the legal factory employment age.

These findings are relevant for designing industrial and trade policies. Many developing countries, including Mexico, have prioritized raising the education level of the workforce at the same time as pursuing an export-oriented industrialization strategy. Given the trade-off between these goals in the Mexican context, it is vital for policymakers to know which types of new manufacturing opportunities pull students out of school and in what context.

There are also policy remedies that do not require altering the type or location of job arrivals. Payments that condition on school attendance would neutralize the negative educational impact of export jobs. ${ }^{54}$ Alternatively, raising the age of earliest employment in export manufacturing ensures that most young workers would have already chosen their final education level before being allowed to work in these plants. Finally, reducing the psychic cost of returning to school in later life would allow adults to obtain the foregone education should the export-manufacturing jobs dry up or should the adult come to regret their decision.

\footnotetext{
${ }^{54}$ The much-studied Progresa program in Mexico does just that, providing cash transfers to parents who keep their children in school up to grade 9 . The roll out was too late to have an impact on my sample.
} 


\section{References}

Airola, C., And J. Juhn (2005): "Wage Inequality in Post-Reform Mexico," Working Papers 2005-01, Department of Economics, University of Houston.

Beaudry, P., And J. DiNardo (1991): "The Effect of Implicit Contracts on the Movement of Wages Over the Business Cycle: Evidence from Micro Data," The Journal of Political Economy, 99(4), 665-688.

Bernard, A. (1995): "Exporters and Trade Liberalization in Mexico: Production Structure and Performance," Discussion paper, MIT.

Bernard, A., And J. Jensen (1995): "Exporters, Jobs, and Wages in US Manufacturing: 1976-1987," Brookings Papers on Economic Activity: Microeconomics, 1995, 67-112.

Bernard, A. B., R. Robertson, and P. K. Schott (2004): "Is Mexico A Lumpy Country?," NBER Working Papers 10898.

Bertrand, M., E. Duflo, and S. Mullainathan (2004): "How Much Should We Trust Differences-in-Differences Estimates?," Quarterly Journal of Economics, 119(1), 249-275.

Chiquiar, D., and G. Hanson (2005): "International Migration, Self-Selection, and the Distribution of Wages: Evidence from Mexico and the United States," Journal of Political Economy, 113(2), 239-281.

CragG, M., and M. Epelbaum (1996): "Why has Wage Dispersion Grown in Mexico? Is it the Incidence of Reforms or the Growing Demand for Skills?," Journal of Development Economics, 51, 99-116.

Duval Hernandez, R. (2006): "Informality, Segmentation and Earnings in Urban Mexico," Discussion paper, Center for U.S.-Mexican Studies.

Edmonds, E., And N. PAvCNIK (2005): "The Effect of Trade Liberalization on Child Labor," Journal of International Economics, 65(2), 401-419.

Edmonds, E. V., N. Pavcnik, and P. Topalova (2010): "Trade Adjustment and Human Capital Investments: Evidence from Indian Tariff Reform," AEJ: Applied Economics, 2(4), 42-75.

Federman, M., And D. Levine (2005): "The Effects of Industrialization on Education and Youth Labor in Indonesia," The BE Journal of Macroeconomics, 5(1), 1.

Findlay, R., AND H. KierzKowski (1983): "International Trade and Human Capital: A Simple General Equilibrium Model," The Journal of Political Economy, 91(6), 957-978.

Frias, J. A., D. Kaplan, and E. Verhoogen (2009): "Exports and Wage Premia: Evidence from Mexican Employer-Employee Data," Discussion paper, Columbia University.

Goldberg, P., And N. PavCnik (2007): "Distributional Effects of Globalization in Developing Countries," Journal of Economic Literature, 65, 39-82.

Goldin, C., and L. Katz (1997): "Why the United States Led in Education: Lessons from Secondary School Expansion, 1910 to 1940," NBER Working Papers 6144.

Hanson, G., and A. HarRison (1999): "Trade Liberalization and Wage Inequality in Mexico," Industrial and Labor Relations Review, pp. 271-288.

Heath, R., and A. M. Mobarak (2015): "Manufacturing Growth and the Lives of Bangladeshi Women," Journal of Development Economics, 115(0), 1 - 15. 
Helper, S., D. Levine, And C. Woodruff (2006): "How Does Economic Liberalization affect Investment in Education?: Evidence from Mexico," Discussion paper, UCSD.

Ibarraran, P. (2004): "Essays on Labor Markets and Economic Integration in Mexico," Ph.D. thesis, University of California, Berkeley.

Jensen, R. (2012): "Do Labor Market Opportunities Affect Young Women's Work and Family Decisions? Experimental Evidence from India," The Quarterly Journal of Economics, 127(2), 753-792.

Kaplan, D. S., G. M. Gonzalez, and R. Robertson (2007): "Mexican Employment Dynamics: Evidence from Matched Firm-Worker Data," Discussion paper, ITAM.

Le Brun, A., S. R. Helper, And D. I. Levine (2011): "The Effect of Industrialization on Children's Education. The Experience of Mexico," Review of Economics and Institutions, 2(2).

LuCAS, R. (1988): "On the Mechanics of Economic Development," Journal of Monetary Economics, 22(1), 3-42.

McKenzie, D., And H. Rapoport (2006): "Can Migration Reduce Educational Attainment? Evidence from Mexico," World Bank Policy Research Working Paper Series 3952.

Minnesota Population Center (2007): "Integrated Public Use Microdata SeriesInternational: Version 3.0," http://international. ipums. org/international.

Munshi, K., And M. Rosenzweig (2006): "Traditional Institutions Meet the Modern World: Caste, Gender, and Schooling Choice in a Globalizing Economy," American Economic Review, 96(4), 1225-1252.

Nicita, A., And M. Olarreaga (2007): "Trade, Production, and Protection Database, 1976-2004," The World Bank Economic Review, 21(1), 165.

Oreopoulos, P., T. von Wachter, and A. Heisz (2012): "The Short- and Long-Term Career Effects of Graduating in a Recession," AEJ: Applied Economics, 4(1), 1-29.

Oster, E., And B. M. Steinberg (2013): "Do IT Service Centers Promote School Enrollment? Evidence from India," Journal of Development Economics, 104, 123-135.

Psacharopoulos, G., E. Velez, A. Panagides, and H. Yang (1996): "Returns to Education During Economic Boom and Recession: Mexico 1984, 1989 and 1992," Education Economics, 4(3), 219-230.

Robertson, R. (2004): "Relative Prices and Wage Inequality: Evidence from Mexico," Journal of International Economics, 64(2), 387-409.

Shastry, G. K. (2012): "Human Capital Response to Globalization Education and Information Technology in India," Journal of Human Resources, 47(2), 287-330.

Stokey, N. L. (1991): "Human Capital, Product Quality, and Growth," The Quarterly Journal of Economics, 106(2), 587-616.

Verhoogen, E. (2008): "Trade, Quality Upgrading and Wage Inequality in the Mexican Manufacturing Sector," Quarterly Journal of Economics, 123(2).

Wood, A., And C. Ridao-Cano (1999): "Skill, Trade, and International Inequality," Oxford Economics Papers, 51(1), 89-119. 
Figure 1: Manufacturing Employment Changes

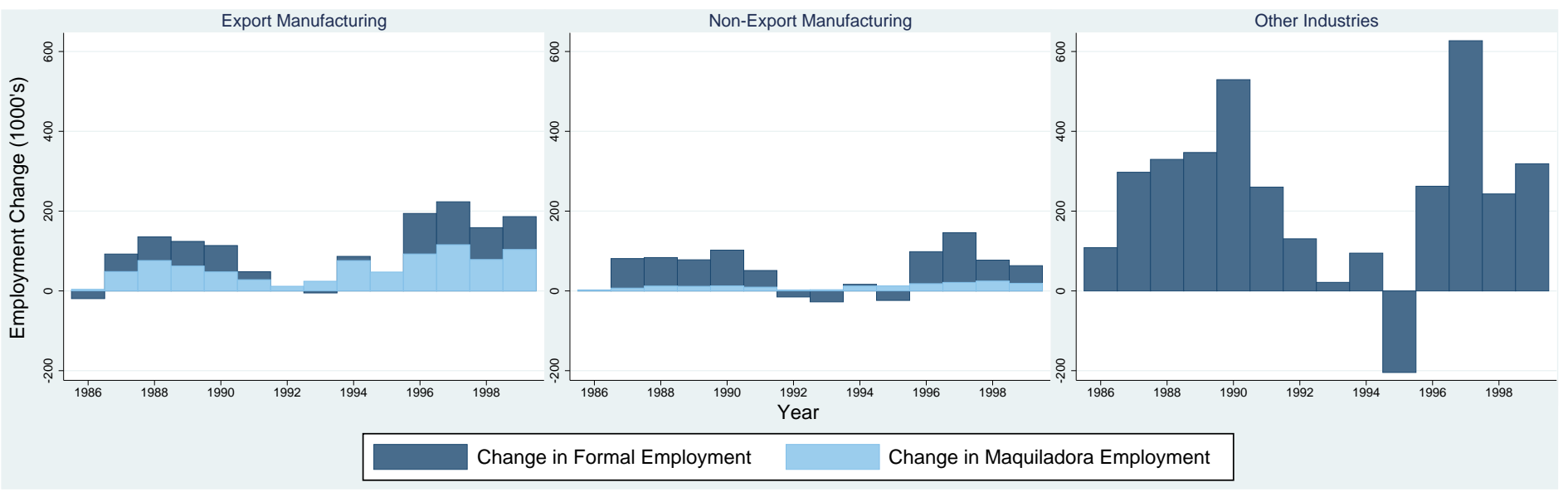

Note: Formal employment changes calculated using IMSS employment data, Maquiladora employment changes using INEGI Maquiladora statistics.

Figure 2: Histogram of Education by Sector (Age 16-28 in 2000, IMSS Insured)

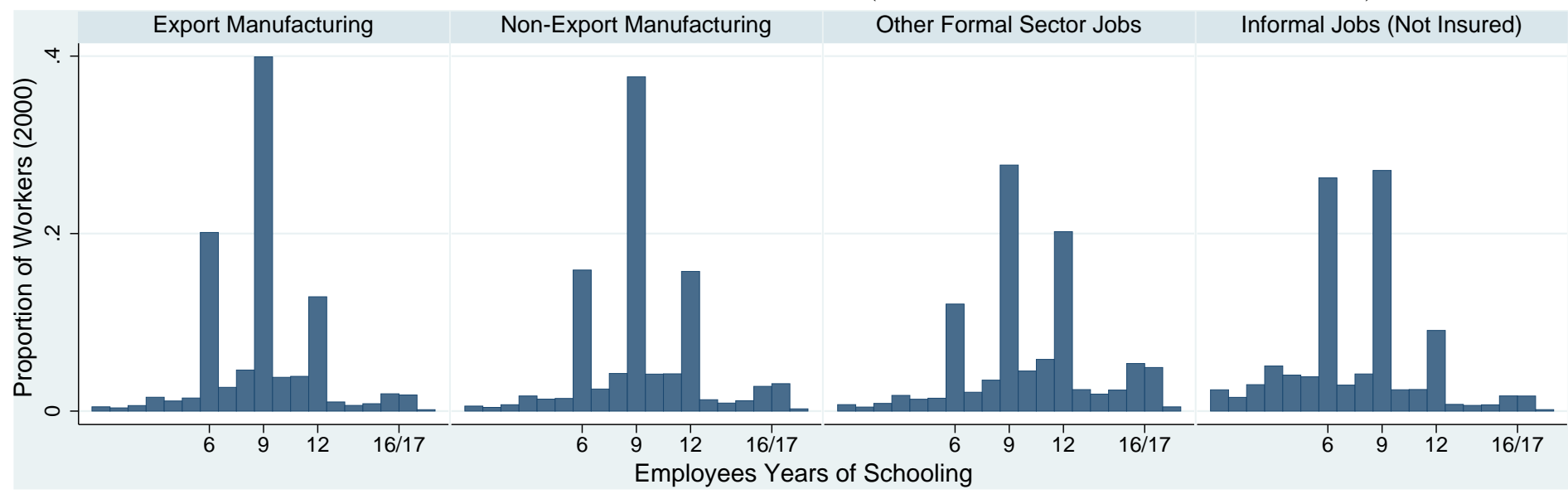

Note: Education distribution calculated using the 2000 census for formal sector workers age 16 to 28 (my sample cohort). A formal worker is defined as a worker insured by IMSS or equivalent insurance scheme.

Figure 3: Changes in School Attendance, Grade Completion and Employment by Age (1990 Census)

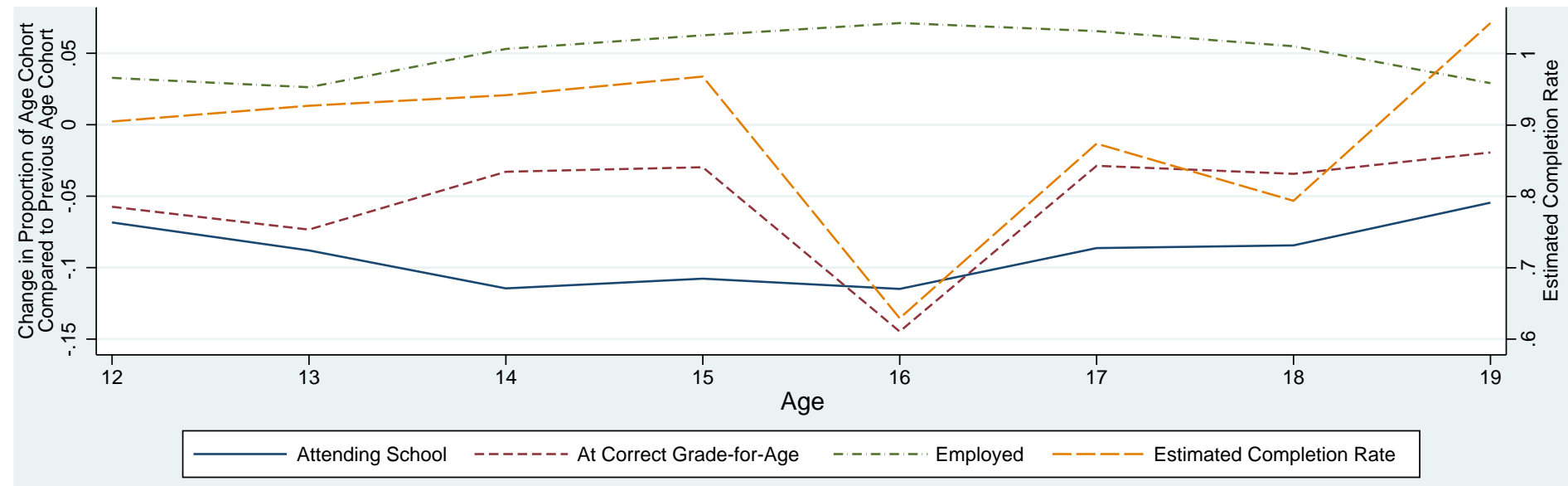

Note: Figure uses 1990 census to plot changes in the proportion of the cohort attending school (solid line), at the correct grade-for-age (dashed line), and in full-time employment (dash-dotted line), all compared to the age cohort one year younger. Correct grade-for-age measured as proportion of cohort at grade age -6 . Long-dashed line shows the estimated completion rate (the proportion of cohort at the correct grade-for-age divided by proportion of cohort one year younger both at the correct grade-for-age and attending school). 
Figure 4: Export Job Shocks at Different Ages of Exposure

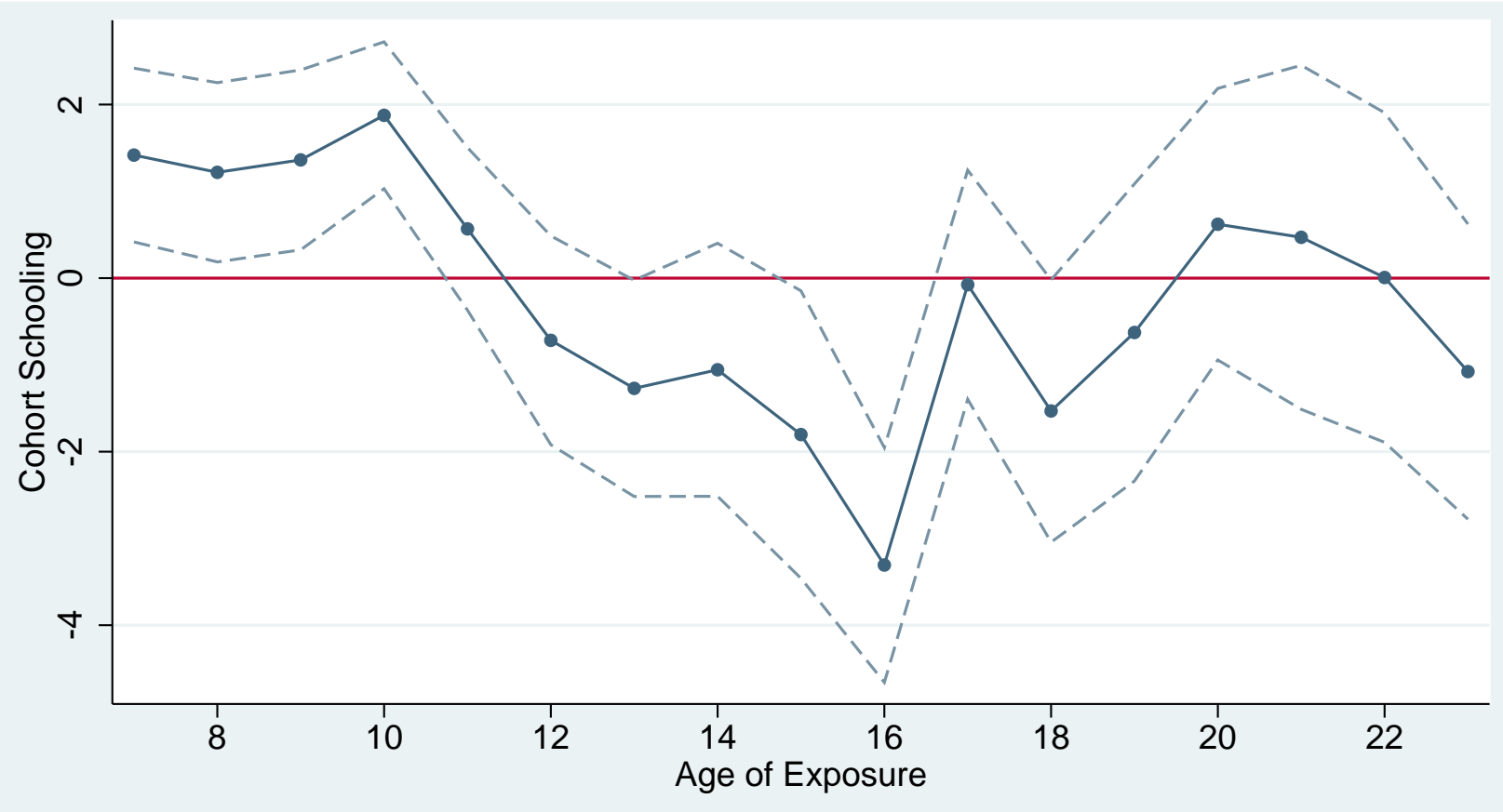

Notes: Figure plots the coefficients from 17 regressions that regress cohort average schooling on net new export manufacturing shocks using the specification in equation 1 but replacing export job shocks at age 16 with export job shocks at one of 17 different ages between 7 and 23. Dashed line shows 95 percent confidence intervals.

Figure 5: Grade 9 and Pre-Grade-9 Dropout at Different Ages of Exposure

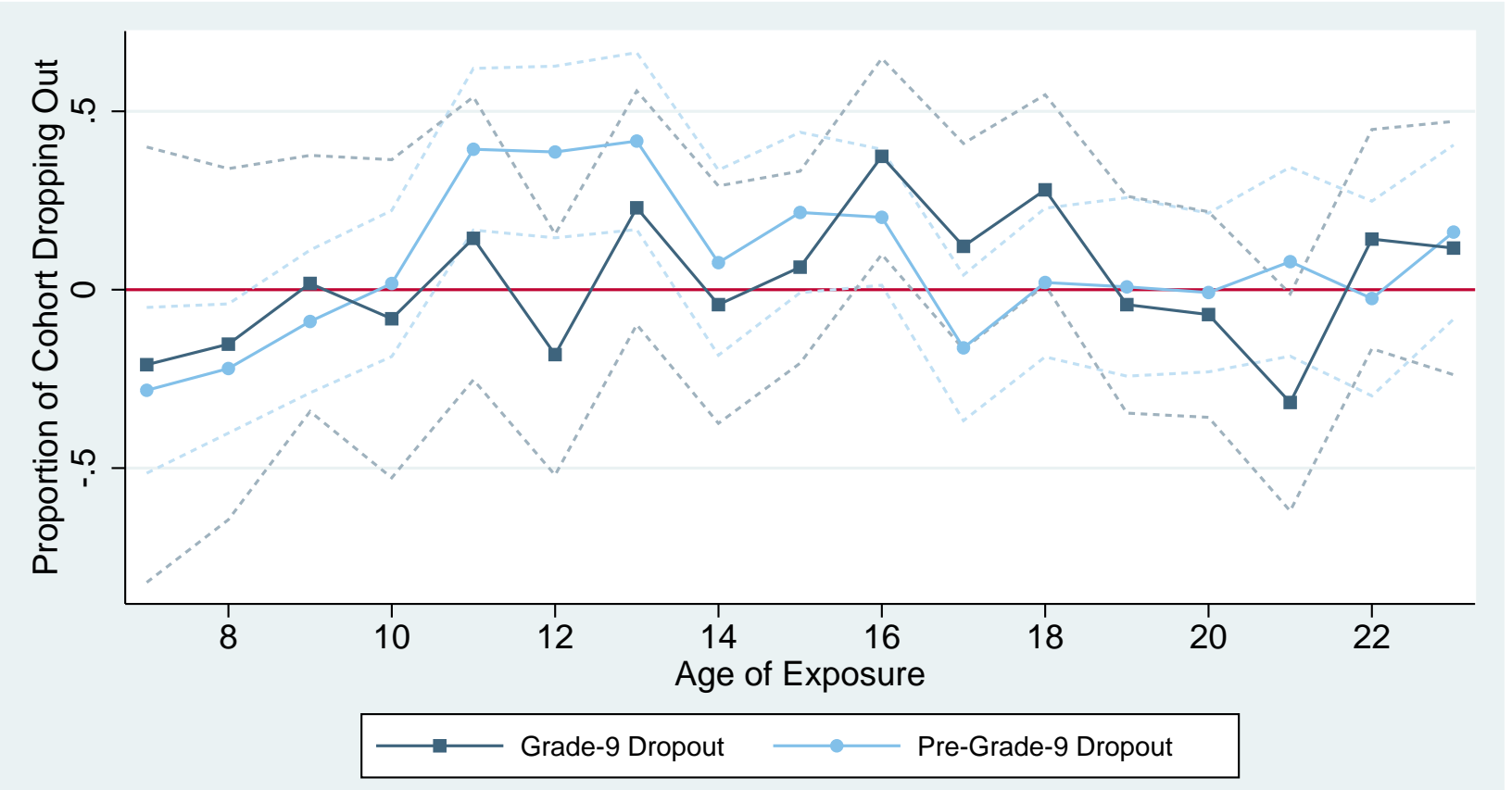

Notes: Each solid line in the figure plots the coefficients from 17 regressions that regress cohort average dropout rates on net new export job shocks. The darker line shows grade-9 dropout rates (i.e. the proportion of the set of students with 9 or more years of schooling who obtain no additional years of schooling beyond 9). The lighter line shows pre-grade-9 dropout rates (i.e. the proportion of students that obtain fewer than 9 years of schooling). Both lines use the specification in equation 1 but replace schooling with the relevant dropout rates and replacing the export job shocks at age 16 with export job shocks at one of 17 different ages between 7 and 23. Dashed lines show 95 percent confidence intervals. 
Figure 6: Cross-Sectional Evidence from the 1990 Census

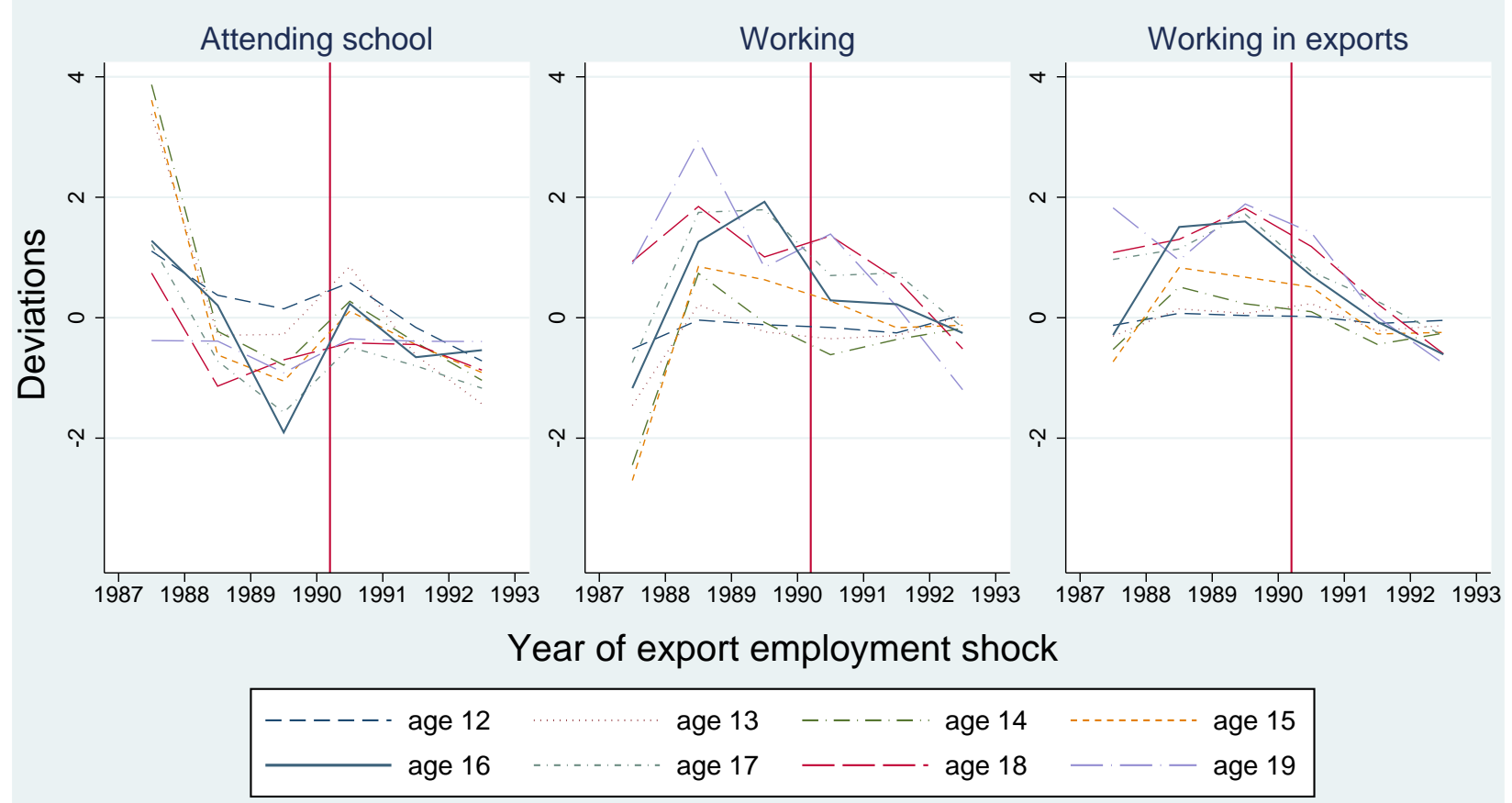

Notes: Each panel plots 48 coefficients from regressions of a binary variable from the 1990 census (denoted by panel title) on export employment shocks in each year between 1987-1992. I include cohorts aged 12-19 and age fixed effects, and allow the coefficients on the shocks to differ by age. Full specification shown in equation 4 of main text. Sample restricted to commuting zones with at least one year of employment growth in export manufacturing between 1987-1992. Lines connect coefficients of same age cohort and x-axis denotes the year of the shock. Vertical lines drawn at the time of the March 1990 census.

Figure 7: Differential Effects of Export and Non-Export Job Shocks

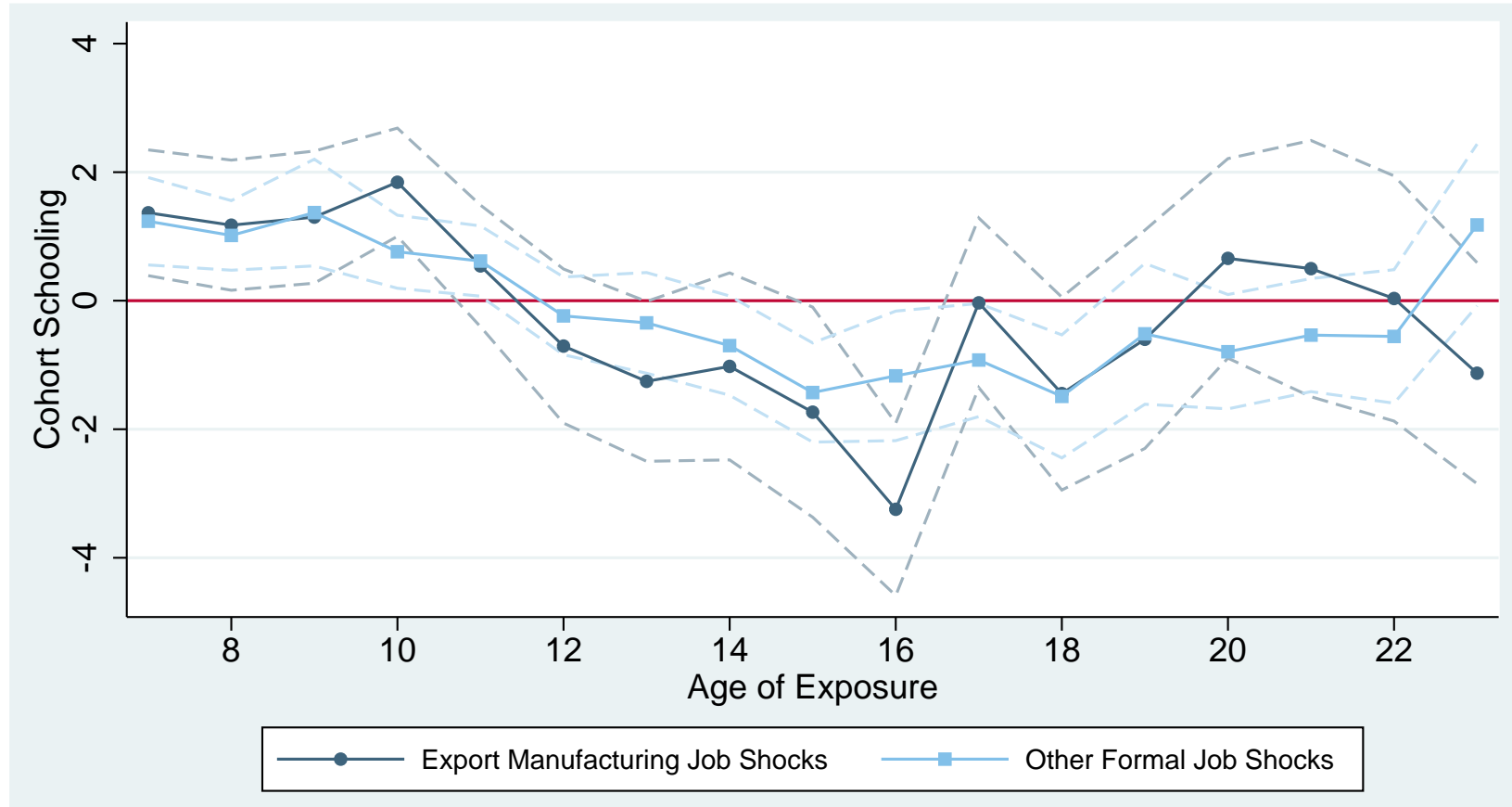

Notes: Figure plots the coefficients from 17 regressions that regress cohort average schooling on both net new export jobs and net new job arrivals in all other sectors using the specification in equation 1 but replacing shocks at age 16 with shocks at one of 17 different ages between 7 and 23. Dashed lines show 95 percent confidence intervals. Coefficients on export job shocks are significantly different from non-export job shocks at age 16 (an F-stat of 6.29 with a p-value of 0.012). 
Figure 8: Skill Differences by Sector
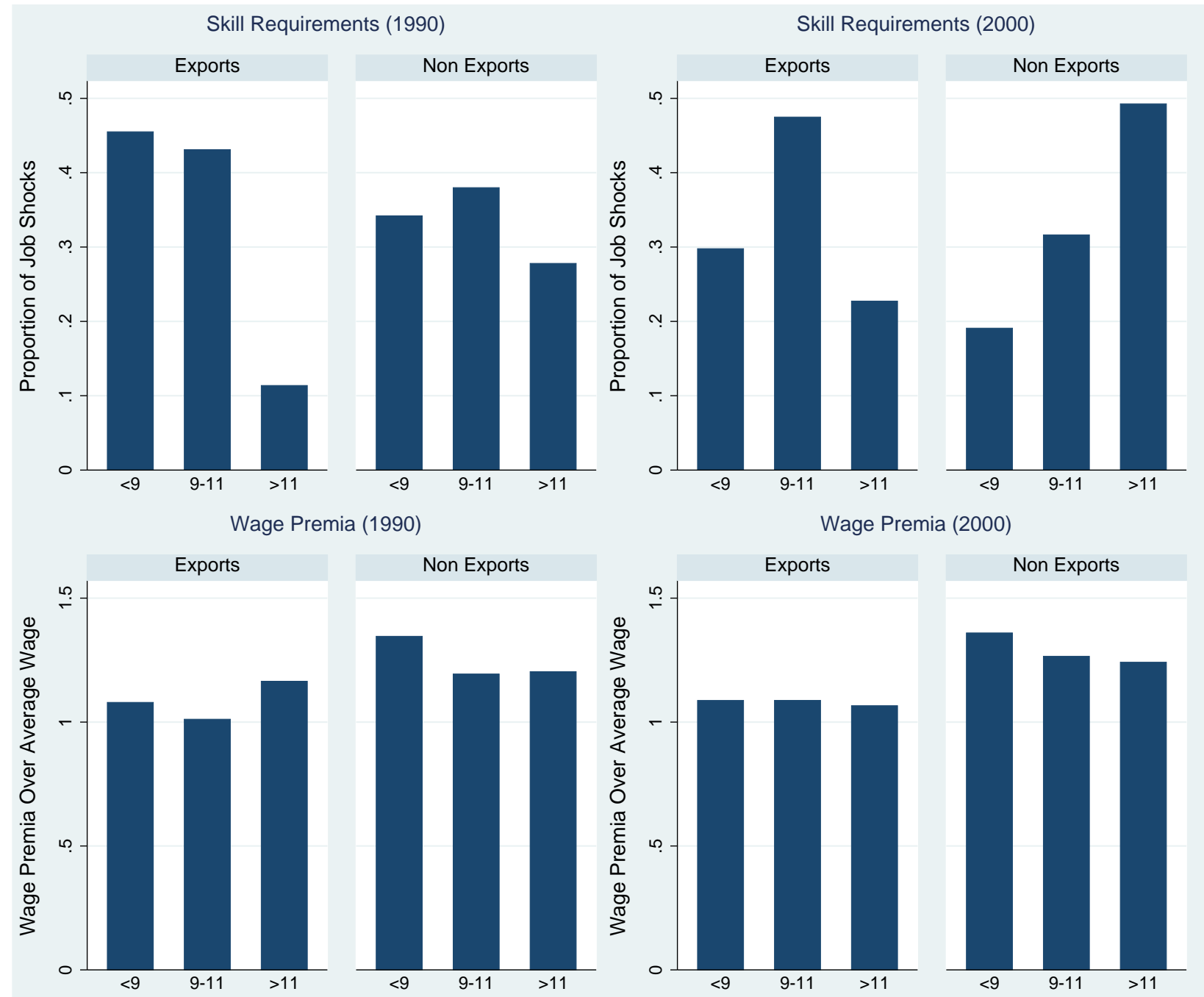

Skill X Density at Dropout Margin (1990)
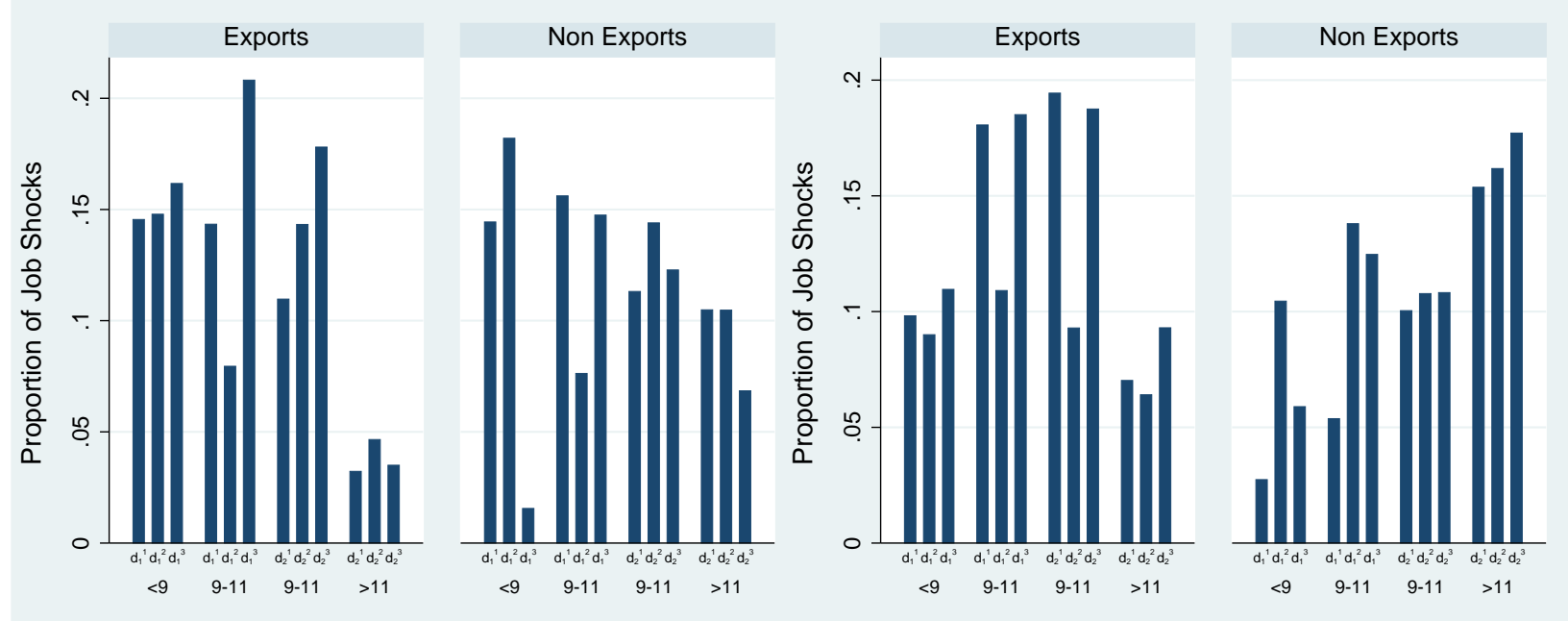

Note: Top row plots skill distribution of net new jobs per worker attributable to large expansions and contractions occurring between 1991 and 1999. Job arrivals categorized into three skill bins based on highest completed educational stage of workers in each state-industry at time of census; primary school (grades $<9$ ), secondary school (grades $9-11$ ), and high school or above (grades $>11$ ). Second row plots wage premia (over the average commuting zone wage for that skill bin) paid by these same net new job arrivals. Bottom row subdivides the skill bins in top row into terciles (denoted by superscripts) of the relevant density of marginal youths for each skill level detailed in equation 10. Left panels use 1990 census information, right panels use 2000 census (where I focus on formal sector employees only). 
Table 1: Sample Means

\begin{tabular}{|c|c|c|c|}
\hline Census Sample (2000, Age 16-28, Non Migrants, Excl. Mexico City) & mean & standard deviation & observations \\
\hline Age & 21.54 & 0.0038 & $1,706,582$ \\
\hline Years of School & 8.51 & 0.0038 & $1,636,520$ \\
\hline Employed $(1=$ yes, $0=$ no $)$ & 0.52 & & $1,706,582$ \\
\hline Insured by IMSS $(1=$ yes, $0=$ no $)$ & 0.42 & & $1,706,582$ \\
\hline Monthly Log Earned Income (Pesos) & 7.47 & 0.0011 & 667,103 \\
\hline Sex $(1=$ male, $0=$ female $)$ & 0.48 & & $1,706,582$ \\
\hline Commuting-Zone (CZ) Size & 8540.26 & 816.7 & 1808 \\
\hline Non-Migrants as Proportion of Full Sample & 0.81 & & $2,060,457$ \\
\hline IMSS Annual Firm Sample (1985-2000) & mean & standard deviation & observations \\
\hline Firm Size (Employees) & 12.08 & 0.044 & $11,365,321$ \\
\hline Firm Size (Firms Changing Employment) & 16.03 & 0.065 & $7,675,094$ \\
\hline Firm Size (Firms Hiring/Firing $\geq 50$ in single year) & 416.41 & 4.140 & 109,263 \\
\hline \multirow[t]{2}{*}{ Worker Sex $(1=$ male, $0=$ female $)$} & 0.68 & & $11,365,321$ \\
\hline & Total in 1985 & Total in 2000 & Unique $1985-2000$ \\
\hline Firms & 372,520 & 912,284 & $2,194,681$ \\
\hline Combined Sample (1986-1999, Weighted by Cell Population) & mean & standard deviation & observations \\
\hline Jobs/Working Age Population (All Sectors) & 0.188761 & 0.155967 & 25,289 \\
\hline Export Jobs/Working Age Population & 0.034833 & 0.057492 & 25,289 \\
\hline Net New Jobs/Working Age Population (All Sectors) & 0.012288 & 0.020343 & 25,289 \\
\hline Net New Export Jobs/Working Age Population & 0.003069 & 0.007928 & 25,289 \\
\hline Net New Jobs/Worker (All Sectors) (Large $\Delta \mathrm{s}$ ) & 0.006189 & 0.014048 & 25,289 \\
\hline Net New Export Jobs/Worker (Large $\Delta \mathrm{s}$ ) & 0.002405 & 0.007072 & 25,289 \\
\hline Positive Net New Export Jobs/Worker (Large $\Delta \mathrm{s}$ ) & 0.006676 & 0.008846 & 1,446 \\
\hline Negative Net New Export Jobs/Worker (Large $\Delta \mathrm{s}$ ) & -0.002354 & 0.006166 & 509 \\
\hline Non-Zero Net New Export Jobs/Worker (Large $\Delta \mathrm{s}$ ) & 0.004448 & 0.009136 & 1,955 \\
\hline Net New Export Jobs/Worker (Large $\Delta \mathrm{s})$ (Demeaned by CZ) & 0.000000 & 0.005495 & 25,289 \\
\hline
\end{tabular}

Table 2: The Effect of New Export-Manufacturing Jobs on Educational Attainment

\begin{tabular}{|c|c|c|c|c|c|}
\hline & (1) & (2) & (3) & (4) & (5) \\
\hline & OLS & $\begin{array}{l}\text { Cohort Averas } \\
\text { IV (Large } \Delta s \text { ) }\end{array}$ & $\begin{array}{l}\text { Re Completed Y } \\
\mathrm{RF} \text { (Large } \Delta \mathrm{s})\end{array}$ & $\begin{array}{l}\text { ears of Schooling } \\
\mathrm{RF} \text { (Large } \Delta \mathrm{s} \text { ) }\end{array}$ & RF and LDV \\
\hline $\begin{array}{l}\text { Net New Export Manufacturing } \\
\text { Jobs/Worker at Age } 16\end{array}$ & $\begin{array}{c}-3.155^{* * *} \\
(0.638)\end{array}$ & $\begin{array}{c}-3.192^{* * *} \\
(0.614)\end{array}$ & $\begin{array}{c}-3.306^{* * *} \\
(0.690)\end{array}$ & $\begin{array}{c}-3.246^{* * *} \\
(0.684)\end{array}$ & $\begin{array}{c}-3.380^{* * *} \\
(0.551)\end{array}$ \\
\hline $\begin{array}{l}\text { Net New Jobs/Worker } \\
\text { at Age } 16 \text { (All Other Sectors) }\end{array}$ & & & & $\begin{array}{c}-1.169^{* *} \\
(0.514)\end{array}$ & \\
\hline L.Cohort Schooling & & & & & $\begin{array}{r}0.309^{* * *} \\
(0.0164)\end{array}$ \\
\hline L2.Cohort Schooling & & & & & $\begin{array}{c}0.274^{* * *} \\
(0.0132)\end{array}$ \\
\hline L3.Cohort Schooling & & & & & $\begin{array}{l}0.171^{* * *} \\
(0.00946)\end{array}$ \\
\hline L4.Cohort Schooling & & & & & $\begin{array}{c}0.132^{* * *} \\
(0.0105)\end{array}$ \\
\hline Observations & 25,289 & 25,289 & 25,289 & 25,289 & 25,192 \\
\hline$R^{2}$ & 0.942 & 0.942 & 0.942 & 0.942 & 0.915 \\
\hline Commuting Zones & 1808 & 1808 & 1808 & 1808 & 1808 \\
\hline Kleibergen-Paap F-stat (1 ${ }^{\text {st }}$ Stage) & & 11121 & & & \\
\hline
\end{tabular}

Notes: Dependent variable is cohort average years of schooling in the year 2000. Independent variable is net new exportmanufacturing jobs per worker arriving in cohort's commuting zone at age 16. The IV column instruments net new jobs per worker by the net new jobs per worker attributable to firms that expand or contract their employment by 50 or more employees in a single year. The RF columns replaces net new jobs per worker with the instrument. State-time dummies, commuting-zone dummies and commuting-zone linear trends not shown. The "RF and LDV" column replaces fixed effects and municipality trends with four lags of cohort schooling. Regressions weighted by cell population, exclude Mexico City and migrants. Commuting-zone clustered standard errors in parentheses. * significant at 10 percent level, ** at 5 percent and *** at 1 percent. 
Table 3: Changes in School Attendance 1990-2000 and New Export-Manufacturing Jobs

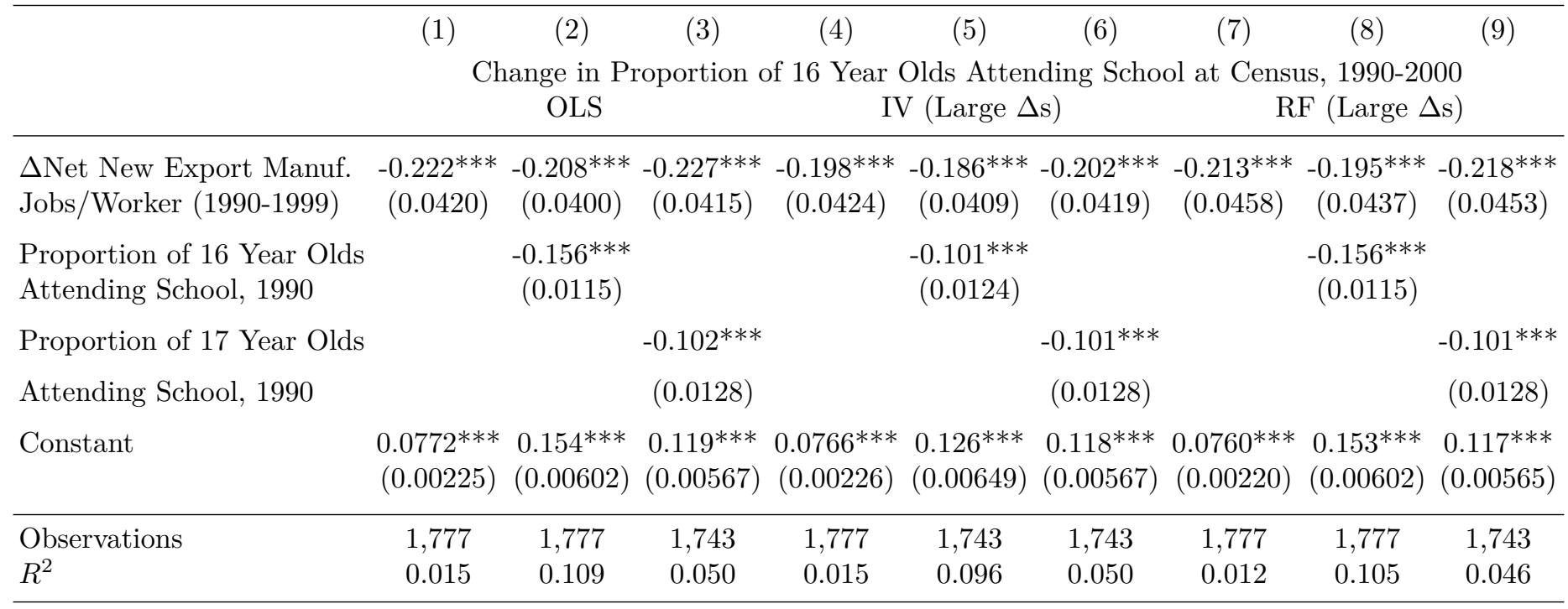

Notes: Dependent variable is the change in proportion of 16 year olds attending school at time of census, 1990-2000. Independent variable is change in net new manufacturing jobs per worker arriving in commuting zone between January 1st 1990 and December 31st 1999. Columns 2, 5 and 8 include initial proportion of 16 year olds attending school as a control (17 year olds in columns 3, 6 and 9). IV and RF columns use the net new jobs per worker attributable to firms that expand or contract employment by 50 or more employees in a single year either as an IV or as main regressor. Regression weighted by commuting-zone population of 16 year olds in 1990 census, excludes Mexico City and migrants. * significant at 10 percent level, ${ }^{* *}$ at 5 percent and ${ }^{* * *}$ at 1 percent.

Table 4: Alternative Exporter Measures

\begin{tabular}{|c|c|c|c|c|c|c|c|c|}
\hline & (1) & $(2)$ & $(3)$ & (4) & $(5)$ & (6) & (7) & (8) \\
\hline & $\begin{array}{l}\text { Exports/ } \\
\text { Worker }\end{array}$ & $\begin{array}{r}\text { RF } \\
\text { Anually } \\
\text { Coded }\end{array}$ & $\begin{array}{l}\text { Cohort Aver } \\
\text { (Large } \Delta \mathrm{s} \text { ) } \\
\text { Maquiladora } \\
\text { Agg. Imp. }\end{array}$ & $\begin{array}{l}\text { age Completed } \\
\text { Maquiladora } \\
\text { Micro Imp. }\end{array}$ & $\begin{array}{l}\text { Years of } \\
\text { (OLS) } \\
\text { EIA } \\
\text { Panel }\end{array}$ & $\begin{array}{l}\text { f Schooling } \\
\text { (RF } \\
\text { Maq. Agg. } \\
\text { + EIA }\end{array}$ & $\begin{array}{l}\text { (OLS) } \\
\text { Maq. Micro } \\
\quad+\text { EIA }\end{array}$ & $\begin{array}{c}\text { (OLS) } \\
\text { EIA } \\
\text { Panel }\end{array}$ \\
\hline $\begin{array}{l}\text { Net New Export Manuf. } \\
\text { Jobs/Worker at Age } 16\end{array}$ & $\begin{array}{c}-4.241^{* * *} \\
(0.885)\end{array}$ & $\begin{array}{c}-2.943^{* * *} \\
(0.759)\end{array}$ & & & & & & \\
\hline $\begin{array}{l}\text { Net New Maquiladora } \\
\text { Jobs/Worker at Age } 16\end{array}$ & & & $\begin{array}{c}-2.106^{* *} \\
(0.881)\end{array}$ & $\begin{array}{c}-1.856^{* *} \\
(0.898)\end{array}$ & & $\begin{array}{c}-2.117^{* *} \\
(0.878)\end{array}$ & $\begin{array}{c}-1.869^{* *} \\
(0.897)\end{array}$ & \\
\hline $\begin{array}{l}\text { Net New EIA Export } \\
\text { Jobs/Worker at Age } 16\end{array}$ & & & & & $\begin{array}{l}4.435 \\
(3.232)\end{array}$ & $\begin{array}{c}4.487 \\
(3.250)\end{array}$ & $\begin{array}{c}4.477 \\
(3.251)\end{array}$ & \\
\hline $\begin{array}{l}\text { Net New EIA Blue Collar } \\
\text { Export Jobs/Worker Age } 16\end{array}$ & & & & & & & & $\begin{array}{l}-17.66 \\
(13.35)\end{array}$ \\
\hline $\begin{array}{l}\text { Net New EIA White Collar } \\
\text { Export Jobs/Worker Age } 16\end{array}$ & & & & & & & & $\begin{array}{l}90.41^{*} \\
(52.51)\end{array}$ \\
\hline Observations & 25,289 & 25,289 & 25,289 & 25,289 & 25,275 & 25,289 & 25,289 & 25,275 \\
\hline$R^{2}$ & 0.942 & 0.942 & 0.942 & 0.942 & 0.942 & 0.942 & 0.942 & 0.942 \\
\hline Commuting Zones & 1808 & 1808 & 1808 & 1808 & 1807 & 1808 & 1808 & 1807 \\
\hline
\end{tabular}

Notes: Dependent variable is cohort average years of schooling in the year 2000. Independent variables are alternate measures of net new jobs per worker created by exporters in cohort's commuting zone at age 16. Columns 1 and 2 use alternate classifications described in main text. Columns 3 and 4 restrict attention to Maquiladoras identified either from matching the IMSS sample to industry-by-municipality Maquiladora aggregates or to the census of Maquiladoras. Columns 5 and 8 focus on employment growth in a panel of large non-Maquiladoras that export more than 25 percent of output. Columns 6 and 7 combine the panel of large non-Maquiladoras with the Maquiladoras. State-time dummies, commuting-zone dummies and commuting-zone linear trends not shown. Regressions weighted by cell population, exclude Mexico City and migrants. Commuting-zone clustered standard errors in parentheses. * significant at 10 percent level, ** at 5 percent and *** at 1 percent. 
Table 5: Sex-Specific Net New Export Jobs and Educational Attainment

\begin{tabular}{|c|c|c|c|c|c|c|c|c|c|c|}
\hline \multirow[b]{3}{*}{ All RF (Large $\Delta \mathrm{s}$ ) } & (1) & $(2)$ & (3) & (4) & $(5)$ & (6) & (7) & (8) & (9) & (10) \\
\hline & \multicolumn{2}{|c|}{ Cohort Schooling } & \multicolumn{4}{|c|}{ NNEM Jobs/Worker at 16} & \multicolumn{4}{|c|}{ Cohort Schooling } \\
\hline & Male & Female & Male & Female & Male & Female & Male & Female & Male & Female \\
\hline $\begin{array}{l}\text { Net New Export Manuf. } \\
\text { Jobs/Worker at Age } 16 \text { (NNEM) }\end{array}$ & $\begin{array}{c}-4.364^{* * *} \\
(1.105)\end{array}$ & $\begin{array}{c}-2.511^{* *} \\
(1.099)\end{array}$ & & & & & & & & \\
\hline $\begin{array}{l}\text { (Male Prop. NNEM Jobs 1985-89) } \\
\quad \times(\text { NNEM Jobs/Worker at Age 16) }\end{array}$ & & & $\begin{array}{c}1.589^{* * *} \\
(0.148)\end{array}$ & $\begin{array}{c}0.459^{* * *} \\
(0.127)\end{array}$ & & & $\begin{array}{c}-5.541^{* *} \\
(2.400)\end{array}$ & $\begin{array}{c}0.517 \\
(2.271)\end{array}$ & & \\
\hline $\begin{array}{l}\text { (Female Prop. of NNEM Jobs 1985-89) } \\
\times(\text { NNEM Jobs/Worker at Age } 16)\end{array}$ & & & $\begin{array}{r}0.724^{* * *} \\
(0.126)\end{array}$ & $\begin{array}{c}1.230^{* * *} \\
(0.116)\end{array}$ & & & $\begin{array}{l}-0.407 \\
(1.712)\end{array}$ & $\begin{array}{l}-2.238 \\
(3.352)\end{array}$ & & \\
\hline $\begin{array}{l}\text { (Male Prop. Export Manuf. Jobs 1985) } \\
\times(\text { NNEM Jobs/Worker at Age 16) }\end{array}$ & & & & & $\begin{array}{c}1.516^{* * *} \\
(0.121)\end{array}$ & $\begin{array}{c}0.506^{* * *} \\
(0.104)\end{array}$ & & & $\begin{array}{c}-6.223^{* * *} \\
(1.693)\end{array}$ & $\begin{array}{l}-2.477 \\
(1.623)\end{array}$ \\
\hline $\begin{array}{l}\text { (Female Prop. Export Manuf. Jobs 1985) } \\
\times(\text { NNEM Jobs/Worker at Age } 16)\end{array}$ & & & & & $\begin{array}{c}0.560^{* * *} \\
(0.101)\end{array}$ & $\begin{array}{c}1.413^{* * *} \\
(0.106)\end{array}$ & & & $\begin{array}{l}-1.869 \\
(2.047)\end{array}$ & $\begin{array}{l}-2.559 \\
(2.478)\end{array}$ \\
\hline Observations & 25,113 & 25,160 & 16,258 & 16,258 & 25,113 & 25,113 & 16,144 & 16,204 & 25,113 & 25,160 \\
\hline$R^{2}$ & 0.885 & 0.913 & 0.960 & 0.936 & 0.953 & 0.931 & 0.903 & 0.926 & 0.885 & 0.913 \\
\hline Commuting Zones & 1808 & 1808 & 1808 & 1808 & 1808 & 1808 & 1806 & 1808 & 1808 & 1808 \\
\hline
\end{tabular}

Notes: Dependent variable in columns 1-2, and 7-10 is the (gender-specific) cohort average years of schooling in the year 2000. Dependent variable in columns 3-6 is the (gender-specific) net new export jobs per worker arriving in cohort's commuting zone at age 16 attributable to firms that expand or contract their employment by 50 or more employees in a single year. Independent variables in columns 1-2 are same export jobs per worker measure but not gender specific. Independent variables in other columns are predicted gender-specific export job shocks obtained by multiplying actual non-gender-specific export job shocks by sex ratios of prior job shocks between 1985-1989 (columns 3-4 and 7-8, where sample excludes cohorts who turned 16 prior to 1990) or sex ratios of factories open in 1985, the first year of the dataset. State-time dummies, commuting-zone dummies and commuting-zone linear trends not shown. Regressions weighted by cell population, exclude Mexico City and migrants. Commuting-zone clustered standard errors in parentheses. ${ }^{*}$ significant at 10 percent level, ${ }^{* *}$ at 5 percent and $* * *$ at 1 percent.

Table 6: Net New Export Jobs and Later Life Income

(1)

Total income

RF (Large $\Delta \mathrm{s})$
(2)

(3)

Earned income Log hourly wage

(including 0s) (including 0s)
(4)

(5)

Log earned income Mincerian returns (full time workers) (full time workers)

\begin{tabular}{lccccc}
\hline \multirow{2}{*}{$\begin{array}{l}\text { Net New Export Manuf. } \\
\text { Jobs/Worker at Age 16 }\end{array}$} & -613.4 & -236.4 & -0.0712 & -0.0494 & -0.101 \\
& $(2,647)$ & $(2,650)$ & $(0.190)$ & $(0.202)$ & $(0.138)$ \\
\hline Observations & 25,287 & 25,288 & 23,934 & 23,724 & 20,611 \\
$R^{2}$ & 0.675 & 0.696 & 0.886 & 0.903 & 0.292 \\
Commuting Zones & 1808 & 1808 & 1808 & 1807 & 1759 \\
\hline
\end{tabular}

Notes: Dependent variable is the cohort average income, earned income, log hourly wage, log earned income or Mincerian returns in the year 2000. Independent variables are net new export jobs per worker arriving in cohort's commuting zone at age and 16 attributable to firms that expand or contract their employment by 50 or more employees in a single year. Log earned income and Mincerian returns restricts attention to workers working at least 20 hours a week. Mincerian returns calculated by regressing log earned income on schooling and a sex dummy separately for workers in every single cohort and commuting zone and taking the coefficient on schooling. State-time dummies, commuting-zone dummies and commuting-zone linear trends not shown. Regressions weighted by cell population, exclude Mexico City and migrants. Commuting-zone clustered standard errors in parentheses. * significant at 10 percent level, ** at 5 percent and *** at 1 percent. 


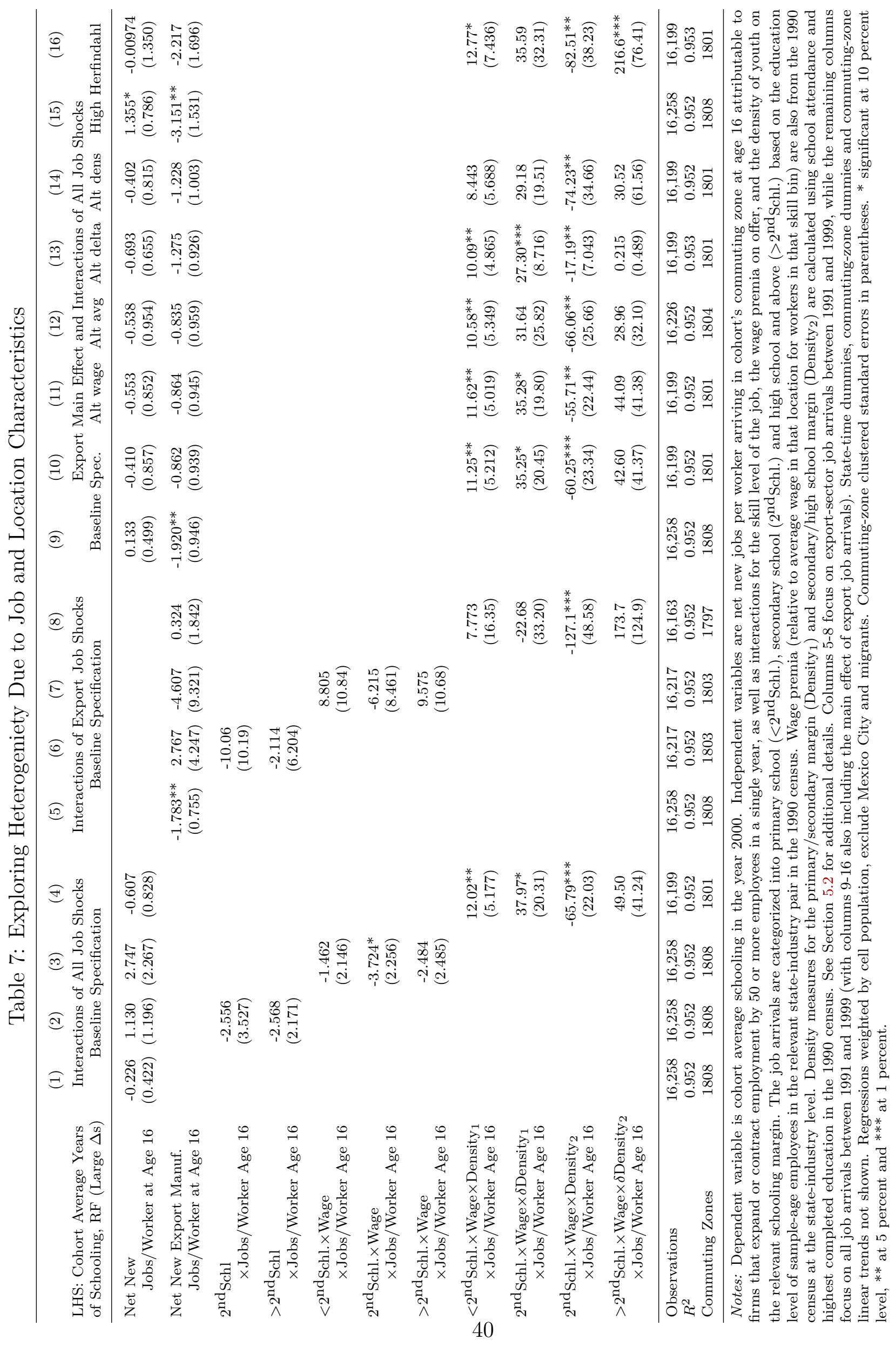




\section{Appendix For Online Publication}

\section{Appendix A Robustness Results}

I present a variety of robustness checks on my key finding, that cohort schooling declines with net new export-manufacturing jobs at age 16. Tables A.1 to A.4 rerun the preferred reduced form specification, repeated in column 1 of each table, with several modifications.

Table A.1 explores how sensitive results are to the removal of the various fixed effects and trends. Columns 2 to 4 sequentially remove the commuting-zone linear trends, the state-specific time dummies and finally the basic time-dummies. Column 5 removes both the commuting-zone fixed effects and linear trends. The coefficient remains negative and becomes about twice as large in magnitude with the removal of the commuting-zone linear trends. One potential explanation is that, with only 14 years of data, the inclusion of a linear trend terms risks over-fitting and causing attenuation due to the inclusion of an excessive number of controls in the regression. Removing the other time fixed effects in columns 3 and 4 results in even larger coefficients. Meanwhile, the removal of the commuting-zone fixed effects and linear trends flips the sign of the relationship. Therefore, the effects I find are

primarily coming from variation within commuting zones across time as opposed to variation across commuting zones within time.

Tables A.2 and A.3 investigate how results vary across different geographic samples. In column 2 of Table A.2, I exclude the 781 commuting zones that had no formal sector employment during the period. As these commuting zones are generally very small, they have little impact on my weighted regression results. Column 3 controls for the fact that the Progresa conditional cash transfer program was rolled out at the end of the sample period. Progresa could potentially be a cause of omitted variable bias as the program encouraged children to stay in school at the tail end of my sample period by offering cash incentives. Therefore, I include a Progresa dummy takes the value 1 in the 1998 and 1999 if more than 10 percent of the commuting-zone population reported receiving Progresa or Procampo payments in the 2000 census (no specific Progresa indicator is available in the census). Column 4 excludes the two large cities in the sample, Monterrey and Guadalajara, which may have been driving my population weighted results. In both columns 3 and 4, results are unchanged. Finally, column 5 reproduces the main specification but without the cohort population weights that are used in all other specifications. The coefficient is slightly smaller, but still highly significant.

In Table A.3, I explore additional geographic subsamples. Columns 1-3 focus on the Northern region, the Central region and the Southern region of Mexico respectively. Results are similar in the North and Center of the country. In the South of the country I find a larger negative coefficient. Since there was very little export job creation in the South, it is perhaps not unsurprising that when these jobs arrived, the impacts were particaulry large. In the 
remaining columns, I replace the state-time fixed effects with region-time fixed effects using three regions of Mexico (North, Center and South). The region-time fixed effects allow me to include Mexico City (which is its own State). Additionally, region-time fixed effects allow me to separately run regressions on various sub-samples for which there is limited variation in the presence of $31 \times 14$ state-time dummies. Column 5 reproduces the standard specification but with region-time fixed effects. The coefficient is similar but slightly smaller than the statetime fixed effects specification. The coefficient changes little in column 6 where I includes the Valle de México metropolitan zone that contains Mexico City. Column 7 restricts the sample to the 54 metropolitan zones in Mexico. Column 8 restricts the sample to the 1754 nonmetropolitan commuting zones in my data set. Results are similar except for the case when I focus only on metropolitan zones where I find no negative schooling effect. These results suggest that the dropout effects I find are coming primarily from smaller towns and cities.

Finally, Table A.4 examines various alternative specifications. One concern is that schooling is mismeasured as I only observe completed schooling in the year 2000 and youths may go on to obtain additional schooling at a later date. In column 2, I cap education at 12 years and recalculate cohort schooling. By capping education at 12 years, most of the sample will have reached their final level of schooling by the year 2000, mitigating concerns that the amount of misreporting varies with the skill level of the commuting zone. I also note that adult education was uncommmon in Mexico over this period. ${ }^{1}$ In column 3 , I further restrict attention only to individuals not at school at the time of the census. Results are very similar in both cases. Therefore, I can be confident that my results are driven by students making school dropout decisions before the end of high school.

Column 4 shows that my results are robust to extending the cutoff threshold of my instrument from changes of 50 employees to changes of 100 employees in a single firm in a single year. One potential worry with my identification strategy is that my variation may be driven by large expansions and contractions at firms that almost always expand (or contract) by more than 50 employees each year. For these firms, the firm-level year-to-year variation may be small and potentially driven by changes in the educational decisions of the cohort aged 16. Columns 5 and 6 show that this is not the case by restricting attention to large

\footnotetext{
${ }^{1}$ The 2003 World Bank report "Status of Education for Out of School Adults in Mexico" (downloaded from http://siteresources.worldbank.org/EDUCATION/Resources/278200-1126210664195/16369711126210694253/Status_Out_School_Mexico.pdf) contains figures on adult education in Mexico. In 1983, just prior to the start of my sample, 13,279 grade school certificates and 13,021 lower secondary school certificates were awarded to adults out of a population of approximately 25 million adults without completed lower secondary schooling. By the end of the sample, the year 2000, 188,800 grade school certificates and 305,500 lower secondary school certificates were awarded to adults out of a population of 32.5 million adults without completed lower secondary schooling. In terms of returning to high school during my sample period, the World Bank report states: "There has been minimal effort in Mexico to reduce the out-of-school adult population that has not completed their upper secondary education. In fact it is only recently in 2001-02, that educational authorities have become aware of the magnitude of the problem."
} 
expansions and contractions that are unusually large for the firm in question. Column 5 restricts attention to shocks where the absolute change in firm-level employment is both above 50 and more than 1 standard deviation above the mean employment change at that firm. Column 6 restricts attention to large shocks at firms that do not experience absolute changes in employment of more than 50 in more than half of the periods in which the firm appears in the data. In both cases, I find similar or larger effect sizes.

Columns 7-8 of Table A.4 separate new export job arrivals into the jobs created (firm expansions or openings) and the jobs destroyed (firm contractions or closures) in each commuting-zone year cell. Column 7 includes only new job creation, labeled hires, and I find similar magnitudes. Column 8 includes both job creation (hires) and job destruction (fires) with the latter coded as negative numbers. The coefficient is of a similar magnitude for both; job expansions lower education, and job contractions raise education. Column 9 interacts new export job arrivals with a positive and a negative indicator dummy. Therefore, I allow for years of net new job losses (negative values of $l_{z c}$ ) to have potentially different effects from years of net new job gains (positive values of $l_{z c}$ ). I find similar coefficients on both.

Finally, column 10 investigates the possibility that there are geographic spillovers. For example, a student may decide to drop out of school due to new export job opportunities in the State capital. I calculate the net new export job arrivals at age 16 in all other commuting zones in the state and divide this number by the working age population of those other commuting zones. I include this state-level job measure as an additional independent variable (and replace state-time dummies with region-time dummies to avoid collinearity). The coefficient on state-level net new export jobs per worker is positive but insignificant, providing limited evidence for this hypothesis.

In summary, there is a robust negative impact of new export-manufacturing jobs at age 16 on cohort schooling. 
Table A.1: Robustness: Fewer Fixed Effects

\begin{tabular}{|c|c|c|c|c|c|}
\hline & $(1)$ & $(2)$ & $(3)$ & $(4)$ & $(5)$ \\
\hline & Baseline & & Fewer $I$ & Effects & \\
\hline & \multicolumn{5}{|c|}{ Cohort Average Completed Years of Schooling (All RF, Large $\Delta \mathrm{s}$ ) } \\
\hline $\begin{array}{l}\text { Net New Export Manufacturing } \\
\text { Jobs/Worker at Age } 16\end{array}$ & $\begin{array}{c}-3.306^{* * *} \\
(0.690)\end{array}$ & $\begin{array}{c}-7.016^{* * *} \\
(1.073)\end{array}$ & $\begin{array}{c}-8.490^{* * *} \\
(1.665)\end{array}$ & $\begin{array}{c}-12.31 * * * \\
(3.062)\end{array}$ & $\begin{array}{c}8.095^{* *} \\
(4.118)\end{array}$ \\
\hline Commuting-Zone Fixed Effects & Yes & Yes & Yes & Yes & No \\
\hline Commuting-Zone Linear Trends & Yes & No & No & No & No \\
\hline State-Time Dummies & Yes & Yes & No & No & Yes \\
\hline Time Dummies & Yes & Yes & Yes & No & Yes \\
\hline Observations & 25,289 & 25,289 & 25,289 & 25,289 & 25,289 \\
\hline$R^{2}$ & 0.942 & 0.904 & 0.892 & 0.876 & 0.327 \\
\hline Commuting Zones & 1808 & 1808 & 1808 & 1808 & 1808 \\
\hline \multicolumn{6}{|c|}{$\begin{array}{l}\text { Notes: Dependent variable is cohort average years of schooling in the year } 2000 \text {. Independent variable is } \\
\text { net new export-manufacturing jobs per worker arriving in cohort's commuting zone at age } 16 \text { attributable } \\
\text { to firms that expand or contract their employment by } 50 \text { or more employees in a single year. Column } 1 \\
\text { repeats the baseline specification with state-time dummies, commuting-zone dummies and commuting-zone } \\
\text { linear trends. Columns } 2-4 \text { sequentially remove commuting-zone linear trends, state-time dummies and time- } \\
\text { dummies. Column } 5 \text { removes commuting-zone fixed effects and linear trends. Regressions weighted by cell } \\
\text { population, exclude Mexico City and migrants. Commuting-zone clustered standard errors in parentheses. * } \\
\text { significant at } 10 \text { percent level, }{ }^{* *} \text { at } 5 \text { percent and }{ }^{* * *} \text { at } 1 \text { percent. }\end{array}$} \\
\hline
\end{tabular}

Table A.2: Robustness: Different Geographical Samples

\begin{tabular}{|c|c|c|c|c|c|}
\hline & $(1)$ & $(2)$ & $(3)$ & $(4)$ & $(5)$ \\
\hline & Baseline & No Informal & Progresa & No Monterrey & Regression \\
\hline & & commuting zones & Dummy & or Guadalajara & Unweighted \\
\hline & \multicolumn{5}{|c|}{ Cohort Average Completed Years of Schooling (All RF, Large $\Delta \mathrm{s}$ ) } \\
\hline $\begin{array}{l}\text { Net New Export Manuf. } \\
\text { Jobs/Worker at Age } 16\end{array}$ & $\begin{array}{c}-3.306^{* * *} \\
(0.690)\end{array}$ & $\begin{array}{c}-3.234^{* * *} \\
(0.691)\end{array}$ & $\begin{array}{c}-3.268^{* * *} \\
(0.693)\end{array}$ & $\begin{array}{c}-3.154^{* * *} \\
(0.690)\end{array}$ & $\begin{array}{c}-2.741^{* * *} \\
(0.880)\end{array}$ \\
\hline Observations & 25,289 & 14,376 & 25,289 & 25,261 & 25,289 \\
\hline$R^{2}$ & 0.942 & 0.939 & 0.943 & 0.935 & 0.806 \\
\hline Commuting Zones & 1808 & 1027 & 1808 & 1806 & 1808 \\
\hline
\end{tabular}

Notes: Dependent variable is cohort average years of schooling in the year 2000. Independent variable is net new export-manufacturing jobs per worker arriving in cohort's commuting zone at age 16 attributable to firms that expand or contract their employment by 50 or more employees in a single year. State-time dummies, commutingzone dummies and commuting-zone linear trends included. Geographic coverage documented in column headings. Progresa dummy included in column 3 takes the value 1 in the 1998 and 1999 if more than 10 percent of the commuting-zone population reported receiving Progresa or Procampo payments in the 2000 census. Regressions weighted by cell population (except column 5 which is unweighted), exclude Mexico City and migrants. Commuting-zone clustered standard errors in parentheses. ${ }^{*}$ significant at 10 percent level, ${ }^{* *}$ at 5 percent and $* * *$ at 1 percent. 


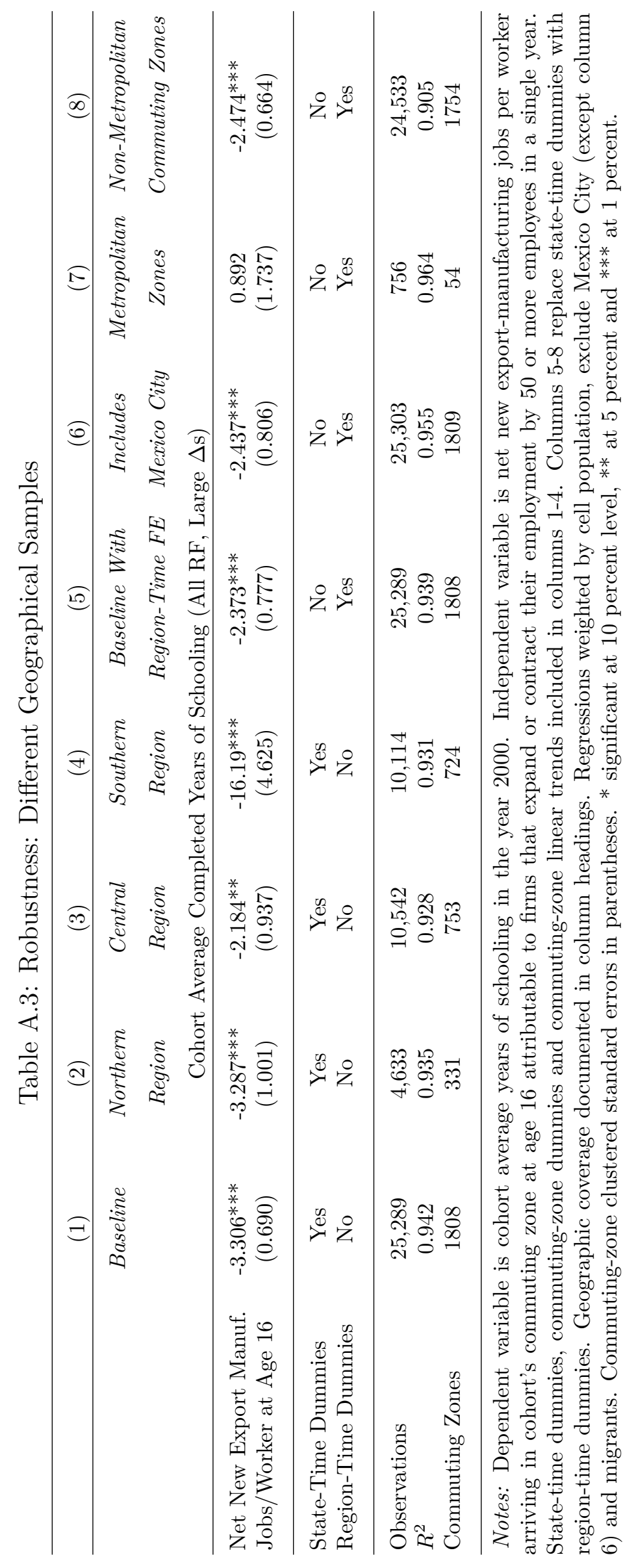




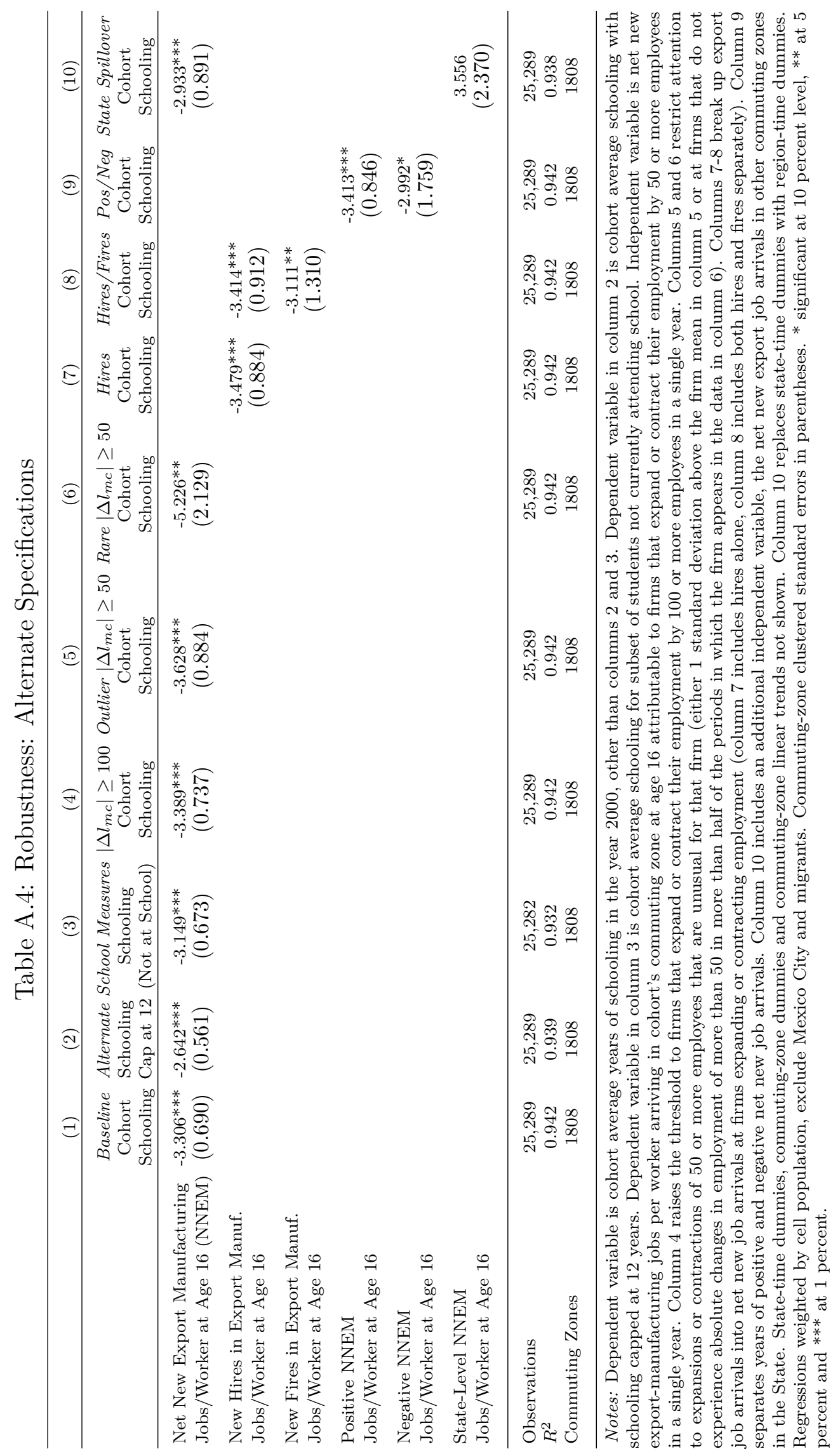




\section{Appendix B Migration}

As discussed in Section 4.5.2, migration could bias my results if local labor market conditions alter the composition of out-migrants. If new export jobs prevent low-education individuals from migrating, the average education of the cohort declines with export job arrivals despite no student altering their schooling decision. I perform two empirical tests in order to dismiss this possible explanation for my findings.

The first test explores the size of different cohorts of non-migrants. If these composition effects are important, and if the less educated are deciding not to migrate, the size of the sample cohort should rise with new jobs in export manufacturing. To test this hypothesis, I replace cohort years of schooling with $\log$ cohort size, $\ln N_{z c}$, in specification $1:^{2}$

$$
\ln N_{z c}=\beta l_{z c}+\delta_{z}+\delta_{z} c+\delta_{r c}+\varepsilon_{z c} .
$$

Column 1 of Table B.1 show the results from this regression. There is no evidence that cohort size responds positively to net new export-manufacturing job arrivals at age 16 . In fact, the basic specification finds a small decline in cohort size. I draw similar conclusions in column 2 where I use an alternate cohort population measure instead of log cohort size: the cohort size divided by the working population at the time of the census. ${ }^{3}$

The second test directly examines the hypothesis that relatively uneducated youths were disproportionately deterred from migrating due to a new factory opening. If this hypothesis is correct, I should find that the education of out-migrants rises relative to the education of non-migrants in a commuting zone when new export-manufacturing jobs arrive.

The 2000 census records where each individual was living in 1995. Therefore, for every commuting-zone cohort pair, I calculate the average education of individuals who lived in the commuting zone in 1995 but not in 2000, $S_{\text {leave }, z c}$, divided by the average education of individuals who lived in the commuting zone in both 1995 and 2000, $S_{\text {stay,zc. }}$ My dependent variable is the mean value of this ratio for the five cohorts who turned 16 between 1995 and 1999, $\frac{1}{5} \sum_{c=1995}^{1999} \frac{S_{\text {leave }, z c}}{S_{\text {stay }, z c}}$. This variable is then regressed on the sum of the changes in exportmanufacturing employment per worker between January 1995 and December 1999. I also include a full set of state dummy variables:

$$
\frac{1}{5} \sum_{c=1995}^{1999} \frac{S_{\text {leave }, z c}}{S_{\text {stay }, z c}}=\beta \sum_{t=1995}^{1999} l_{z t}+\delta_{r}+\varepsilon_{m} .
$$

If my finding that new export jobs reduce schooling is driven by the less educated remaining

${ }^{2}$ I use $\log$ cohort size as commuting-zone populations vary greatly. Therefore, I am considering proportional changes in cohort size. Net new jobs are already scaled, as they are divided by the number of workers in the commuting zone.

${ }^{3}$ If cohorts aged 16 at the time of large export shocks have differential migration patterns compared to less heavily exposed cohorts, these cohorts should have differential sizes compared to older and younger cohorts within the same commuting zone. 
in the commuting zone, the ratio of leavers to stayers education will increase with net new export job arrivals between 1995 and $1999(\beta>0)$.

Results are reported in column 3 of Table B.1. $\beta$ is significantly negative, not positive. New export-manufacturing jobs keep the more educated youth in the commuting zone. This is strong evidence, at least for the later years in the sample, that when new export jobs arrive, out-migration effects tend to raise cohort education through composition effects. This result only applies to internal migrants, but Chiquiar and Hanson (2005) find that emigrants to the United States are also drawn from relatively educated portions of the population. Taken together, the magnitude of my finding that new export-manufacturing jobs reduce schooling is likely to be attenuated by out-migration.

In-migration may generate heterogeneity in the impact of new export-manufacturing jobs. In the extreme, if only migrants are employed in export manufacturing in a particular commuting zone and labor markets are segmented, then new job arrivals should have no impact on the education decisions of local youth. In this scenario, these export jobs do not enter into a local youth's choice set. In less extreme cases, large numbers of migrants are likely to reduce the local manufacturing wage and hence make new export-manufacturing jobs less attractive alternatives to schooling.

I test this hypothesis using the in-migrants I identify in the 2000 census. I interact new export job arrivals at age 16 (potentially broken down by skill) by $\vartheta_{z}$, the proportion of formal export manufacturing jobs held by migrants in the year 2000 in each commuting zone:

$$
S_{z c}=\beta l_{z c}+\gamma \vartheta_{z} l_{z c}+\delta_{z}+\delta_{z} c+\delta_{r c}+\varepsilon_{z c}
$$

If the presence of a large number of migrants reduces the impact of new job arrivals on the local population, I expect $\beta$ to be negative, and $\gamma$ to be positive.

I report results in columns 4 of Table B.1. Column 5 reports a similar specification but using the proportion of migrants in employment more generally. I find the expected sign patterns, and the negative coefficient on the migrant interaction is the same size as the positive coefficient on the main effect implying that if all the employees are migrants there is no effect at all (although the standard error is equally large so the interaction is not significant). Hence, in the absence of internal migration in Mexico, local education would decline even more with the arrival of new export-manufacturing opportunities at age 16. 


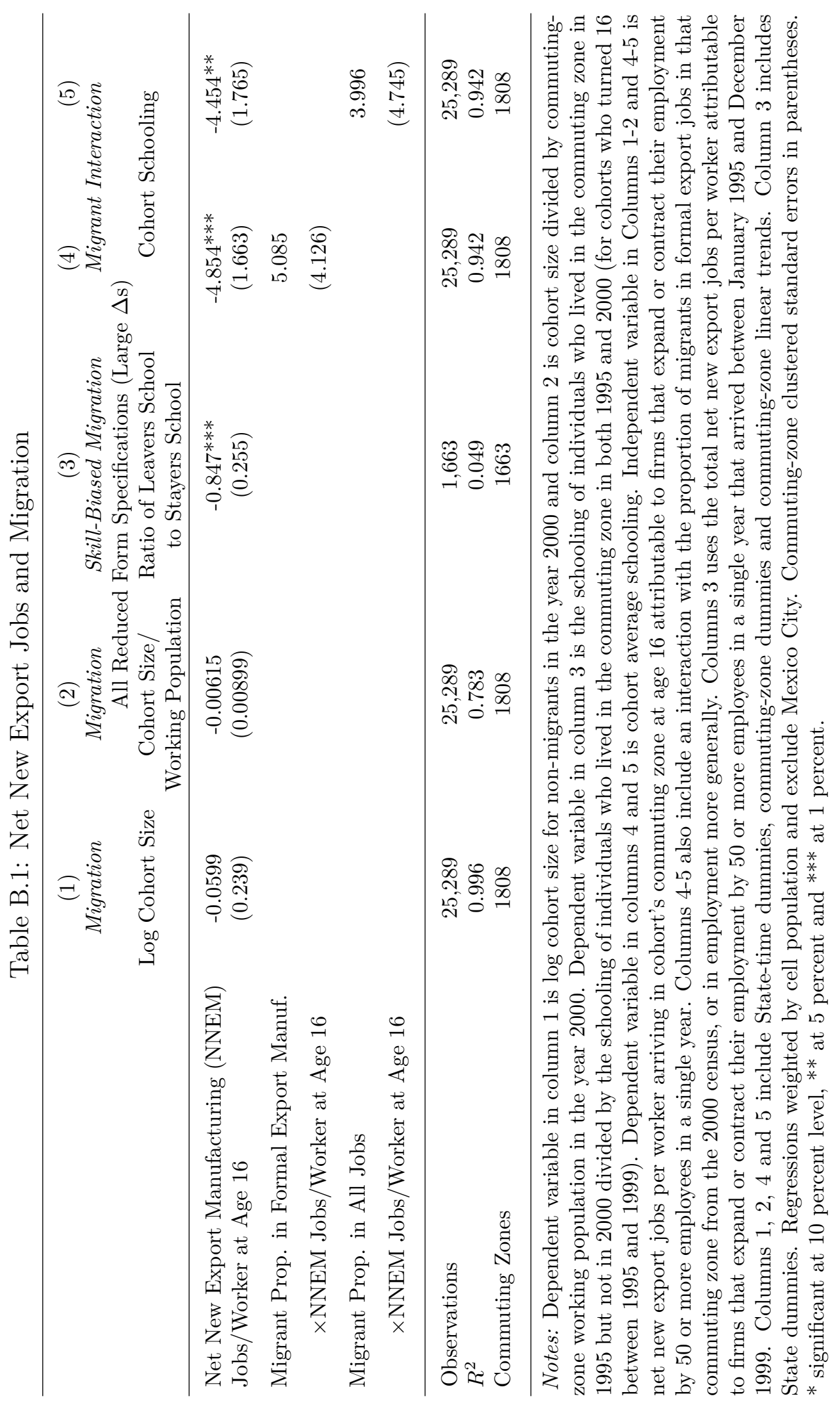




\section{Appendix C Additional Figures and Tables}

Figure C.1: Manufacturing Industry Features

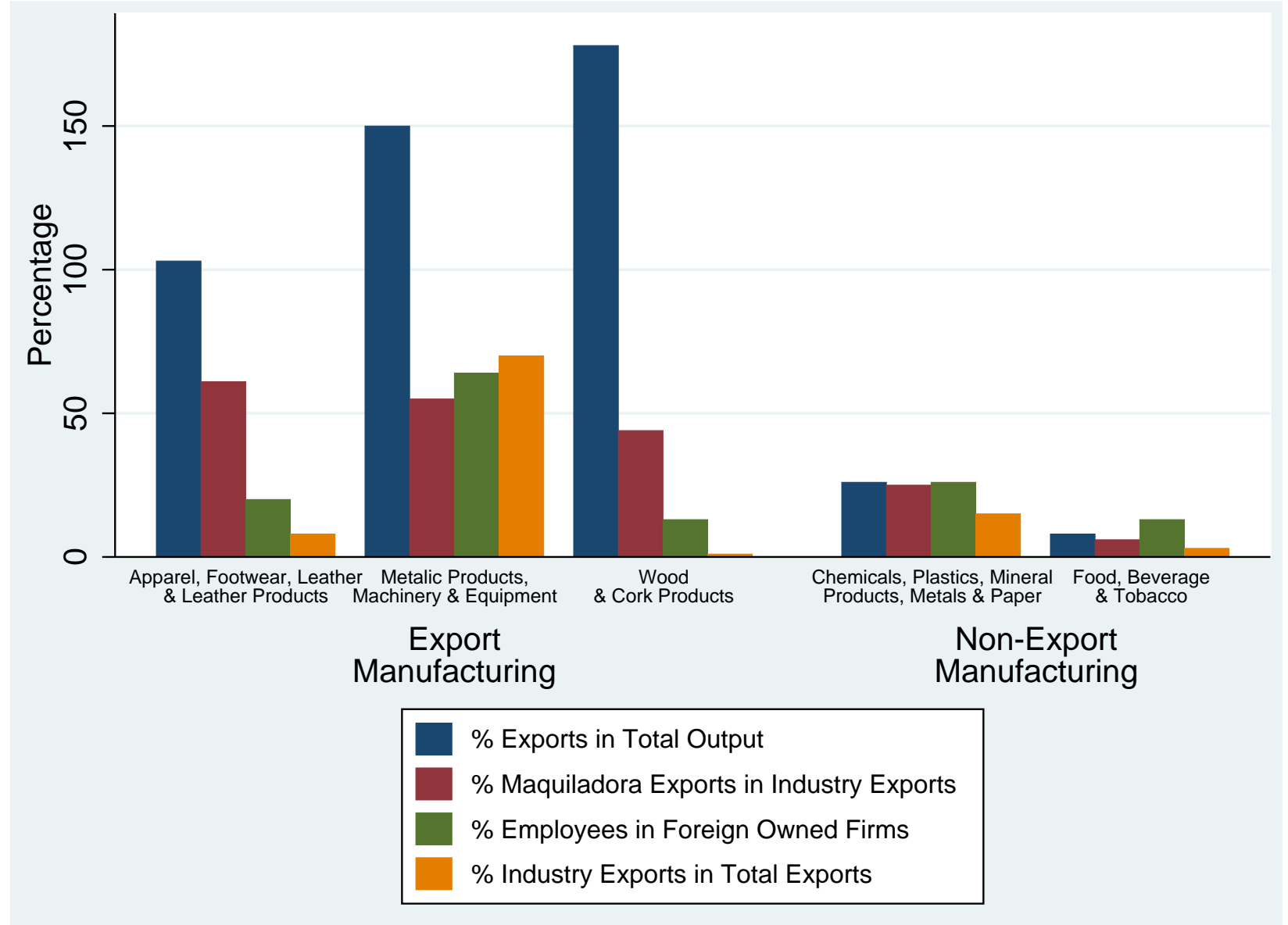

Notes: These data cover the whole of Mexico and originate from Nicita and Olarreaga (2007) (exports in total output), Banco de Mexico (Maquiladora and industry shares of exports) and Ibarraran (2004) (employees in foreign owned firms). The measure of output used by Nicita and Olarreaga (2007) does not properly account for all the imported intermediate components that typify the Mexican export production, hence the major export assembly industries show export ratios of over 100 percent. As these various sources report at different levels of aggregation, textiles are included in the apparel et al. category despite being classified as a non-export industry using the export threshold described in Section 2.1. Similarly, petroleum refinement is included in the chemicals et al. category despite being classified as an export industry. The metal products et al. category includes: metal products; electronic and mechanical machinery; electrical machinery; transport equipment; and scientific and optical equipment. 
Figure C.2: Histogram of Age by Industry Grouping (Age 16-28 in 2000, Insured by IMSS)

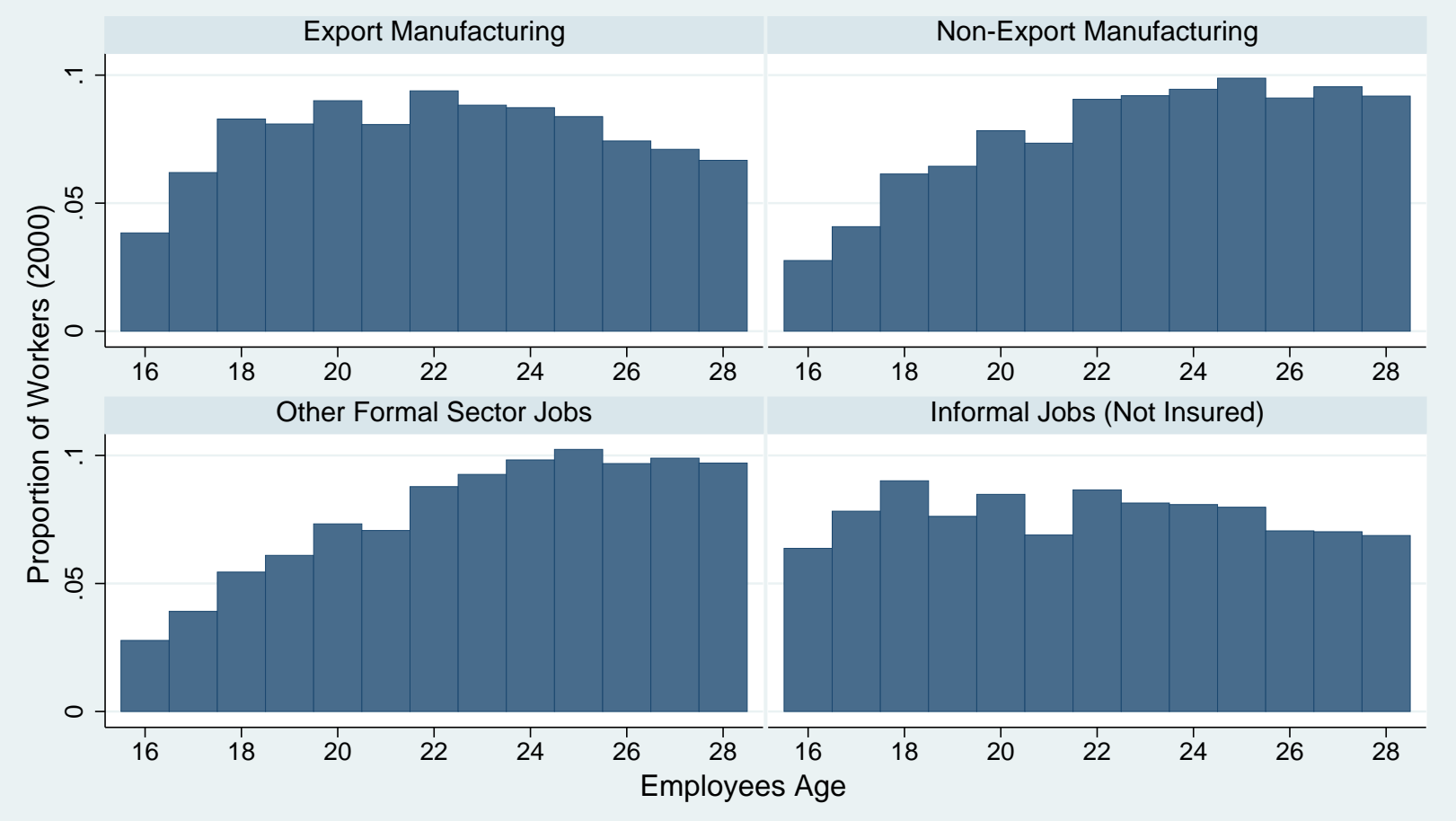

Note: The age distribution is calculated using the year 2000 census for formal sector workers age 16 to 28 (my sample cohort). A formal worker is defined as a worker insured by IMSS or equivalent insurance scheme. 
Figure C.3: Visual Identification for 30 Commuting Zones with Largest Export Job Shocks

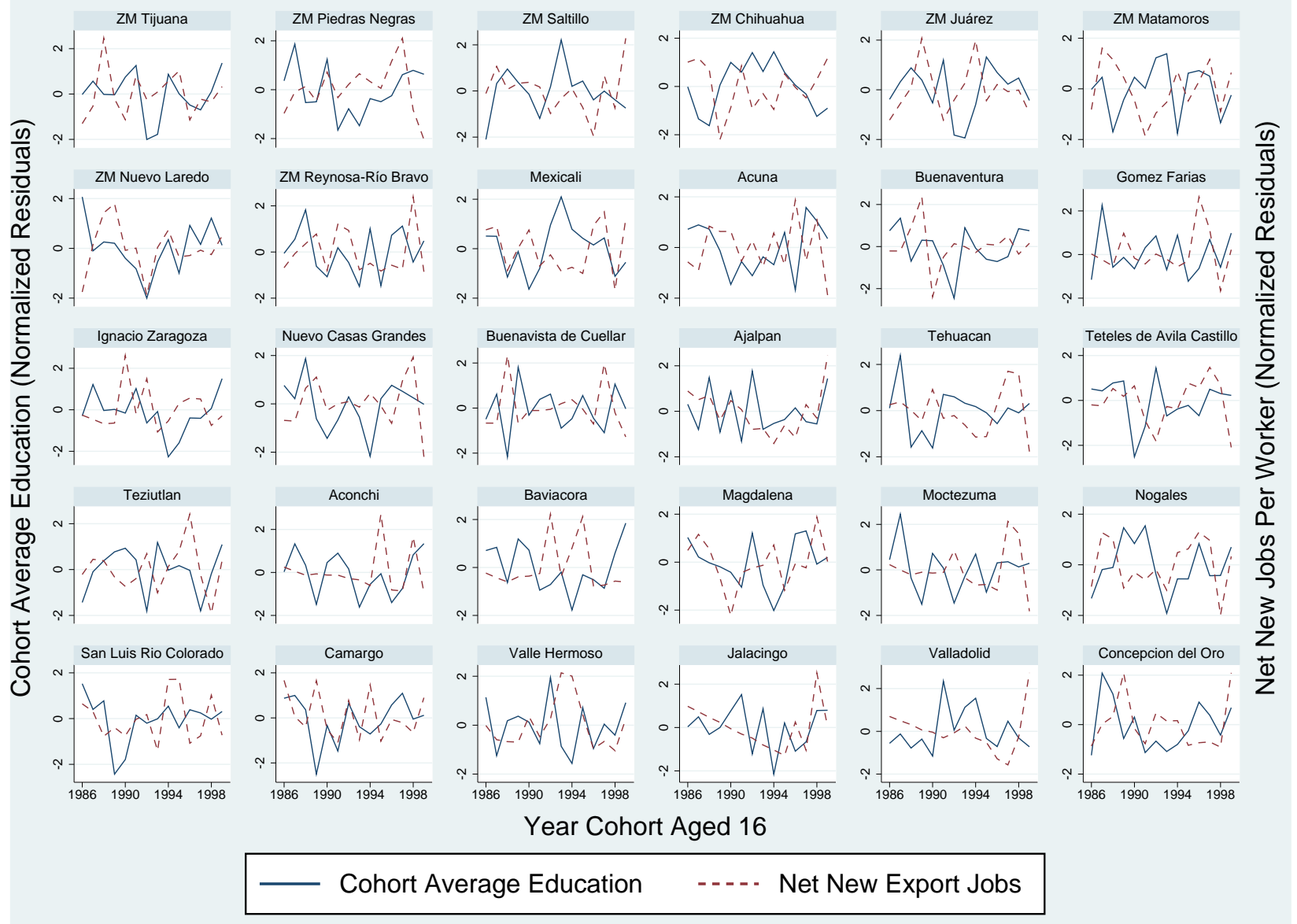

Note: Residuals from regressions of cohort schooling and net new export jobs at age 16 on state-time dummies, commuting-zone dummies and commuting-zone linear trends (i.e. the remaining terms in equation 1). Residuals are plotted against the year the cohort turned 16 for the 30 commuting zones with largest cumulative export job arrivals per worker. 
Figure C.4: Cross-Sectional Evidence from the 1990 Census (Including Commuting-Zone FE)

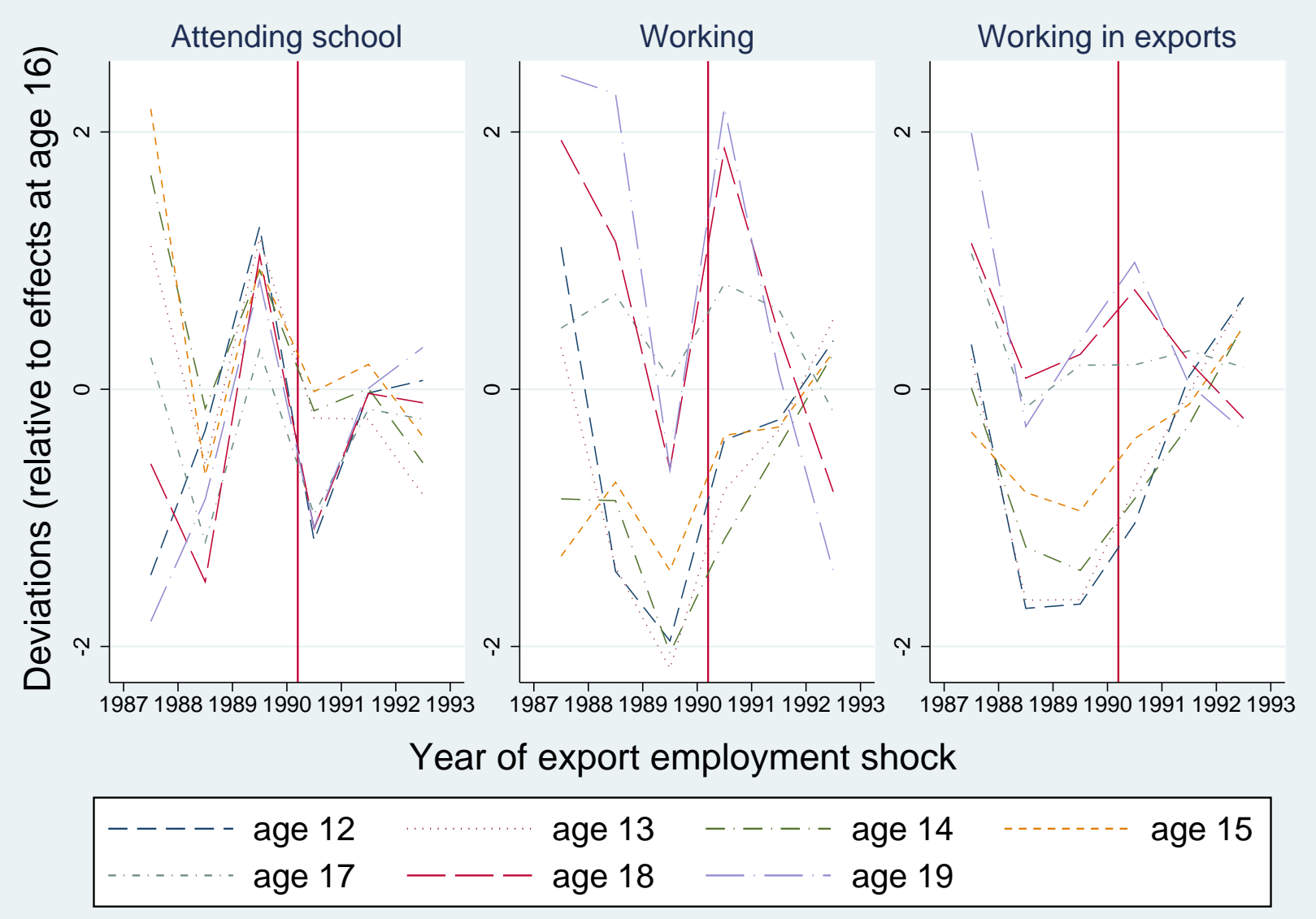

Notes: Each panel plots 48 coefficients obtained from regressing a binary variable from the 1990 census (denoted by panel title) on export employment shocks in each year between 1987-1992. I include cohorts aged 12-19 and age fixed effects, and allow the coefficients on the shocks to differ by age cohort. The full specification is shown in equation 4 of the main text except here I also include commuting-zone fixed effects. The omitted category is shocks at age 16. Sample restricted to commuting zones with at least one year of employment growth in export manufacturing between 1987-1992. Lines connect coefficients of the same age group and x-axis denotes the year of the shock. Vertical lines drawn in March 1990, the month of the 1990 census. 
Figure C.5: Cross-Sectional Evidence from Both Censuses

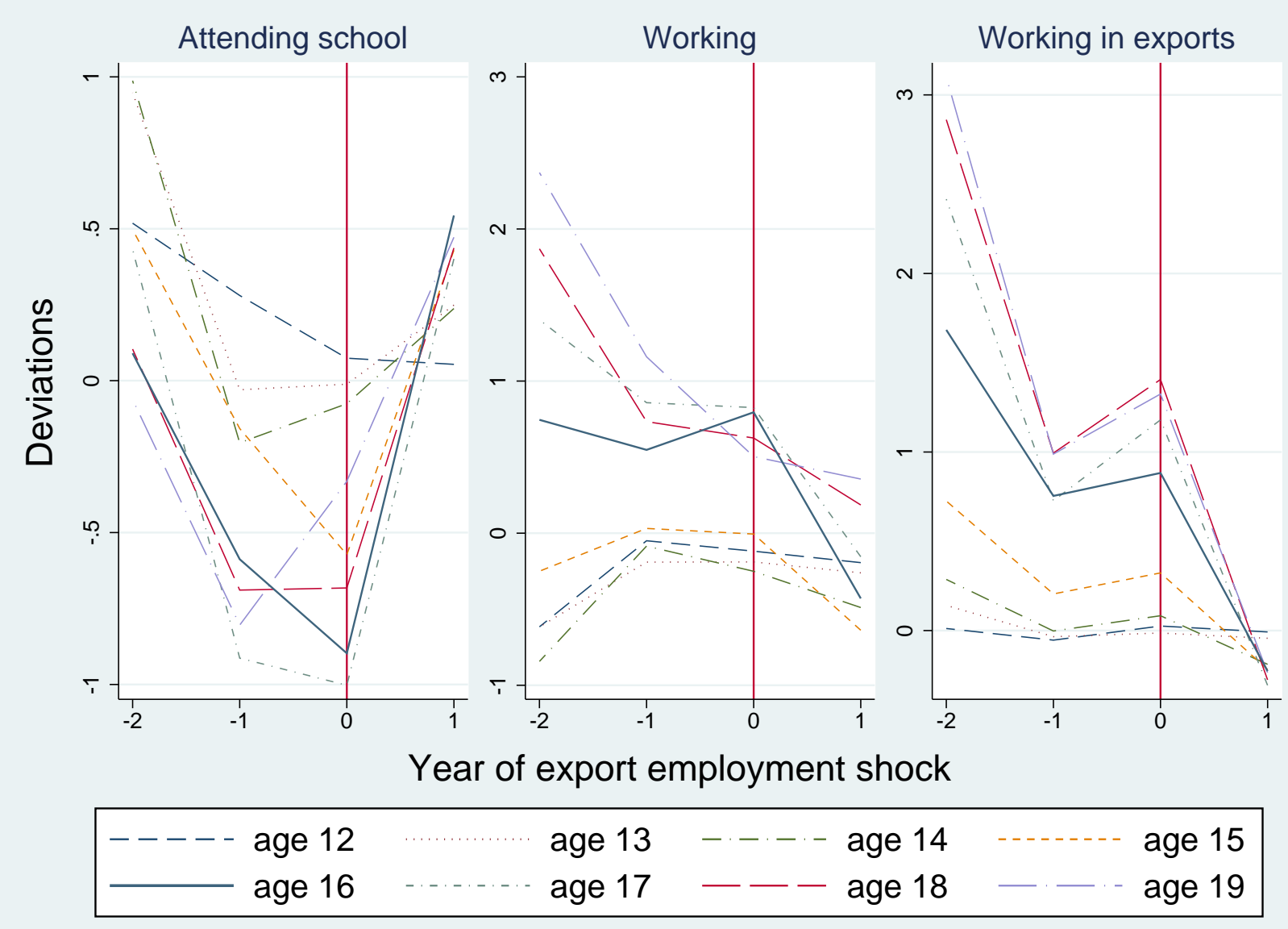

Notes: Each panel plots the 32 coefficients obtained from regressing the dependent variable (denoted by the panel title) on export employment shocks in each year between 1987 and 1990 (for 1990 census data) or between 1997 and 2000 (for 2000 census data). I include cohorts aged 12-19 and age-census fixed effects, and allow the coefficients on the shocks to differ by age cohort. The full specification is shown in equation 4 of the main text. Lines connect coefficients of the same age group and the x-axis denotes the year of the shock with 0 denoting the shock immediately preceding the census (1989 or 1999). 
Figure C.6: Job Propensities: Cross-Sectional Evidence from the 1990 Census

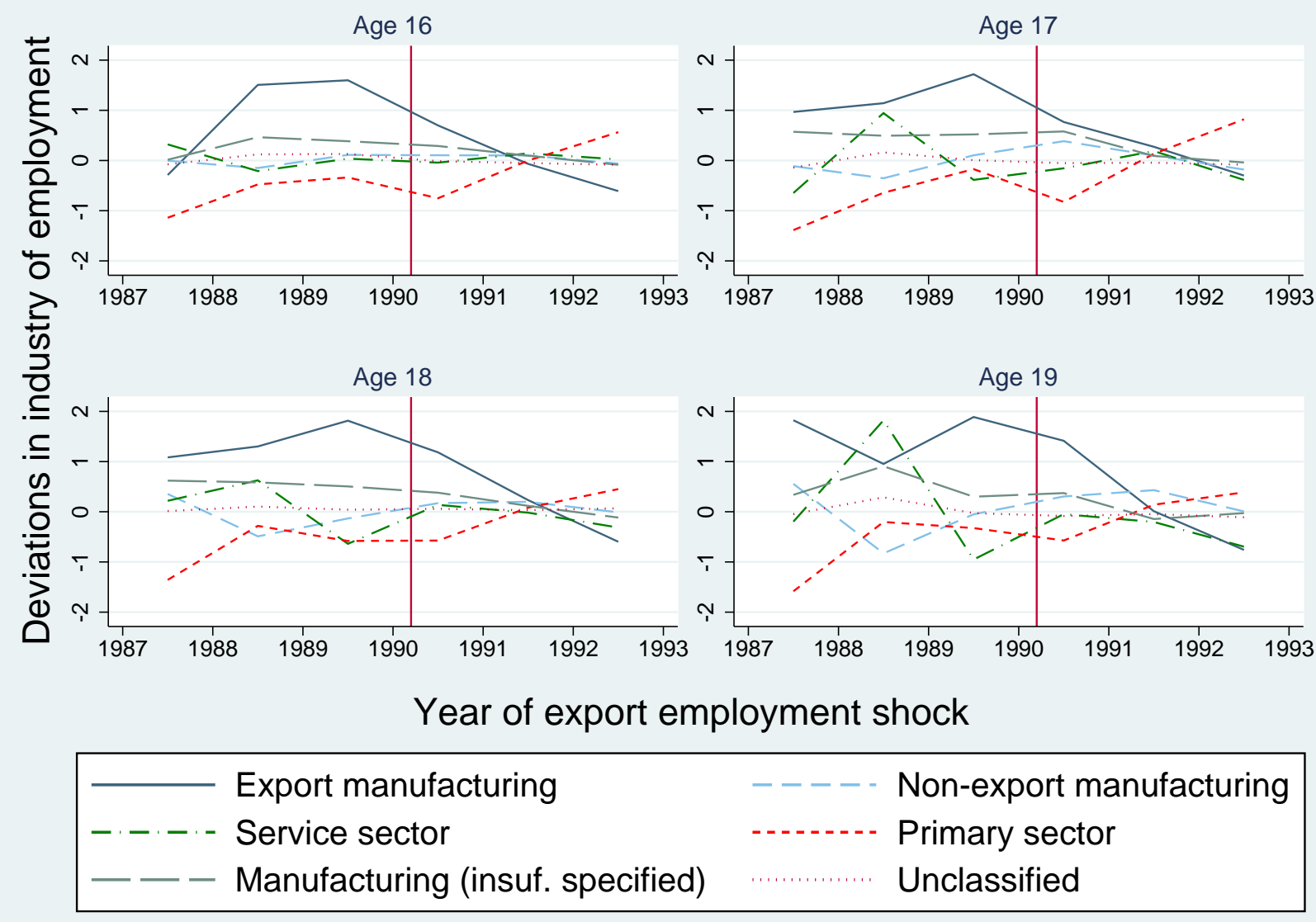

Notes: Panels plots coefficients obtained from regressing the dependent variable from the 1990 census (dummies for employment in the industry denoted by the legend for the relevant line) on export employment shocks in each year between 1987 and 1992 . I include cohorts aged 16-19 and age fixed effects, and allow the coefficients on the shocks to differ by age cohort. Sample restricted to commuting zones with at least one year of employment growth in export manufacturing between 1987 and 1992. Each panel plots results for four different industries for a single cohort. The full specification is shown in equation 4 of the main text. Lines connect coefficients of the same industry and the x-axis denotes the year of the shock. Vertical lines drawn in March 1990, the month of the 1990 census. 
Figure C.7: Parental/Sibling Channels: Cross-Sectional Evidence from the 1990 Census

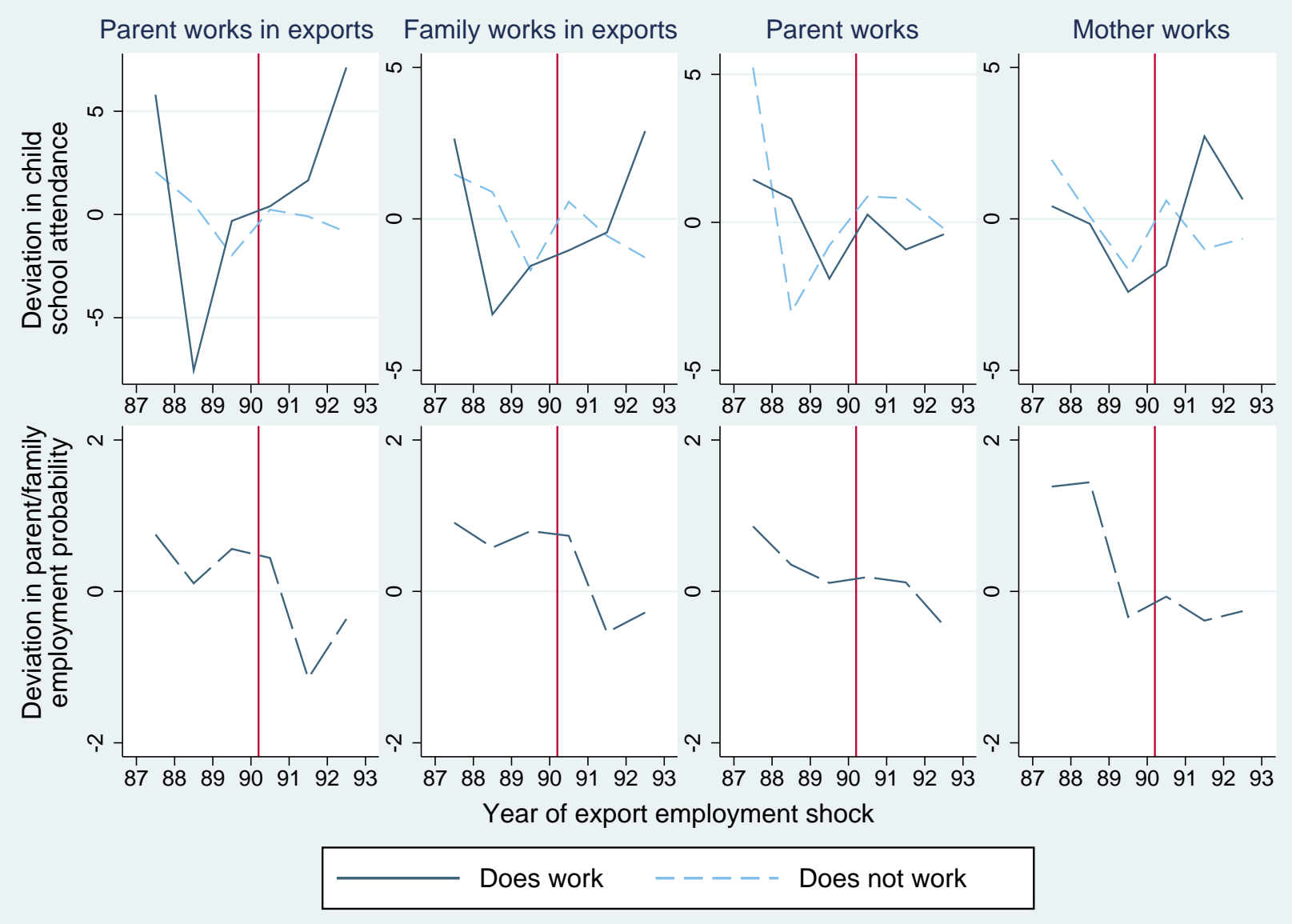

Notes: Each panel plots the coefficients obtained from regressing the dependent variable from the 1990 census (either school attendance in the top panel, or family employment dummies denoted column headings in the lower panel) on export employment shocks in each year between 1987 and 1992. Sample restricted to cohort aged 16 at the time of the 1990 census and to commuting zones with at least one year of employment growth in export manufacturing between 1987 and 1992. For school attainment in the upper panels, the coefficient on each of these shocks is allowed to differ depending on household employment status denoted in the column header. Lines connect coefficients for the same household employment status. The lower panels plots family employment propensities for the categories denoted in the header. The x-axis denotes the year of the shock in all panels. Vertical lines drawn in March 1990, the month of the 1990 census. 


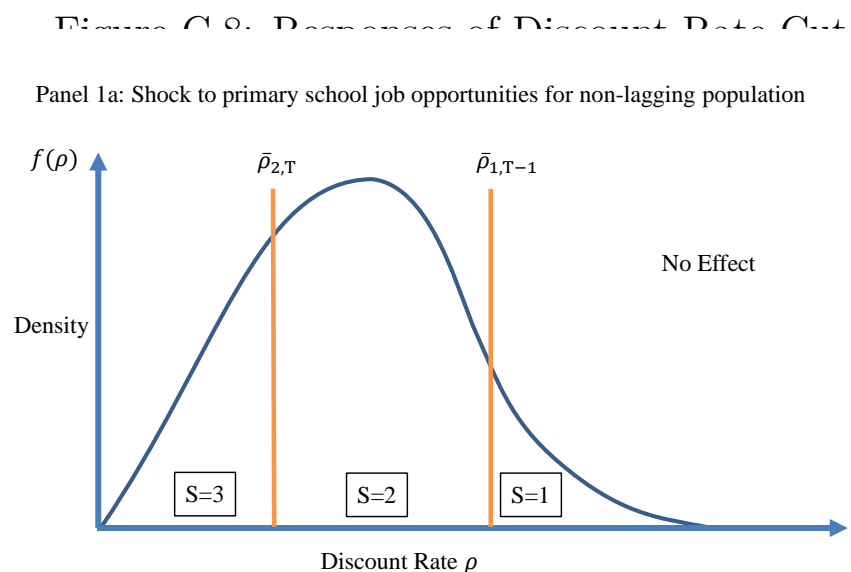

Panel 2a: Shock to secondary school job opportunities for non-lagging population

Panel 1b: Shock to primary school job opportunities for lagging population

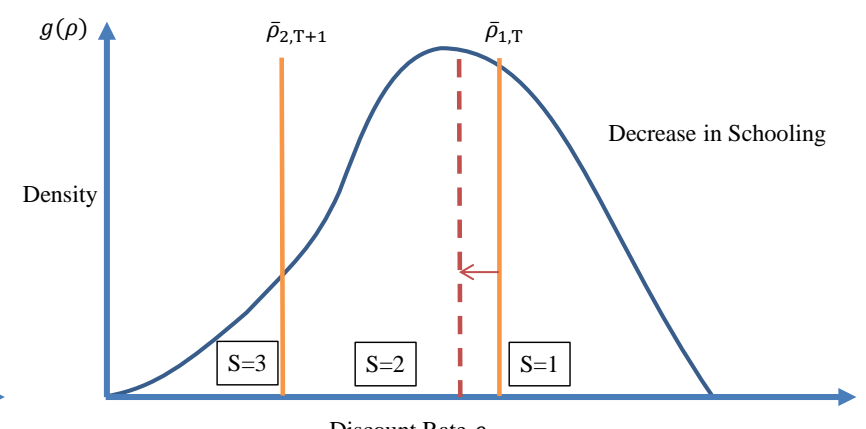

Discount Rate $\rho$

Panel 2b: Shock to secondary school job opportunities for lagging population

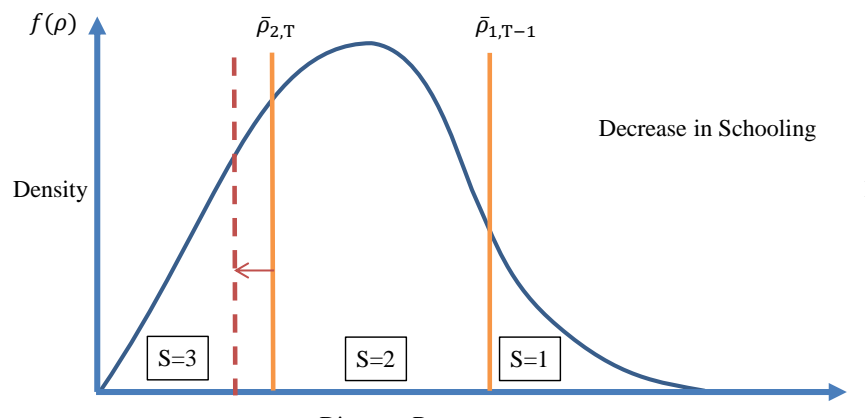

Discount Rate $\rho$

Panel 3a: Shock to high school job opportunities for non-lagging population

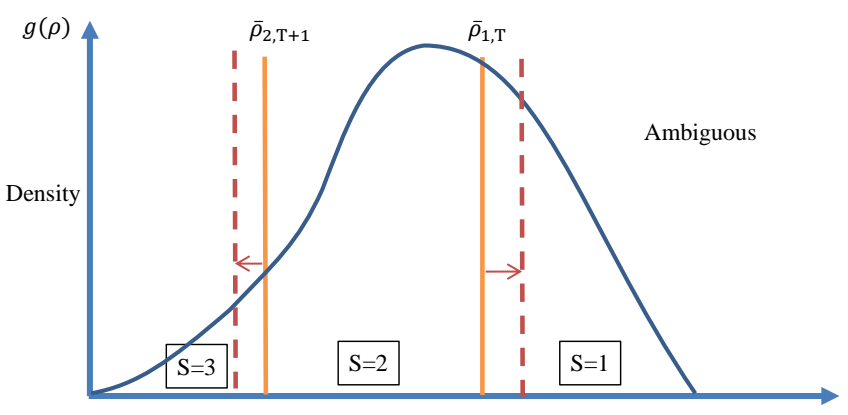

Discount Rate $\rho$

Panel 3b: Shock to high school job opportunities for lagging population
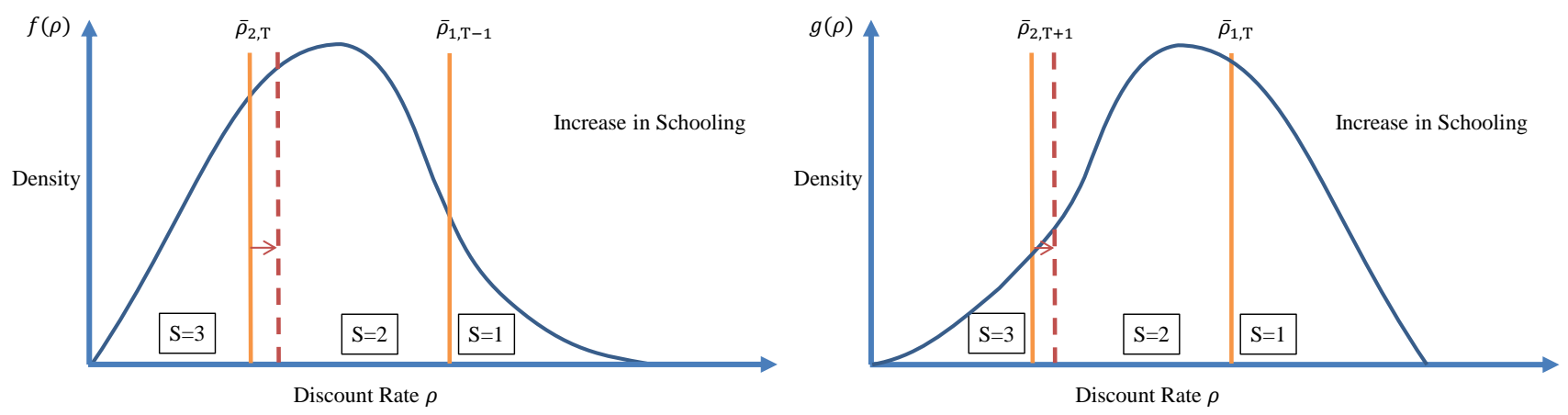

Notes: Figure shows the various movements of the discount-rate cutoffs for the cohort aged 16 at the time of an unanticipated new factory opening described in Section 5.1.1 of the main text. The left column of panels shows movements in cutoffs for non-lagging youths, those with $S-2$ at the time of the shock. The right column of panels shows movements in cutoffs for lagging youths, those with $S=1$ at the time of the shock. The first row shows the impact of shocks to jobs requiring $S=1$, the second row shocks to jobs requiring $S=2$, and the third row shocks to jobs requiring $S=3$. 
Figure C.9: Skill Differences by Sector (All Job Shocks, All Years)

Skill Requirements (1990)
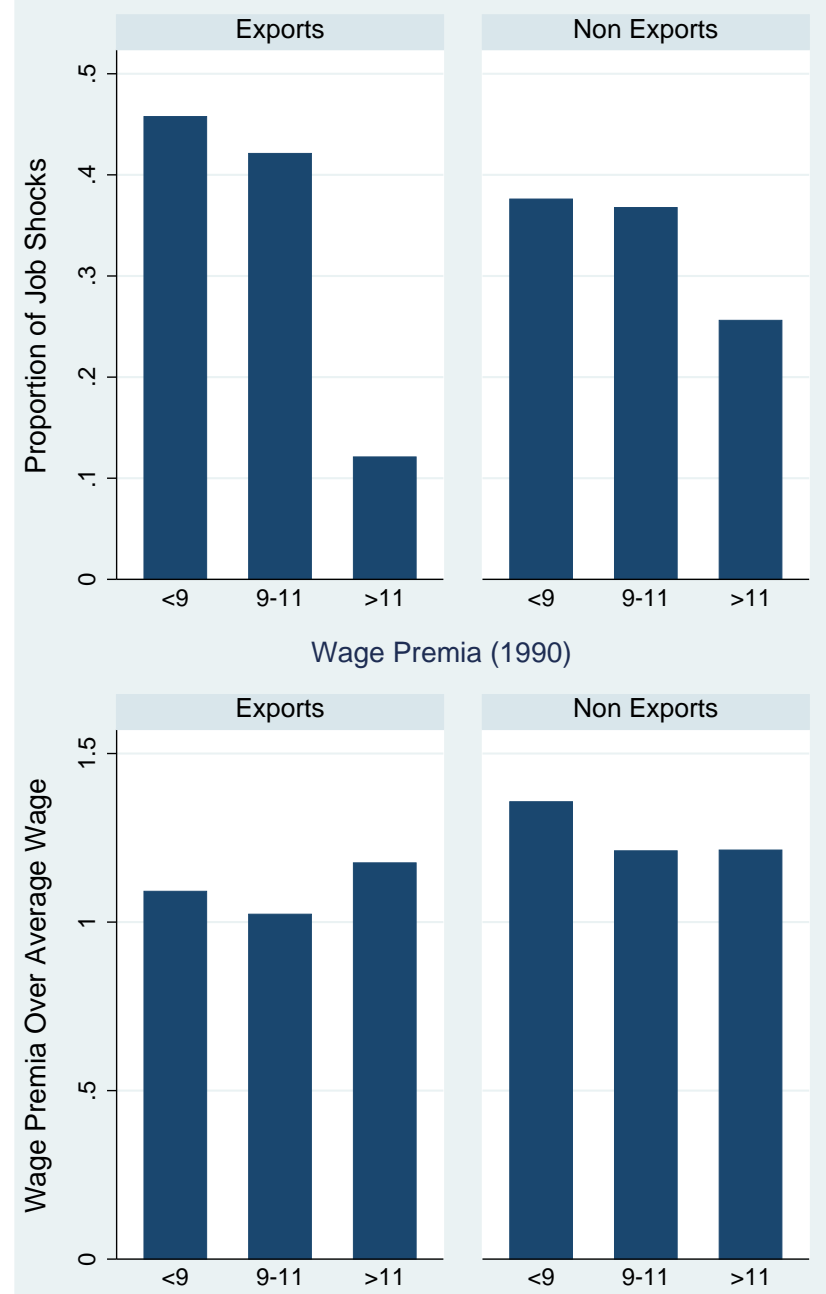

Skill X Density at Dropout Margin (1990)
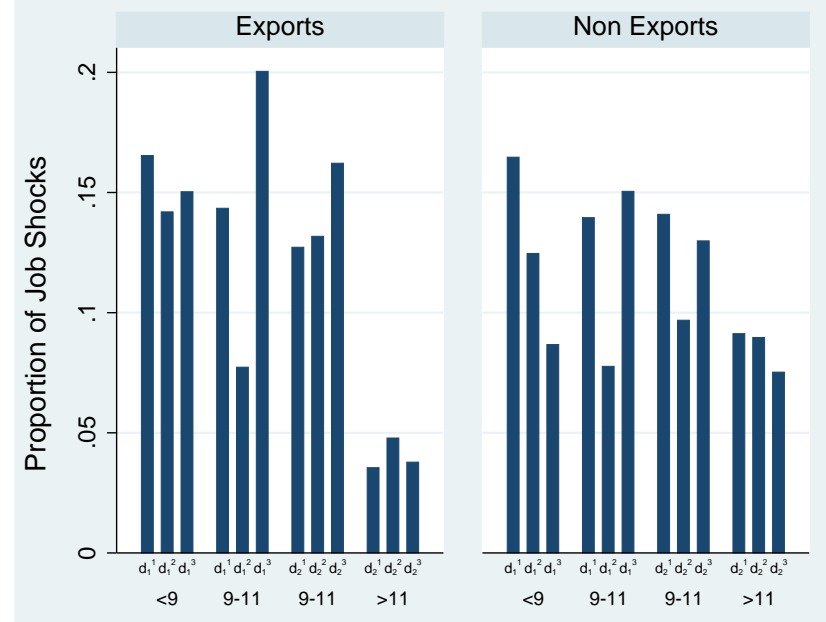

Skill Requirements (2000)
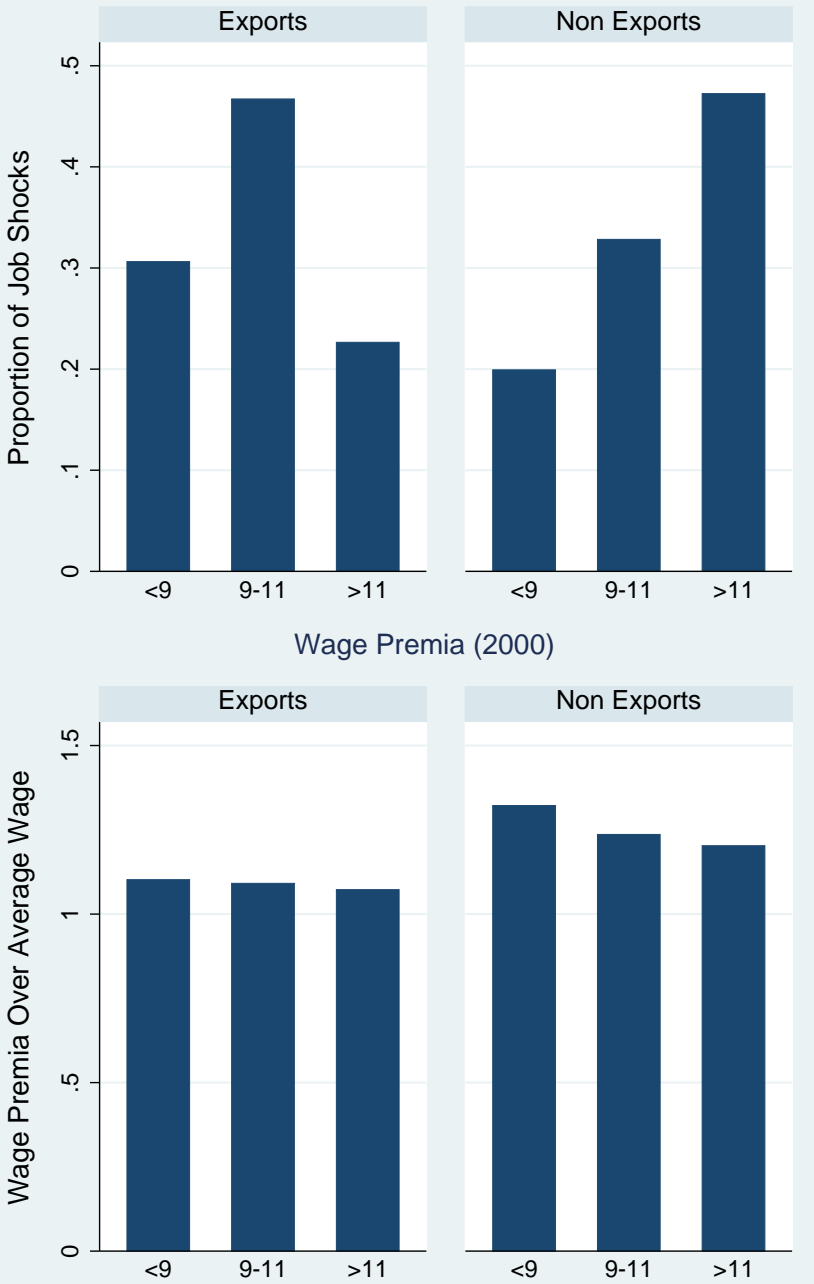

Skill X Density at Dropout Margin (2000)

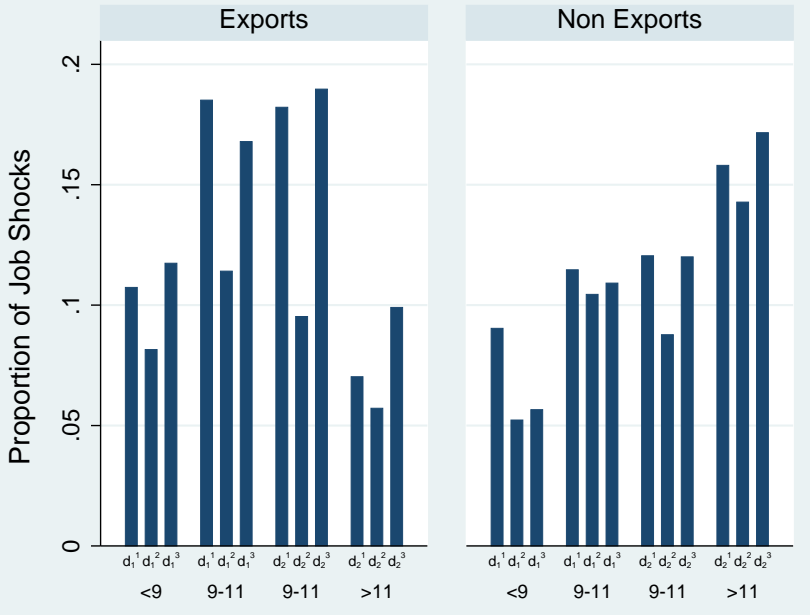

Note: Top row plots skill distribution of net new jobs per worker occurring between 1986 and 1999 . Job arrivals categorized into three skill bins based on highest completed educational stage of workers in each state-industry at time of census; primary school (grades $<9$ ), secondary school (grades $9-11$ ), and high school or above (grades $>11$ ). Second row plots wage premia (over the average commuting zone wage for that skill bin) paid by these same net new job arrivals. Bottom row subdivides the skill bins in top row into terciles (denoted by superscripts) of the relevant density of marginal youths for each skill level detailed in equation 10. Left panels use 1990 census information, right panels use 2000 census (where I focus on formal sector employees only). 
Table C.1: Net New Export Jobs at Different Ages of Exposure

\begin{tabular}{lcccccc}
\hline & $(1)$ & $(2)$ & $(3)$ & $(4)$ & $(5)$ & $(6)$ \\
All RF (Large $\Delta$ s) & & \multicolumn{2}{c}{ Education Metric (All Cohort Averages) } & \\
& Years of & Grade-9 & Pre-Grade-9 & Years of & Grade-9 & Pre-Grade-9 \\
& School & Dropout & Dropout & School & Dropout & Dropout \\
\hline Age 11 Net New Export & & & & -0.372 & 0.196 & 0.168 \\
Manuf. Jobs/Worker & & & & $(1.082)$ & $(0.254)$ & $(0.198)$ \\
Age 12 Net New Export & & & & -1.763 & -0.164 & 0.269 \\
Manuf. Jobs/Worker & & & & $(1.085)$ & $(0.217)$ & $(0.179)$ \\
Age 13 Net New Export & & & & $-2.133^{*}$ & 0.279 & $0.367^{* *}$ \\
Manuf. Jobs/Worker & & & & $(1.118)$ & $(0.215)$ & $(0.169)$ \\
Age 14 Net New Export & -0.605 & -0.131 & -0.0143 & $-1.650^{*}$ & -0.00726 & 0.134 \\
Manuf. Jobs/Worker & $(1.287)$ & $(0.239)$ & $(0.153)$ & $(0.897)$ & $(0.232)$ & $(0.137)$ \\
Age 15 Net New Export & -0.955 & 0.0935 & -0.0159 & $-1.925^{* *}$ & 0.0854 & $0.295^{* *}$ \\
Manuf. Jobs/Worker & $(1.340)$ & $(0.210)$ & $(0.159)$ & $(0.828)$ & $(0.216)$ & $(0.136)$ \\
Age 16 Net New Export & $-4.090^{* * *}$ & $0.407^{*}$ & $0.303^{*}$ & & & \\
Manuf. Jobs/Worker & $(1.149)$ & $(0.231)$ & $(0.161)$ & & & \\
Age 17 Net New Export & 0.753 & 0.0660 & $-0.301^{* *}$ & & & \\
Manuf. Jobs/Worker & $(0.932)$ & $(0.189)$ & $(0.138)$ & & & \\
Age 18 Net New Export & $-1.601^{*}$ & $0.329^{*}$ & 0.0233 & & & \\
Manuf. Jobs/Worker & $(0.923)$ & $(0.173)$ & $(0.128)$ & & & \\
\hline Observations & 18,063 & 17,206 & 18,063 & 18,066 & 15,739 & \\
$R^{2}$ & 0.952 & 0.731 & 0.941 & 0.953 & 0.778 & 0.944 \\
Commuting Zones & 1808 & 1806 & 1808 & 1808 & 1805 & 1808 \\
\hline & & & & & & \\
\hline
\end{tabular}

Notes: Dependent variable is a cohort education metric, either average completed schooling, grade-9 dropout rates (i.e. the proportion of the set of students with 9 or more years of schooling who obtain no additional years of schooling beyond 9) or pre-grade-9 dropout rates (i.e. the proportion of students that obtain fewer than 9 years of schooling). Independent variables are net new export manufacturing jobs per worker arriving in cohort's commuting zone at various ages between 11 and 18 attributable to firms that expand or contract their employment by 50 or more employees in a single year. State-time dummies, commuting-zone dummies and commuting-zone linear trends not shown. Regressions weighted by cell population, exclude Mexico City and migrants. Commutingzone clustered standard errors in parentheses. ${ }^{*}$ significant at 10 percent level, ${ }^{* *}$ at 5 percent and ${ }^{* * *}$ at 1 percent. 
Table C.2: Cross-Sectional Evidence from the 1990 Census

(1)

(2)

(3)

(4)

$(5)$

(6)

School Attendance in March 1990

\begin{tabular}{|c|c|c|c|c|c|c|}
\hline $\begin{array}{l}\text { All RF } \\
(\text { Large } \Delta s)\end{array}$ & $\begin{array}{c}\text { Export Shock } \\
\text { in } 1987\end{array}$ & $\begin{array}{c}\text { Export Shock } \\
\text { in } 1988\end{array}$ & $\begin{array}{c}\text { Export Shock } \\
\text { in } 1989\end{array}$ & $\begin{array}{c}\text { Export Shock } \\
\text { in } 1990\end{array}$ & $\begin{array}{l}\text { Export Shock } \\
\text { in } 1991\end{array}$ & $\begin{array}{l}\text { Export Shock } \\
\text { in } 1992\end{array}$ \\
\hline 12 year olds & $\begin{array}{c}1.106 \\
(1.025)\end{array}$ & $\begin{array}{c}0.374 \\
(0.603)\end{array}$ & $\begin{array}{c}0.147 \\
(0.326)\end{array}$ & $\begin{array}{c}0.582 \\
(0.365)\end{array}$ & $\begin{array}{c}-0.162 \\
(0.520)\end{array}$ & $\begin{array}{l}-0.717 \\
(0.567)\end{array}$ \\
\hline 13 year olds & $\begin{array}{l}3.380^{*} \\
(1.736)\end{array}$ & $\begin{array}{l}-0.291 \\
(1.248)\end{array}$ & $\begin{array}{l}-0.277 \\
(0.598)\end{array}$ & $\begin{array}{c}0.850 \\
(0.688)\end{array}$ & $\begin{array}{l}-0.625 \\
(0.974)\end{array}$ & $\begin{array}{l}-1.432 \\
(1.076)\end{array}$ \\
\hline 14 year olds & $\begin{array}{l}3.871^{* *} \\
(1.892)\end{array}$ & $\begin{array}{l}-0.224 \\
(1.479)\end{array}$ & $\begin{array}{l}-0.788 \\
(0.738)\end{array}$ & $\begin{array}{c}0.273 \\
(0.830)\end{array}$ & $\begin{array}{l}-0.411 \\
(1.269)\end{array}$ & $\begin{array}{l}-1.039 \\
(1.443)\end{array}$ \\
\hline 15 year olds & $\begin{array}{l}3.613^{*} \\
(1.955)\end{array}$ & $\begin{array}{l}-0.617 \\
(1.677)\end{array}$ & $\begin{array}{l}-1.052 \\
(0.779)\end{array}$ & $\begin{array}{c}0.110 \\
(0.757)\end{array}$ & $\begin{array}{l}-0.446 \\
(1.385)\end{array}$ & $\begin{array}{l}-0.911 \\
(1.464)\end{array}$ \\
\hline 16 year olds & $\begin{array}{c}1.278 \\
(1.913)\end{array}$ & $\begin{array}{c}0.205 \\
(1.792)\end{array}$ & $\begin{array}{c}-1.904^{* *} \\
(0.880)\end{array}$ & $\begin{array}{c}0.231 \\
(0.910)\end{array}$ & $\begin{array}{l}-0.656 \\
(1.449)\end{array}$ & $\begin{array}{l}-0.538 \\
(1.436)\end{array}$ \\
\hline 17 year olds & $\begin{array}{c}1.216 \\
(1.274)\end{array}$ & $\begin{array}{l}-0.721 \\
(1.457)\end{array}$ & $\begin{array}{c}-1.574^{* *} \\
(0.766)\end{array}$ & $\begin{array}{l}-0.488 \\
(0.721)\end{array}$ & $\begin{array}{l}-0.799 \\
(1.160)\end{array}$ & $\begin{array}{l}-1.171 \\
(1.254)\end{array}$ \\
\hline 18 year olds & $\begin{array}{c}0.741 \\
(1.188)\end{array}$ & $\begin{array}{l}-1.137 \\
(1.364)\end{array}$ & $\begin{array}{l}-0.700 \\
(0.877)\end{array}$ & $\begin{array}{l}-0.419 \\
(0.720)\end{array}$ & $\begin{array}{l}-0.445 \\
(0.847)\end{array}$ & $\begin{array}{l}-0.870 \\
(1.023)\end{array}$ \\
\hline 19 year olds & $\begin{array}{c}-0.379 \\
(1.228)\end{array}$ & $\begin{array}{c}-0.389 \\
(1.473)\end{array}$ & $\begin{array}{l}-0.915 \\
(0.874)\end{array}$ & $\begin{array}{c}-0.352 \\
(0.747)\end{array}$ & $\begin{array}{c}-0.390 \\
(0.897)\end{array}$ & $\begin{array}{c}-0.395 \\
(1.020)\end{array}$ \\
\hline $\begin{array}{l}\text { Observations } \\
R^{2} \\
\text { Commuting Zones }\end{array}$ & & & & & & $\begin{array}{c}675,299 \\
0.669 \\
178\end{array}$ \\
\hline
\end{tabular}

Notes: Dependent variable is a dummy for school attendance at the time of the 1990 census. Independent variables are net new export manufacturing jobs per worker attributable to firms that expand or contract their employment by 50 or more employees in a single year arriving in youth's commuting zone in each year between 1987 and 1992. I include cohorts aged 12-19 and age fixed effects (not shown), and allow the coefficients on the shocks to differ by age cohort. Sample restricted to commuting zones with at least one year of employment growth in export manufacturing between 1987 and 1992. Regression weighted by cell population, excludes Mexico City and migrants. Commuting-zone clustered standard errors in parentheses. * significant at 10 percent level, ${ }^{* *}$ at 5 percent and ${ }^{* * *}$ at 1 percent. 
Table C.3: Cross-Sectional Evidence from the 1990 Census (Including Commuting-Zone FE)

(1)

$(2)$
(3)

School Attendance in March 1990
(5)

\begin{tabular}{lcccccc} 
All RF & Export Shock & Export Shock & Export Shock & Export Shock & Export Shock & Export Shock \\
$($ Large $\Delta \mathrm{s})$ & in 1987 & in 1988 & in 1989 & in 1990 & in 1991 & in 1992 \\
\hline 12 year olds & -1.445 & -0.319 & 1.264 & -1.178 & -0.0292 & 0.0683 \\
& $(1.397)$ & $(1.544)$ & $(0.928)$ & $(0.894)$ & $(1.190)$ & $(1.177)$ \\
13 year olds & 1.112 & -0.589 & $1.174^{* *}$ & -0.225 & -0.233 & -0.821 \\
& $(0.787)$ & $(0.895)$ & $(0.587)$ & $(0.564)$ & $(0.697)$ & $(0.689)$ \\
14 year olds & $1.664^{*}$ & -0.150 & $0.924^{* *}$ & -0.168 & 0.00500 & -0.572 \\
& $(0.857)$ & $(0.756)$ & $(0.409)$ & $(0.553)$ & $(0.513)$ & $(0.693)$ \\
15 year olds & $2.179^{* * *}$ & -0.670 & $0.951^{* * *}$ & -0.0186 & 0.193 & -0.368 \\
& $(0.596)$ & $(0.511)$ & $(0.332)$ & $(0.363)$ & $(0.310)$ & $(0.460)$ \\
17 year olds & 0.246 & $-1.189^{* *}$ & 0.304 & $-0.975 * * *$ & -0.154 & -0.233 \\
& $(0.798)$ & $(0.567)$ & $(0.261)$ & $(0.314)$ & $(0.455)$ & $(0.450)$ \\
18 year olds & -0.580 & $-1.498^{*}$ & $1.040^{* *}$ & $-1.082^{*}$ & -0.0326 & -0.106 \\
& $(0.934)$ & $(0.790)$ & $(0.524)$ & $(0.604)$ & $(0.800)$ & $(0.758)$ \\
19 year olds & $-1.805^{*}$ & -0.856 & 0.848 & -1.075 & 0.00812 & 0.325 \\
& $(1.054)$ & $(0.826)$ & $(0.594)$ & $(0.704)$ & $(0.841)$ & $(0.873)$ \\
\hline Observations & & & & & & $1,244,386$ \\
$R^{2}$ & & & & & 0.239 \\
Municipalities & & & & & 1808
\end{tabular}

Notes: Dependent variable is a dummy for school attendance at the time of the 1990 census. Independent variables are net new export manufacturing jobs per worker attributable to firms that expand or contract their employment by 50 or more employees in a single year arriving in cohort's commuting zone in each year between 1987 and 1992. I include cohorts aged 12-19 and both age and commuting-zone fixed effects (not shown), and allow the coefficients on the shocks to differ by age cohort. Cohort aged 16 is the omitted category. Regression weighted by cell population, excludes Mexico City and migrants. Commuting-zone clustered standard errors in parentheses. ${ }^{*}$ significant at 10 percent level, $* *$ at 5 percent and ${ }^{* * *}$ at 1 percent. 
Table C.4: Counterfactual Job Types from the 1990 Census

\begin{tabular}{|c|c|c|c|c|c|c|}
\hline \multirow[b]{3}{*}{ All RF (Large $\Delta s$ ) } & (1) & $(2)$ & (3) & $(4)$ & $(5)$ & $(6)$ \\
\hline & \multicolumn{6}{|c|}{ Cohort Employment Propensities in March 1990} \\
\hline & $\begin{array}{l}\text { Export } \\
\text { Manuf. }\end{array}$ & $\begin{array}{l}\text { Non-export } \\
\text { Manuf. }\end{array}$ & $\begin{array}{l}\text { Service } \\
\text { Sector }\end{array}$ & $\begin{array}{l}\text { Primary } \\
\text { Sector }\end{array}$ & $\begin{array}{c}\text { Manuf. } \\
\text { (insuf. specified) }\end{array}$ & Unclassified \\
\hline 1987 Export Shock: Age 16 & $\begin{array}{l}-0.288 \\
(0.718)\end{array}$ & $\begin{array}{c}-0.00268 \\
(0.216)\end{array}$ & $\begin{array}{c}0.321 \\
(0.355)\end{array}$ & $\begin{array}{l}-1.140 \\
(0.727)\end{array}$ & $\begin{array}{l}0.0157 \\
(0.349)\end{array}$ & $\begin{array}{l}-0.0766 \\
(0.0886)\end{array}$ \\
\hline 1987 Export Shock: Age 17 & $\begin{array}{c}0.968 \\
(0.795)\end{array}$ & $\begin{array}{l}-0.112 \\
(0.270)\end{array}$ & $\begin{array}{l}-0.647 \\
(0.625)\end{array}$ & $\begin{array}{l}-1.386 \\
(0.912)\end{array}$ & $0.573^{*}$ & -0.142 \\
\hline 1987 Export Shock: Age 18 & $\begin{array}{c}1.083 \\
(0.776)\end{array}$ & $\begin{array}{c}0.355 \\
(0.321)\end{array}$ & $\begin{array}{c}0.219 \\
(0.680)\end{array}$ & $\begin{array}{l}-1.357 \\
(0.911)\end{array}$ & $\begin{array}{c}(0.040) \\
0.620 \\
(0.405)\end{array}$ & $\begin{array}{l}0.0141 \\
(0.118)\end{array}$ \\
\hline 1987 Export Shock: Age 19 & $\begin{array}{c}1.824^{* * *} \\
(0.699)\end{array}$ & $\begin{array}{c}0.556 \\
(0.458)\end{array}$ & $\begin{array}{l}-0.197 \\
(0.964)\end{array}$ & $\begin{array}{l}-1.583^{*} \\
(0.824)\end{array}$ & $\begin{array}{c}0.337 \\
(0.372)\end{array}$ & $\begin{array}{c}-0.0470 \\
(0.179)\end{array}$ \\
\hline 1988 Export Shock: Age 16 & $\begin{array}{c}1.507^{* * *} \\
(0.497)\end{array}$ & $\begin{array}{l}-0.149 \\
(0.172)\end{array}$ & $\begin{array}{l}-0.210 \\
(0.326)\end{array}$ & $\begin{array}{l}-0.475 \\
(0.724)\end{array}$ & $\begin{array}{c}0.465^{* *} \\
(0.199)\end{array}$ & $\begin{array}{c}0.123 \\
(0.0840)\end{array}$ \\
\hline 1988 Export Shock: Age 17 & $\begin{array}{c}1.142^{* *} \\
(0.560)\end{array}$ & $\begin{array}{l}-0.353 \\
(0.236)\end{array}$ & $\begin{array}{l}0.944^{*} \\
(0.501)\end{array}$ & $\begin{array}{l}-0.642 \\
(0.805)\end{array}$ & $\begin{array}{c}0.494^{* *} \\
(0.235)\end{array}$ & $\begin{array}{l}0.162^{* *} \\
(0.0794)\end{array}$ \\
\hline 1988 Export Shock: Age 18 & $\begin{array}{l}1.302^{* *} \\
(0.567)\end{array}$ & $\begin{array}{c}-0.490^{* *} \\
(0.248)\end{array}$ & $\begin{array}{c}0.627 \\
(0.640)\end{array}$ & $\begin{array}{l}-0.281 \\
(0.786)\end{array}$ & $\begin{array}{c}0.585^{* *} \\
(0.267)\end{array}$ & $\begin{array}{c}0.103 \\
(0.103)\end{array}$ \\
\hline 1988 Export Shock: Age 19 & $\begin{array}{l}0.953^{*} \\
(0.538)\end{array}$ & $\begin{array}{c}-0.828^{* *} \\
(0.348)\end{array}$ & $\begin{array}{l}1.823^{* *} \\
(0.863)\end{array}$ & $\begin{array}{l}-0.203 \\
(0.835)\end{array}$ & $\begin{array}{c}0.907 * * * \\
(0.324)\end{array}$ & $\begin{array}{l}0.288^{*} \\
(0.165)\end{array}$ \\
\hline 1989 Export Shock: Age 16 & $\begin{array}{c}1.599^{* * *} \\
(0.338)\end{array}$ & $\begin{array}{c}0.113 \\
(0.119)\end{array}$ & $\begin{array}{l}0.0365 \\
(0.196)\end{array}$ & $\begin{array}{l}-0.338 \\
(0.369)\end{array}$ & $\begin{array}{l}0.385^{* *} \\
(0.166)\end{array}$ & $\begin{array}{l}0.131^{* *} \\
(0.0539)\end{array}$ \\
\hline 1989 Export Shock: Age 17 & $\begin{array}{c}1.719^{* * *} \\
(0.407)\end{array}$ & $\begin{array}{c}0.104 \\
(0.192)\end{array}$ & $\begin{array}{l}-0.386 \\
(0.295)\end{array}$ & $\begin{array}{l}-0.171 \\
(0.438)\end{array}$ & $\begin{array}{l}0.520 * * \\
(0.221)\end{array}$ & $\begin{array}{l}0.00766 \\
(0.0565)\end{array}$ \\
\hline 1989 Export Shock: Age 18 & $\begin{array}{c}1.815^{* * * *} \\
(0.404)\end{array}$ & $\begin{array}{l}-0.133 \\
(0.168)\end{array}$ & $\begin{array}{l}-0.639^{*} \\
(0.333)\end{array}$ & $\begin{array}{l}-0.581 \\
(0.419)\end{array}$ & $\begin{array}{l}0.505^{* *} \\
(0.219)\end{array}$ & $\begin{array}{c}0.0416 \\
(0.0878)\end{array}$ \\
\hline 1989 Export Shock: Age 19 & $\begin{array}{c}1.888^{* * *} \\
(0.404)\end{array}$ & $\begin{array}{l}-0.0502 \\
(0.213)\end{array}$ & $\begin{array}{c}-0.952^{* *} \\
(0.378)\end{array}$ & $\begin{array}{l}-0.324 \\
(0.435)\end{array}$ & $\begin{array}{c}0.300^{* *} \\
(0.131)\end{array}$ & $\begin{array}{l}-0.0267 \\
(0.0759)\end{array}$ \\
\hline 1990 Export Shock: Age 16 & $\begin{array}{c}0.699^{* *} \\
(0.327)\end{array}$ & $\begin{array}{c}0.106 \\
(0.145)\end{array}$ & $\begin{array}{c}-0.0424 \\
(0.266)\end{array}$ & $\begin{array}{c}-0.751^{*} \\
(0.422)\end{array}$ & $\begin{array}{c}0.289^{*} \\
(0.164)\end{array}$ & $\begin{array}{c}-0.0128 \\
(0.0534)\end{array}$ \\
\hline 1990 Export Shock: Age 17 & $\begin{array}{l}0.768^{* *} \\
(0.364)\end{array}$ & $\begin{array}{c}0.386^{* *} \\
(0.192)\end{array}$ & $\begin{array}{l}-0.155 \\
(0.285)\end{array}$ & $\begin{array}{c}-0.825^{*} \\
(0.471)\end{array}$ & $\begin{array}{c}0.579 * * * \\
(0.193)\end{array}$ & $\begin{array}{l}-0.0525 \\
(0.0699)\end{array}$ \\
\hline 1990 Export Shock: Age 18 & $\begin{array}{c}1.184^{* * *} \\
(0.375)\end{array}$ & $\begin{array}{c}0.172 \\
(0.222)\end{array}$ & $\begin{array}{c}0.137 \\
(0.399)\end{array}$ & $\begin{array}{l}-0.574 \\
(0.405)\end{array}$ & $\begin{array}{c}0.380 \\
(0.244)\end{array}$ & $\begin{array}{c}0.0592 \\
(0.0885)\end{array}$ \\
\hline 1990 Export Shock: Age 19 & $\begin{array}{c}1.414^{* * *} \\
(0.392)\end{array}$ & $\begin{array}{c}0.305 \\
(0.293)\end{array}$ & $\begin{array}{l}-0.0474 \\
(0.432)\end{array}$ & $\begin{array}{l}-0.572 \\
(0.477)\end{array}$ & $\begin{array}{l}0.373^{*} \\
(0.193)\end{array}$ & $\begin{array}{l}-0.0836 \\
(0.0845)\end{array}$ \\
\hline 1991 Export Shock: Age 16 & $\begin{array}{c}-0.0673 \\
(0.623)\end{array}$ & $\begin{array}{c}0.100 \\
(0.185)\end{array}$ & $\begin{array}{c}0.142 \\
(0.291)\end{array}$ & $\begin{array}{c}0.000953 \\
(0.405)\end{array}$ & $\begin{array}{l}0.0969 \\
(0.137)\end{array}$ & $\begin{array}{l}-0.0494 \\
(0.0675)\end{array}$ \\
\hline 1991 Export Shock: Age 17 & $\begin{array}{c}0.274 \\
(0.604)\end{array}$ & $\begin{array}{l}0.0980 \\
(0.268)\end{array}$ & $\begin{array}{c}0.189 \\
(0.378)\end{array}$ & $\begin{array}{c}0.135 \\
(0.438)\end{array}$ & $\begin{array}{l}0.0919 \\
(0.163)\end{array}$ & $\begin{array}{l}-0.0437 \\
(0.0778)\end{array}$ \\
\hline 1991 Export Shock: Age 18 & $\begin{array}{c}0.233 \\
(0.624)\end{array}$ & $\begin{array}{c}0.198 \\
(0.276)\end{array}$ & $\begin{array}{l}-0.0177 \\
(0.427)\end{array}$ & $\begin{array}{l}0.0821 \\
(0.413)\end{array}$ & $\begin{array}{c}0.118 \\
(0.140)\end{array}$ & $\begin{array}{c}0.0324 \\
(0.0740)\end{array}$ \\
\hline 1991 Export Shock: Age 19 & $\begin{array}{l}0.0117 \\
(0.680)\end{array}$ & $\begin{array}{c}0.431 \\
(0.347)\end{array}$ & $\begin{array}{l}-0.203 \\
(0.445)\end{array}$ & $\begin{array}{l}0.140 \\
(0.394)\end{array}$ & $\begin{array}{l}-0.144 \\
(0.153)\end{array}$ & $\begin{array}{l}-0.0469 \\
(0.0806)\end{array}$ \\
\hline 1992 Export Shock: Age 16 & $\begin{array}{l}-0.609 \\
(0.656)\end{array}$ & $\begin{array}{r}-0.0618 \\
(0.198)\end{array}$ & $\begin{array}{l}0.0220 \\
(0.293)\end{array}$ & $\begin{array}{l}0.566 \\
(0.532)\end{array}$ & $\begin{array}{c}-0.0849 \\
(0.137)\end{array}$ & $\begin{array}{l}-0.0858 \\
(0.0818)\end{array}$ \\
\hline 1992 Export Shock: Age 17 & $\begin{array}{l}-0.299 \\
(0.710)\end{array}$ & $\begin{array}{l}-0.180 \\
(0.278)\end{array}$ & $\begin{array}{l}-0.386 \\
(0.412)\end{array}$ & $\begin{array}{c}0.822 \\
(0.601)\end{array}$ & $\begin{array}{r}-0.0387 \\
(0.184)\end{array}$ & $\begin{array}{c}-0.0827 \\
(0.0674)\end{array}$ \\
\hline 1992 Export Shock: Age 18 & $\begin{array}{l}-0.598 \\
(0.709)\end{array}$ & $\begin{array}{c}-0.00965 \\
(0.307)\end{array}$ & $\begin{array}{c}-0.315 \\
(0.458)\end{array}$ & $\begin{array}{c}0.452 \\
(0.579)\end{array}$ & $\begin{array}{l}-0.115 \\
(0.180)\end{array}$ & $\begin{array}{c}0.0682 \\
(0.147)\end{array}$ \\
\hline 1992 Export Shock: Age 19 & $\begin{array}{l}-0.760 \\
(0.796)\end{array}$ & $\begin{array}{c}0.00682 \\
(0.455)\end{array}$ & $\begin{array}{l}-0.695 \\
(0.557)\end{array}$ & $\begin{array}{c}0.388 \\
(0.651)\end{array}$ & $\begin{array}{l}-0.0261 \\
(0.212)\end{array}$ & $\begin{array}{l}-0.109 \\
(0.140)\end{array}$ \\
\hline Observations & 650,454 & 650,454 & 650,454 & 650,454 & 650,454 & 650,454 \\
\hline$R^{2}$ & 0.066 & 0.042 & 0.144 & 0.078 & 0.023 & 0.012 \\
\hline Municipalities & 178 & 178 & 178 & 178 & 178 & 178 \\
\hline
\end{tabular}

Notes: Dependent variables are dummy variables for employment in each of six industries at the time of the 1990 census. Independent variables are net new export manufacturing jobs per worker attributable to firms that expand or contract their employment by 50 or more employees in a single year arriving in cohort's commuting zone in each year between 1987 and 1992. I include cohorts aged 16-19 at the time of the census and age fixed effects (not shown), and allow the coefficients on the shocks to differ by age cohort. Sample restricted to commuting zones with at least one year of employment growth in export manufacturing between 1987 and 1992. Regressions weighted by cell population, exclude Mexico City and migrants. Commuting-zone clustered standard errors in parentheses. * significant at 10 percent level, ** at 5 percent and *** at 1 percent. 


\section{Appendix D Robustness Using Highly Agglomerated Industries}

As noted in Section 2.4, the demand for exports is primarily driven by external demand shifts. ${ }^{4}$ However, demand for domestic goods and services may be driven by local demand shocks which correlate with other time-location-varying omitted variables. For example, a positive shock to income may raise local demand and schooling, and upwards bias the job arrivals coefficient. In order to mitigate this concern, I use the IMSS employment data to calculate a Herfindahl index for state-level industrial concentration in the year 2000 at the lowest level of industrial classification in the database (276 industries).

The Herfindahl index for industry $j$ is equal to $\sum_{r}\left(s_{j r}-s_{r}\right)^{2}$, where $s_{j r}$ is state $r$ 's share of total employment in industry $j$, and $s_{r}$ is state $r$ 's share of total manufacturing employment. The values for the Herfindahl index range from 0.0017 for "services of repair, washing, lubrication, verification of emission of polluting agents and parking of vehicles" to a value of 0.75 for the "manufacture of pencils, rubbers, pens and ball-point pens" or for "Sulfur extraction". The value of the Herfindahl is above 0.1 for 95 industries (73 of which are in manufacturing) and 181 industries have Herfindahls below that number (53 of which are in manufacturing).

If an industry is highly concentrated in a few states, demand is likely to be driven by national rather than local demand shifters. Therefore, as a robustness check, I repeat the analysis of Section 5 but replace the net new jobs per worker measures with job growth only in the industries which have Herfindahl indexes below 0.1.

These results are reported in Figure D.1 which mimics Figure 7 by plotting the coefficients on both export manufacturing job shocks and other formal job shocks from separate regressions at every age between 10 and 23 (except here only using job shocks in heavily agglomerated industries). As with Figure 7, the impacts of job shocks in export and non-export sectors diverge at age 16 with a significantly more negative coefficient on export shocks at age 16 compared to non-export shocks at that age (an F-stat of 4.96 with a p-value of 0.026). In fact, there is no negative impact of non-export job shocks at age 16 at all (a coefficient of 0.123 with a standard error of 0.619).

As discussed in Section 5.2, Column 15 of Table 7 reproduces the regression for exposure at age 16 for highly-agglomerated industries, but just for job shocks post 1990. Column 16 of Table 7 further includes the four triple interactions to control for job characteristics suggested by equation 10 .

\footnotetext{
${ }^{4}$ Foreign demand shocks, such as a US recession, are swept out in aggregate by the time fixed effects. The variation remaining comes from the fact that export factories are located unevenly across Mexico, coupled with the fact that there are industry-specific export demand shocks.
} 
Figure D.1: Differential Effects of Export and Non-Export Job Shocks (Highly-Agglomerated Industries Only)

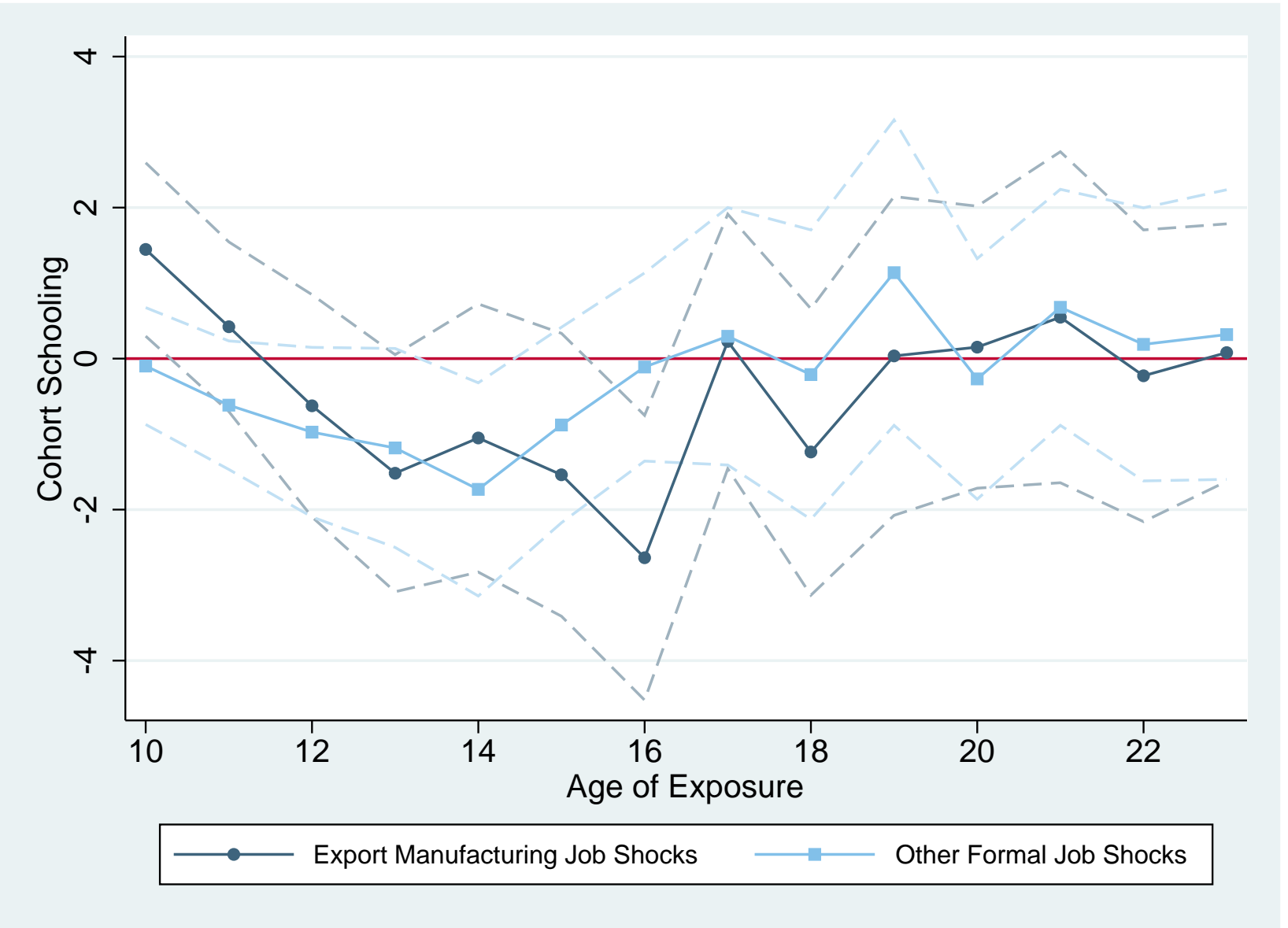

Notes: Figure plots the coefficients from 14 regressions that regress cohort average schooling on both net new export job shocks and net new job shocks in all other sectors using the specification in equation 1 but replacing shocks at age 16 with shocks at one of 14 different ages between 10 and 23 and restricting attention to highly agglomerated 4-digit industries in both sectors. Dashed lines show 95 percent confidence intervals. Coefficients on export manufacturing job shocks are significantly different from non-export job shocks at age 16 (an F-stat of 4.96 with a p-value of 0.026). 